VITOR MORI

AVALIAÇÃO DE PARÂMETROS DA MECÂNICA RESPIRATÓRIA PELA TÉCNICA DAS OSCILAÇOESS FORÇADAS EM PEQUENOS ANIMAIS SOB A PRESENÇA DE RESPIRAÇÃO ESPONTÂNEA 
VITOR MORI

\section{AVALIAÇÃO DE PARÂMETROS DA MECÂNICA RESPIRATÓRIA PELA TÉCNICA DAS OSCILAÇÖES FORÇADAS EM PEQUENOS ANIMAIS SOB A PRESENÇA DE RESPIRAÇÃO ESPONTÂNEA}

Tese apresentada à Escola Politécnica da

Universidade de São Paulo para obtenção do título de Doutor em Ciências. 
VITOR MORI

\section{AVALIAÇÃO DE PARÂMETROS DA MECÂNICA RESPIRATÓRIA PELA TÉCNICA DAS OSCILAÇÔES FORÇADAS EM PEQUENOS ANIMAIS SOB A PRESENÇA DE RESPIRAÇÃO ESPONTÂNEA}

Tese apresentada à Escola Politécnica da Universidade de São Paulo para obtenção do título de Doutor em Ciências.

Área de Concentração:

Engenharia Biomédica

Orientador:

Prof. Dr. Henrique Takachi Moriya 
Autorizo a reprodução e divulgação total ou parcial deste trabalho, por qualquer meio convencional ou eletrónico, para fins de estudo e pesquisa, desde que citada a fonte.

Este exemplar foi revisado e corrigido em relaçăo à versăo original, sob responsabilidade única do autor e com a anuência de seu orientador.

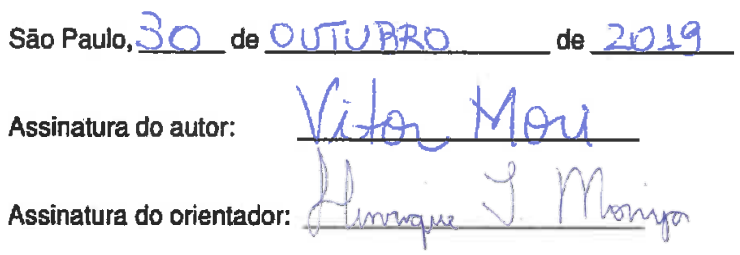

Catalogação-na-publicação

Mori, Vitor

Avaliação de Parâmetros da Mecânica Respiratória Pela Técnica das

Oscilações Forçadas em Pequenos Animais Sob a Presença de Respiração

Espontânea / V. Mori -- versāo corr. -- Sāo Paulo, 2019.

$77 \mathrm{p}$.

Tese (Doutorado) - Escola Politécnica da Universidade de Sāo Paulo. Departamento de Engenharia de Telecomunicaçōes e Controle.

1.Técnica das Oscilaçōes Forçadas 2.Impedância Respiratória de Entrada 3.Modelo de Fase Constante 4.índice de Distorção Harmônica 5.Esforços de Respiração Espontânea I.Universidade de São Paulo. Escola Politécnica. Departamento de Engenharia de Telecomunicaçōes e Controle II.t. 


\section{AGRADECIMENTOS}

Primeiramente agradeço ao professor Henrique por toda a dedicação empreendida em minha orientação, desde a iniciação científica, passando pelo mestrado e indo até o doutorado. Seu apoio incondicional, sua compreensão e seus conselhos preciosos foram fundamentais. Levo-o como exemplo de professor, pesquisador e pessoa para minha vida.

Agradeço ao Prof. Jason HT Bates da Universidade de Vermont por ter me acolhido no período de Doutorado Sanduíche entre 2017 e 2018. Foi uma experiência muito importante para o meu crescimento acadêmico e amadurecimento pessoal. Também agradeço a confiança do Prof. Bates por delegar projetos importantes e que me abriram novos horizontes de pesquisa.

Um grande agradecimento também a todos os colegas de laboratório. Ao Renato, colega de LEB, e à Cida, do Instituto de Ciências Biomédicas da USP, pela coleta de dados extremamente cuidadosa e bem feita, sendo parte fundamental desse trabalho. Também ao professor Wothan, do Laboratório de Fisiopatologia da Inflamação Experimental do Instituto de Ciências Biomédicas da USP, por gentilmente disponibilizar seu laboratório e equipamentos para a realização de experimentos.

Agradeço a todos os colegas e amigos da Universidade de Vermont, em especial aos professores Matt Kinsey e Gilman Allen e aos colegas de laboratório Ubong Peters, Dan Idelkope, Greg Roy, Isaac de La Bruere, Nirav Daphtary e Minara Aliyeva. Também aos professores Bela Suki da Universidade de Boston e Bradford Smith da Universidade do Colorado pelas produtivas conversas e sugestões no desenvolvimento de artigos.

Agradeço a toda minha família, em especial meus pais, Marcos e Cecília e minha irmã Emi. Também agradeço à minha esposa Ana Cecília pelo companheirismo e apoio incondicional em toda essa jornada.

Agradeço a todos os amigos e colegas que de forma direta ou indireta me apoiaram nesses 4 anos.

A CAPES, pelo financiamento no período de doutorado e no período de doutorado sanduíche. 


\section{RESUMO}

Nesse trabalho propusemos uma manipulação alternativa para o processamento digital de sinais quando um ruído devido a esforços de respiração espontânea, que consiste numa queda abrupta no sinal de pressão de saída num curto intervalo de tempo, se manifesta durante a realização da Técnica das Oscilações Forçadas (FOT), por meio da utilização de um equipamento comercial (flexiVent, SCIREQ, Montreal, Canadá). Uma vez que o sinal mais utilizado nesse equipamento consiste em 2 períodos de 2 segundos com sobreposição de meio período, totalizando um sinal de 3 segundos (QuickPrime-3), caso tal ruído surja no primeiro ou no último segundo, ainda seria possível a análise de um período completo sem disrupção. Dessa forma, hipotetizamos que com um período completo de 2 segundos ainda seria possível a extração de informações fisiológicas relevantes de pequenos animais mesmo na presença desse tipo específico de ruído, fazendo com que dados que seriam descartados possam ser reaproveitados e, eventualmente, evitando a utilização e consequente sacrifício de um número maior de animais.

Testamos nossa hipótese em um conjunto previamente adquirido de dados da FOT em camundongos submetidos a metacolina por injeções em bolus e infusão contínua, em diferentes doses ou taxas de infusão, onde a disrupção foi simulada computacionalmente como uma queda abrupta no sinal de pressão de saída num curto intervalo de tempo. Avaliamos não só os parâmetros do Modelo de Fase Constante $(C P M)$ como também a qualidade do ajuste do modelo à impedância estimada (Coeficiente de Determinação, $C O D)$ e o índice de distorção harmônica que visa quantificar o grau de não linearidade do sistema.

Observamos que não houve diferença estatisticamente significante entre o sinal completo de 3 segundos sem ruído e o período completo de 2 segundos sem ruído para a comparação entre os parâmetros do Modelo de Fase Constante (Resistência, Viscância e Elastância), em nenhuma dose ou taxa de infusão de metacolina para a administração de broncoconstritor por meio de injeções em bolus ou infusão contínua. Além disso, observamos que, a menos do valor basal do índice de distorção harmônica (após administração de solução salina) não há diferença estatística na comparação do índice de distorção harmônica de ambos os sinais. Dessa forma, concluímos que, apesar das limitações do trabalho, a utilização de um período completo de 2 segundos se mostra uma alternativa simples e de fácil implementação para se extrair informações fisiológicas de realizações da FOT onde esforços de respiração espontânea se manifestam.

Palavras-Chave - Técnica das Oscilações Forçadas, Impedância Respiratória de Entrada, Modelo de Fase Constante, Índice de Distorção Harmônica, Esforços de Respiração Espontânea. 


\section{ABSTRACT}

In this thesis we proposed an alternative approach to the signal processing when noise from spontaneous breathing efforts, consisting in a sharp drop in the output pressure signal within a short timescale, manifests during the Forced Oscillations Technique (FOT) realization through a commercial device (flexiVent, SCIREQ, Montreal, Canada). Once the most widely used signal consists in 2 2-seconds epochs with a half period overlap, leading to a 3-seconds signal (QuickPrime-3), such noise in the first or in the last second of the signal would still have a full non-disrupted period. Therefore, we hypothesized that a single 2-second full period would be able to provide relevant physiological information in small animals even when disruptions from spontaneous breathing efforts manifest. Consequently, data sets that would have been discarded could be used, avoiding the sacrifice of more animals.

We tested our hypothesis in a previous collected FOT dataset in mice under bronchoconstriction due to methacholine administration by bolus injections or continuous infusion in different doses or infusion rates. Disruption was computationally simulated as a sharp drop in pressure level within a short timescale. We assessed not only Constant Phase Model $(C P M)$ parameters but also model goodness of fit (Coefficient of Determination, $C O D)$ and the index of harmonic distortion, aiming to estimate system nonlinearity degree.

We found no statistically significant difference between the original 3-s signal and the 2-s epoch without disruption in Constant Phase Model parameters (resistance, tissue damping and elastance) comparisons for both, bolus injections and continuous infusion of methacholine, in different doses or infusion rates. Furthermore, we also found that the difference between bronchoconstricted and baseline harmonic distortion index values in both signals do not show statistically significant differences. Hence we can conclude that although the proposed technique presents limitations, it is a simple and of easy implementation tool in order to extract physiological information from FOT data in which spontaneous breathing efforts manifest.

Keywords - Forced Oscillations Technique, Input Respiratory Impedance, Constant Phase Model, Harmonic Distortion Index, Spontaneous Breathing Efforts. 


\section{LISTA DE SIGLAS E ABREVIAÇÕES}

$\delta Y_{\text {lin }}$ Desvio na Aproximação Linear do Sinal de Saída Devido ao Ajuste do Modelo

$\delta Z_{m} \quad$ Erro do Modelo Linear Numa Frequência Qualquer

$\dot{v} \quad$ Sinal de Fluxo no Domínio do Tempo

$\epsilon \quad$ Erro no Ajuste do Modelo aos Dados

$\hat{S}_{\dot{v} \dot{v}} \quad$ Estimação da Densidade Espectral de Potência de $R_{\dot{v}}(t)$

$\hat{S}_{p \dot{v}} \quad$ Estimação da Densidade Espectral de Potência de $R_{p \dot{v}}(t)$

Z Estimação da Impedância Respiratória de Entrada

$\mathfrak{F} \quad$ Transformada de Fourier

$\omega \quad$ Frequência Angular

$\Phi \quad$ Função Custo Para Ajuste do Modelo de Fase Constante

E Elastância do Componente Parenquimal no Modelo de Compartimento Único Viscoelástico

f $\quad$ Frequência

$f_{0} \quad$ Frequência Fundamental do Sinal Multifrequencial

$f_{I} \quad$ Conjunto das Frequências Presentes no Sinal de Entrada

$f_{N I} \quad$ Conjunto de Frequências Espúrias Múltiplas de $f_{0}$

G Viscância no Modelo de Fase Constante

$g_{I m} \quad$ Fator de Correção da Parte Imaginária Devido a Aproximação do Cerne de Volterra de Primeira Ordem pelo Modelo de Fase Constante

$g_{R e} \quad$ Fator de Correção da Parte Real Devido a Aproximação do Cerne de Volterra de Primeira Ordem pelo Modelo de Fase Constante

H Elastância no Modelo de Fase Constante 
$H_{n} \quad$ n-ésimo Cerne da Série de Volterra no Domínio da Frequência

$h_{n} \quad$ n-ésimo Cerne da Série de Volterra no Domínio do Tempo

I Inertância no Modelo de Fase Constante

Im Componente Imaginária do Número Complexo

j $\quad$ Unidade Imaginária

$k_{d} \quad$ Índice de Distorção Harmônica

L Número de Frequências Diferentes, Múltiplos da Frequência Fundamental Dentro do Intervalo Entre o Maior e o Menor Valor de $f_{I}$

NP Potência Média do Ruído em Cada Raia Espectral

$p \quad$ Sinal de Pressão no Domínio do Tempo

$p_{0} \quad$ Pressão Atmosférica Externa

$P_{N I} \quad$ Potência do Sinal de Saída em Frequências Diferentes das Frequências de Entrada

$P_{T} \quad$ Potência Total do Sinal

$R \quad$ Resistência no Modelo de Fase Constante

$R_{\dot{v}} \quad$ Função de Autocorrelação do Processo $\dot{v}$

$R_{a w}$ Resistência das Vias Aéreas no Modelo de Compartimento Único Viscoelástico

$R_{p \dot{v}} \quad$ Função de de Correlação Cruzada dos processos $\dot{v}$ e $p$

$R_{t} \quad$ Resistência do Componente Parenquimal no Modelo de Compartimento Único Viscoelástico

Re Componente Real do Número Complexo

$S_{\dot{v} \dot{v}} \quad$ Densidade Espectral de Potência de $R_{\dot{v} \dot{v}}(t)$

$S_{p \dot{v}} \quad$ Densidade Espectral de Potência de $R_{p \dot{v}}(t)$

$t \quad$ Tempo

u Função Degrau Unitário

$v \quad$ Volume no Domínio do Tempo 
X Sinal de Entrada no Domínio da Frequência

Y Sinal de Saída no Domínio da Frequência

$Y_{\text {lin }}$ Conjunto de Frequências Espúrias Múltiplas de $f_{0}$

$Y_{\text {lin }} \quad$ Sinal de Saída Devido Apenas às Contribuições Lineares do Sistema

Z Impedância Respiratória de Entrada

z $\quad$ Resposta do Sistema Respiratório ao Impulso Unitário

$Z_{d} \quad$ Impedância Estimada a Partir dos Sinais de Entrada e Saída

$Z_{m} \quad$ Impedância Modelada Pelo Modelo de Fase Constante

$Z_{a p p}$ Impedância Aproximadamente Linear

$Z_{\text {lin }} \quad$ Função de Transferência do Subsistema Linear

$A D C$ Conversor Analógico-Digital

COD Coeficiente de Determinação

CPM Modelo de Fase Constante

$D A C$ Conversor Digital-Analógico

LVDT Linear Variable Differential Transformer

NSND Non-Sum Non-Difference

PEEP Pressão Positiva Expiratória Final

$S A V$ Ventilador Para Pequenos Animais

SNR Relação Sinal-Ruído

IV Via Intravenosa

MCh Metacolina

PBS Solução Salina Tamponada de Fosfato

SAMR1 Modelo Murino de Senescência Acelerada

SEM Erro Padrão da Média 
VA Válvula Animal

VE Válvula Expiratória

VI Válvula Inspiratória

VR Válvula Refil 


\section{LISTA DE FIGURAS}

1 Diagrama da realização da FOT em humanos. Um sinal de fluxo $(\dot{v})$ é aplicado na entrada do sistema respiratório e o sinal de pressão $\left(p_{a o}\right)$ é adquirido na saída do sistema. . . . . . . . . . . . . . . . . . . . . 20

2 Diagrama da realização da FOT pelo método convencional em pequenos animais. Um sinal de fluxo é aplicado na entrada do sistema respiratório a partir da utilização de um pistão dentro de um cilindro hermeticamente vedado e o sinal de pressão é adquirido na saída do sistema. Uma coluna de água é utilizada para a aplicação de uma pressão estática no final da expiração. . . . . . . . . . . . . . . . . . . . . .

3 Diagrama da realização da FOT pelo método do wavetube em pequenos animais. Um sinal é gerado por um alto-falante dentro de uma caixa de som. A perturbação é conduzida até o sistema respiratório por um tubo longo e fino no qual são posicionados transdutores de pressão em suas extremidades. Próximo a entrada do sistema respiratório uma válvula manual alterna a entrada de ar entre a caixa de som (que gera o sinal perturbatório multifrequencial) e um ventilador mecânico externo ligado à uma coluna d'água (que realiza a respiração do animal quando a FOT não está sendo

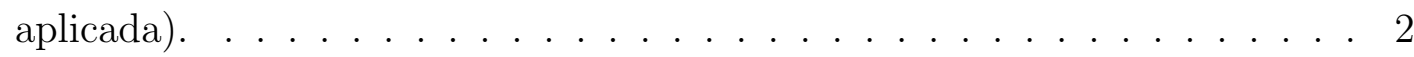

4 Impedância respiratória de entrada de um camundongo sujeito à $F O T$, cujo sinal de entrada é uma composição de senóides com frequências entre 1 e

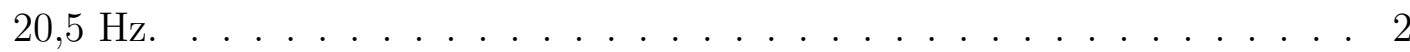

O modelo de compartimento único viscoelástico. . . . . . . . . . . . . . . 24

6 De cima para baixo, sinal de fluxo em função do tempo, sinal de volume em função do tempo, sinal de pressão adquirido e ajuste do modelos de compartimento único viscoelástico, e resíduos do modelo. . . . . . . . . . . 25 
8 A) Sinal multifrequencial de volume no domínio do tempo (QuickPrime-3) gerado pelo $S A V$. Entre as linhas verticais cheias temos o primeiro período completo (0-2 s). Já entre as linhas verticais não preenchidas temos o segundo período completo. Entre as linhas não preenchidas e preenchidas (1-2 s) temos a sobreposição de $50 \%$ do sinal. B) Sinal multifrequencial de volume no domínio da frequência contendo raias nos 13 primeiros múltiplos inteiros primos de $0,5 \mathrm{~Hz}$ e com amplitude proporcional ao inverso da frequência. . . . . . . . . . . . . . . . . . . . . . . 31

9 A) Sinal de pressão de saída no domínio do tempo adquirido por um transdutor de pressão. B) Sinal de pressão de saída no domínio do tempo convoluído por uma janela de Hanning, que possui queda suave a zero nas extremidades. . . . . . . . . . . . . . . . . . . 32

10 A) Parte real da impedância respiratória de entrada. B) Parte imaginária da impedância respiratória de entrada. . . . . . . . . . . . . . . . . . 33

11 Modelos não lineares de Wiener e Hammerstein para o sistema respiratório com um sinal de fluxo de entrada $(\dot{v}(t))$ e um sinal de pressão de saída $(p(t)) .35$

12 Sinal de fluxo na entrada do sistema respiratório no domínio da frequência (gráfico superior) e sinal de pressão na saída do sistema respiratório (gráfico inferior). Em A, observamos a ausência de raia espectral no sinal de entrada e a presença no sinal de saída, indicando a presença de uma contribuição não linear. Já em B temos a superposição de uma contribuição linear e de uma contribuição não linear. . . . . . . . . . . . . . . . . . . . . . 37

13 Sinal de pressão de saída no domínio do tempo coletado na realização da FOT em um camundongo com a adição computacional de ruído simulando a respiração espontânea do animal entre $2-3$ s. . . . . . . . . . . . . . . . . 43

14 Protocolo para realização da FOT em camundongos com administração de broncoconstritor por injeções em bolus. . . . . . . . . . . . . . . . 46

15 Protocolo para realização da FOT em camundongos com administração de broncoconstritor por infusão contínua. . . . . . . . . . . . . . . . . . 47

16 Média \pm 2 SEM de 100 simulações computacionais do ruído no domínio da frequência. . . . . . . . . . . . . . . . . . . . . . . 49 
17 Média \pm 2 SEM do $C O D$ de 15 animais obtidos a partir do ajuste do $C P M$ à impedância respiratória de entrada estimada após a administração de broncoconstritor por injeções em bolus em 75 realizações da FOT utilizando o sinal A) Original (quadrado cinza) e Janelado (triângulo preto) B) Corrompido (círculo preto). ${ }^{*} p<0,05,{ }^{\times} p<0,01 \mathrm{e}^{+} p<0,001 . \ldots . .50$

18 Média $\pm 2 \mathrm{SEM}$ do $C O D$ de 10 animais obtidos a partir do ajuste do $C P M$ à impedância respiratória de entrada estimada após a administração de broncoconstritor por infusão contínua em 60 realizações da FOT utilizando o sinal A) Original (quadrado cinza) e Janelado (triângulo preto) B) Corrompido (círculo preto). ${ }^{*} p<0,05,{ }^{\times} p<0,01 \mathrm{e}^{+} p<0,001 . \ldots . .51$

19 Média \pm 2 SEM dos parâmetros do $C P M$ de 15 animais após a administração de broncoconstritor por injeções em bolus em 75 realizações da FOT com os sinais Original (quadrado cinza) e Janelado (triângulo preto) A) Resistência de vias aéreas $(R)$ B) Viscância $(G)$ e C) Elastância $(H)$. * $p<0,05,{ }^{\times} p<0,01 \mathrm{e}^{+} p<0,001 \ldots \ldots \ldots \ldots . \ldots \ldots 4 . \ldots \ldots$

20 Média \pm 2 SEM dos parâmetros do $C P M$ de 15 animais após a administração de broncoconstritor por injeções em bolus em 75 realizações da FOT com o sinal Corrompido (triângulo cinza) A) Resistência de vias aéreas $(R)$ B) Viscância $(G)$ e C) Elastância $(H) .{ }^{*} p<0,05,{ }^{\times} p<0,01 \mathrm{e}^{+} p<0,001.55$

21 Média \pm 2 SEM dos parâmetros do $C P M$ de 10 animais após a administração de broncoconstritor por infusão contínua em 60 realizações da FOT com os sinais Original (quadrado cinza) e Janelado (triângulo preto) A) Resistência de vias aéreas $(R)$ B) Viscância $(G)$ e C) Elastância $(H)$. * $p<0,05,{ }^{\times} p<0,01 \mathrm{e}^{+} p<0,001 \ldots \ldots \ldots \ldots \ldots$

22 Média \pm 2 SEM dos parâmetros do $C P M$ de 10 animais após a administração de broncoconstritor por infusão contínua em 60 realizações da FOT com o sinal Corrompido (triângulo cinza) A) Resistência de vias aéreas $(R)$ B) Viscância $(G)$ e C) Elastância $(H) .{ }^{*} p<0,05,{ }^{\times} p<0,01 \mathrm{e}^{+} p<0,001.57$

23 Média \pm 2 SEM do índice de distorção harmônica de 15 animais obtidos a partir da metodologia descrita na seção 2.7, após a administração de broncoconstritor por injeções em bolus em 75 realizações da FOT utilizando o sinal A) Original (quadrado cinza) e Janelado (triângulo preto) B) Corrompido (triângulo cinza). ${ }^{*} p<0,05,{ }^{\times} p<0,01 \mathrm{e}^{+} p<0,001 \ldots$. . . 58 
24 Média \pm 2 SEM do índice de distorção harmônica de 10 animais obtidos a partir da metodologia descrita na seção 2.7, após a administração de broncoconstritor por infusão contínua em 60 realizações da FOT utilizando o sinal A) Original (quadrado cinza) e Janelado (triângulo preto) B) Corrompido (triângulo cinza). ${ }^{*} p<0,05,{ }^{\times} p<0,01 \mathrm{e}^{+} p<0,001 \ldots$. . . 59

25 A) Média \pm 2 SEM do índice de distorção harmônica de 15 animais obtidos a partir da metodologia descrita na seção 3.2 (triângulo preto) e na seção 2.7 (triângulo cinza), após a administração de broncoconstritor por injeções em bolus em 75 realizações da FOT e B) Diferença entre o índice obtido pelas seções 3.2 e 2.7. ${ }^{*} p<0,05,{ }^{\times} p<0,01 \mathrm{e}^{+} p<0,001 . \ldots \ldots$

26 A) Média \pm 2 SEM do índice de distorção harmônica de 10 animais obtidos a partir da metodologia descrita na seção 3.2 (triângulo preto) e na seção 2.7 (triângulo cinza), após a administração de broncoconstritor por infusão contínua em 60 realizações da FOT e B) Diferença entre o índice obtido pelas seções 3.2 e 2.7. ${ }^{*} p<0,05,{ }^{\times} p<0,01 \mathrm{e}^{+} p<0,001 . \ldots . . . .61$

27 Média \pm 2 SEM do índice de distorção harmônica de 15 animais obtidos a partir da metodologia descrita na seção 2.7 após a administração de broncoconstritor por injeções em bolus em 60 realizações da FOT subtraído do valor médio do índice nas 15 realizações da FOT após administração de solução salina utilizando o sinal A) Original (quadrado cinza) e Janelado (triângulo preto) B) Corrompido (triângulo cinza). ${ }^{*} p<0,05,{ }^{\times} p<0,01$

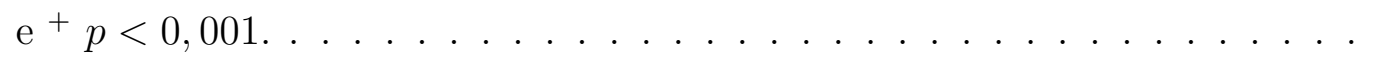

28 Média \pm 2 SEM do índice de distorção harmônica de 10 animais obtidos a partir da metodologia descrita na seção 2.7 após a administração de broncoconstritor por infusão contínua em 45 realizações da FOT subtraído do valor médio do índice nas 15 realizações da FOT após administração de solução salina utilizando o sinal A) Original (quadrado cinza) e Janelado (triângulo preto) B) Corrompido (triângulo cinza). ${ }^{*} p<0,05,{ }^{\times} p<0,01$

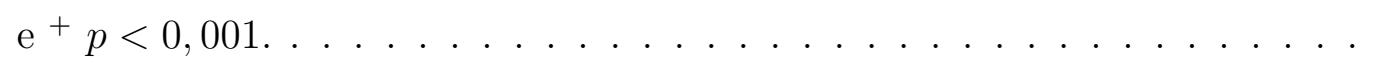




\section{SUMÁRIO}

1 Introdução $\quad 16$

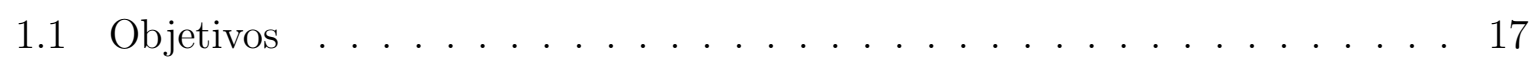

1.1.1 Objetivo principal . . . . . . . . . . . . 17

1.1 .2 Objetivos secundários . . . . . . . . . . . . . . 17

1.2 Justificativas . . . . . . . . . . . . . . . . . . . . 18

2 Revisão Bibliográfica $\quad 19$

2.1 Técnica das Oscilações Forçadas . . . . . . . . . . . . . . . . . . 19

2.2 Impedância Respiratória de Entrada . . . . . . . . . . . . . . . . . 21

2.3 O Modelo de Fase Constante $(C P M) \ldots \ldots \ldots \ldots$

2.4 O Ventilador Para Pequenos Animais $(S A V) \ldots \ldots \ldots \ldots$

2.5 Processamento Digital de Sinais no $S A V \ldots \ldots \ldots$. . . . . . . . 30

2.6 Não Linearidades No Sistema Respiratório . . . . . . . . . . . . . . . . . . 34

2.7 O Índice de Distorção Harmônica . . . . . . . . . . . . . . . . . . . . . . 38

3 Materiais e Métodos $\quad 42$

3.1 A Presença de Ruído Na Estimação da Impedância Respiratória de Entrada 42

3.2 A Correção do Índice de Distorção Harmônica na Presença de Ruído . . 43

3.3 Experimentos com Animais . . . . . . . . . . . . . . 44

3.4 Análise dos Dados . . . . . . . . . . . . . . . . . 46

$\begin{array}{lll}4 & \text { Resultados } & 48\end{array}$

4.1 Análise do Ruído Simulado . . . . . . . . . . . . . . . . . . . . 48

4.2 Coeficientes de Determinação . . . . . . . . . . . . . . . . . 48

4.3 Parâmetros do $C P M \ldots \ldots \ldots \ldots$. . . . . . . . . . . . . 49 
4.4 Índices de Distorção Harmônica . . . . . . . . . . . . . . . . . . . . . . . . 51

4.5 Correção do Índice de Distorção Harmônica . . . . . . . . . . . . . . . . 52

4.6 Variação do Índice de Distorção Harmônica com Relação ao Valor Basal . . 52

5 Discussão $\quad 64$

6 Conclusão $r 2$

7 Referências Bibliográficas $\quad 73$ 


\section{INTRODUÇÃO}

A Técnica das Oscilações Forçadas (FOT, do inglês Forced Oscillations Technique) emergiu como uma alternativa para a avaliação mecânica do sistema respiratório (BATES, 2009; KACZKA; DELLACÁ, 2011), tanto de animais em biologia experimental (MORI; SMITH; SUKI; BATES, 2019; MORI et al., 2017; HAMLINGTON et al., 2018; SMITH et al., 2017) quanto em humanos (FARRÉ; NAVAJAS, 2016; HANTOS et al., 2015), sendo um procedimento rápido e pouco invasivo capaz de oferecer informações fisiológicas complementares à espirometria (OOSTVEEN et al., 2003; LUNDBLAD; PIITULAINEN; WOLLMER, 2017). O crescente interesse na FOT levou ao surgimento de diversos equipamentos comerciais, tanto para a realização em humanos, como o tremoFlo (Thorasys Medical Systems, Montreal, Canadá), Resmon Pro (Restech srl, Milão, Itália) e o Jaeger Masterscope CT IOS (CareFusion, Hoechberg, Alemanha)(ZIMMERMANN et al., 2017), quanto em biologia experimental, onde o flexiVent (SCIREQ, Montreal, Canadá), desenvolvido por Schuessler e Bates (1995) se destaca por sua facilidade de manuseio, sendo amplamente utilizado pela comunidade científica.

A FOT consiste na aplicação de um sinal de fluxo multifrequencial na entrada do sistema respiratório e na aquisição do sinal de pressão na saída do mesmo (DUBOIS; BRODY; LEWIS; JR, 1956). A partir dos sinais aquisitados e da aproximação do sistema como linear e invariante no tempo, se torna possível a estimação da função de transferência, comumente referida como impedância respiratória de entrada (BATES, 2009). A interpretação fisiológica da impedância é feita com o auxílio de modelos matemáticos, sendo o Modelo de Fase Constante ( $C P M$, do inglês Constant Phase Model) (HANTOS et al., 1992) o mais popular para pequenos animais, tendo a capacidade de discernir contribuições de vias aéreas e tecidos, bem como de componentes dissipativas e conservativas no sistema respiratório, a partir da análise do sistema no domínio da frequência.

No entanto, uma série de condições deve ser imposta aos animais submetidos à FOT, sendo o controle da sedação um dos pontos mais delicados. Deve-se administrar uma quantidade suficiente de anestésico e paralisante neuromuscular nos momentos corretos 
para garantir a ausência de contribuições espúrias devido a esforços de respiração espontânea, ao mesmo tempo que doses muito altas podem levar o animal a óbito. Soma-se a isso flutuações naturais de tamanho e metabolismo entre os animais, fazendo com que o sucesso experimental dependa fortemente da sensibilidade do operador do experimento em controlar tais variáveis.

Devido a esse contexto, mesmo cientistas e técnicos com larga experiência podem ter problemas com o controle da sedação, de forma que não é incomum que uma parcela dos animais apresentem ruídos provenientes da respiração espontânea (MCGOVERN et al., 2013; HARTNEY; ROBICHAUD, 2013). Observa-se que, nesses casos, o sinal de pressão no domínio do tempo apresenta uma acentuada queda do nível do seu valor pré esforço respiratório para um ponto entre 0 à $-1 \mathrm{~cm} \mathrm{H}_{2} \mathrm{O}$ em um curto intervalo de tempo $(0,2-$ 0,4 s). Com relação a impedância respiratória, o principal efeito desse fenômeno é uma estimação enviesada da mesma, fazendo com que seus valores não correspondam apenas a transferência linear de energia a partir do sinal de entrada, mas também a energia associada à respiração espontânea.

Tal fenômeno prejudica e, por vezes, inviabiliza a estimação dos parâmetros do $C P M$, podendo levar ao descarte de dados de animais que passaram por longos e custosos procedimentos e, consequentemente, ao sacrifício extra de animais. Dessa forma, nesse trabalho, propomos uma alternativa para a extração de informações fisiologicamente relevantes de animais sob tais condições.

\subsection{Objetivos}

Nesta seção, são apresentados os objetivos principais e secundários que motivaram a realização deste trabalho.

\subsubsection{Objetivo principal}

Comparar os resultados obtidos pela FOT em pequenos animais na ausência de respiração espontânea, com a adição de um ruído simulado computacionalmente e a partir do janelamento de um período completo do sinal sem a presença do ruído.

\subsubsection{Objetivos secundários}

Este trabalho possui dois objetivos complementares: 
O entendimento detalhado dos métodos de processamento de sinais utilizados pelo flexiVent (Scireq, Montreal, Canadá) para a estimação da impedância respiratória, permitindo sua reprodução em um ambiente de programação matemática a partir dos sinais de volume de entrada e de pressão de saída.

O aprofundamento no estudo de não linearidades no sistema respiratório a partir da estimação do índice de distorção harmônica buscando compreender as origens da distorção harmônica e da intermodulação a partir de um sinal de entrada multifrequencial bem como a implementação do cálculo do índice de distorção harmômica (ZHANG; SUKI; LUTCHEN, 1995).

\subsection{Justificativas}

A redução no número de animais sacrificados na biologia experimental tem sido objeto de grande debate e uma importante meta buscada pela comunidade científica, seguindo o princípio dos 3 R's (redução, refinamento e reposição) (GUHAD, 2005; FLECKNELL, 2002). Na análise do sistema respiratório de pequenos animais através da FOT, uma das principais causas de descarte de dados é a presença de ruído devido a respiração espontânea do animal. Tal disrupção se caracteriza por uma queda aguda no sinal de pressão num curto intervalo de tempo.

O efeito prático desse evento é a presença de componentes espectrais espúrias quando o sinal de pressão é analisado no domínio do tempo, alterando significativamente a impedância respiratória de entrada do padrão normal observado e levando a um ajuste ruim da impedância ao $C P M$, quantificado a partir do Coeficiente de Determinação $(C O D)$. Uma vez que o valor do $C O D$ é utilizado como critério de aceitabilidade para os dados da FOT (VITORASSO, 2016), a presença de ruído acaba, por vezes, levando a utilização de um maior número de animais.

Uma vez que o sinal de excitação multifrequencial mais utilizado pelo flexiVent (Scireq, Montreal, Canadá) consiste em dois períodos completos de 2 segundos com sobreposição de 50\%, caso o ruído se manifeste no primeiro ou no último segundo do sinal, ainda assim seria possível efetuar um janelamento isolando um ciclo completo sem disrupção do sinal. A partir desse janelamento, acreditamos ser possível extrair informações fisiológicas relevantes de animais que teriam seus dados descartados, evitando assim o desperdício de animais e eventuais sacrifícios. 


\section{REVISÃO BIBLIOGRÁFICA}

Nesse capítulo apresentaremos uma breve revisão dos conteúdos centrais utilizados no desenvolvimento desse trabalho.

\subsection{Técnica das Oscilações Forçadas}

A técnica das oscilações forçadas (FOT) foi originalmente proposta por DuBois, Brody, Lewis e JR (1956) e consiste na avaliação do sistema respiratório como uma caixa preta a partir da resposta do sistema à um sinal multifrequencial aplicado em sua entrada. Em geral, aplica-se na entrada do sistema respiratório um sinal de fluxo composto pela soma de múltiplas senóides com diferentes frequências, fases e amplitudes, e adquirese na saída do sistema um sinal de pressão (SMITH; REINHOLD; GOLDMAN, 2005; OOSTVEEN et al., 2003) (figura 1). Uma vez que, em primeira aproximação, podemos considerar o sistema respiratório como um sistema linear invariante no tempo para pequenas deformações, a partir do princípio da superposição e do uso da Transformada de Fourier, podemos analisar o comportamento de cada senóide de maneira individual por meio da determinação da função de transferência, promovendo uma avaliação rápida, ampla e pouco invasiva do sistema biológico (BATES, 2009).

Devido a grande dificuldade em se adquirir um sinal de fluxo com alto valor da razão sinal por ruído ( $S N R$ do inglês signal to noise ratio), especialmente em pequenos animais, onde o volume de ar aplicado é consideravelmente baixo, alternativas foram desenvolvidas. Schuessler e Bates (1995) desenvolveram um ventilador para pequenos animais ( $S A V$, do inglês Small Animal Ventilator), que futuramente se converteria no flexiVent (SCIREQ, Montreal, Canadá). Nele, utilizaram-se de um pistão em um cilindro hermeticamente vedado para geração do sinal de fluxo. A partir da área de seção transversal do pistão e do deslocamento horizontal do mesmo, pode-se determinar o volume de ar deslocado para o sistema respiratório do animal como função do tempo com grande precisão, permitindo também a determinação do sinal de fluxo através da derivada temporal (figura 2). 
Figura 1: Diagrama da realização da FOT em humanos. Um sinal de fluxo $(\dot{v})$ é aplicado na entrada do sistema respiratório e o sinal de pressão $\left(p_{a o}\right)$ é adquirido na saída do sistema.

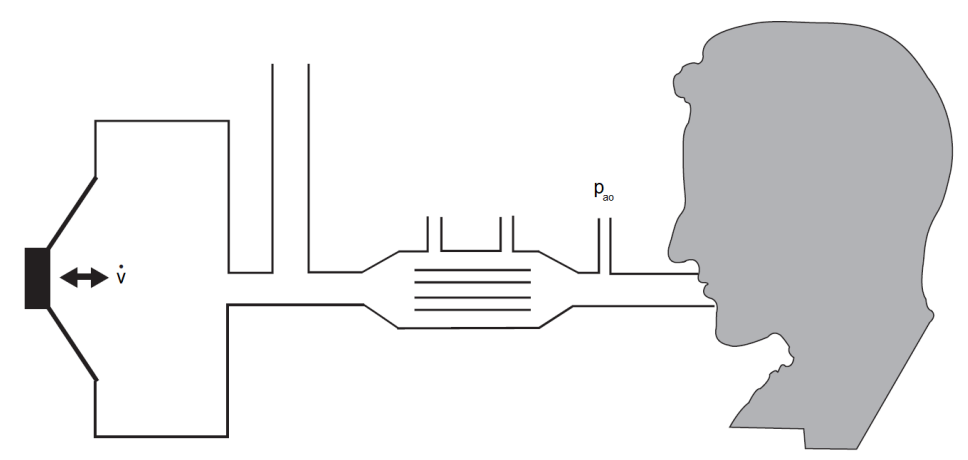

Fonte: adaptado de Bates (2009)

Figura 2: Diagrama da realização da FOT pelo método convencional em pequenos animais. Um sinal de fluxo é aplicado na entrada do sistema respiratório a partir da utilização de um pistão dentro de um cilindro hermeticamente vedado e o sinal de pressão é adquirido na saída do sistema. Uma coluna de água é utilizada para a aplicação de uma pressão estática no final da expiração.

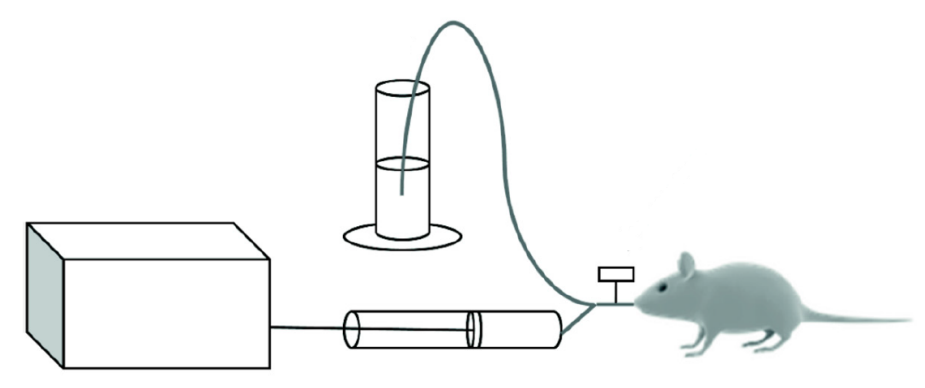

Fonte: Mori et al. (2017)

Uma segunda alternativa foi a utilização de um tubo longo e fino como uma linha de transmissão mecânica entre o gerador de oscilações e a entrada do sistema respiratório. Dessa forma, a partir da aquisição dos sinais de pressão nas extremidades do tubo, bem como de um modelo teórico para estimação da impedância e admitância do tubo, tornase possível a determinação da função de transferência do sistema respiratório, método também conhecido como wavetube (WOESTIJNE et al., 1981) (figura 3).

Vale ressaltar que atualmente grande parte das pesquisas científicas que se utilizam da FOT em pequenos animais se baseiam na utilização ou do flexiVent (MORI; SMITH; SUKI; BATES, 2019; HAMLINGTON et al., 2018) ou do wavetube (SLY; SHACKLETON; CZOVEK; HANTOS, 2018; LORX et al., 2017). No entanto, apesar de ambos os equipamentos se basearem na FOT, nuances presentes em cada um podem impossibilitar 
Figura 3: Diagrama da realização da FOT pelo método do wavetube em pequenos animais. Um sinal é gerado por um alto-falante dentro de uma caixa de som. A perturbação é conduzida até o sistema respiratório por um tubo longo e fino no qual são posicionados transdutores de pressão em suas extremidades. Próximo a entrada do sistema respiratório uma válvula manual alterna a entrada de ar entre a caixa de som (que gera o sinal perturbatório multifrequencial) e um ventilador mecânico externo ligado à uma coluna d'água (que realiza a respiração do animal quando a FOT não está sendo aplicada).

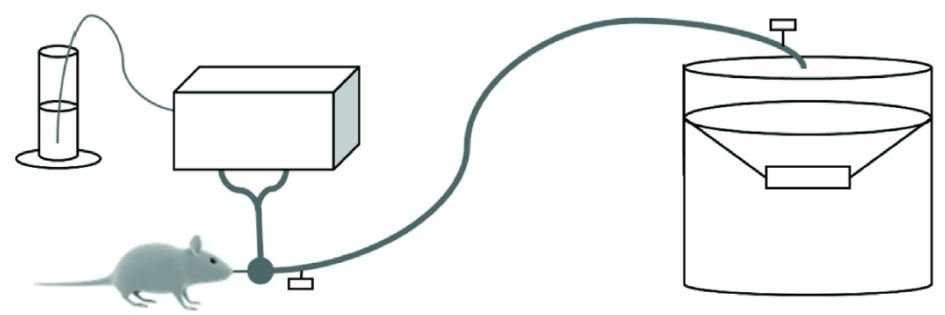

Fonte: Mori et al. (2017)

a comparação direta de resultados obtidos quando um mesmo animal é sujeito a diferentes equipamentos (MORI et al., 2017).

\subsection{Impedância Respiratória de Entrada}

A partir dos sinais de entrada e de saída de um sistema linear invariante no tempo, pode-se caracterizar o mesmo a partir da função de transferência (LATHI, 2017). Tal conceito pode ser aplicado à avaliação do sistema respiratório pela FOT onde também é denominado impedância respiratória de entrada, ou apenas impedância (BATES, 2009). Vale ressaltar que a origem do termo impedância na mecânica respiratória provém da analogia elétrica de conceitos da mecânica dos fluídos, num princípio de impedimento mecânico do fluxo de fluído (MEAD, 1960; LANDSER et al., 1976), também comum no estudo do sistema circulatório (WESTERHOF; BOSMAN; VRIES; NOORDERGRAAF, 1969; MURGO; WESTERHOF; GIOLMA; ALTOBELLI, 1980), devendo-se assim, evitar a confusão da impedância elétrica com a função de transferência, conceitos distintos em Engenharia Elétrica.

A impedância respiratória mecânica $Z(\omega)$ pode ser definida da seguinte forma (BATES, 2009):

$$
Z(\omega)=\frac{\mathfrak{F}[p(t)]}{\mathfrak{F}[\dot{v}(t)]}
$$

onde $\mathfrak{F}[p(t)]$ representa a transformada de Fourier da pressão na entrada das vias aéreas, 
$\mathfrak{F}[\dot{v}(t)]$ a transformada de Fourier do fluxo de ar imposto e $\omega=2 \pi f$, sendo $f$ as frequências presentes no sinal de fluxo.

A impedância respiratória possui uma componente real monotonicamente decrescente, também chamada de resistência, e uma componente imaginária monotonicamente crescente, também chamada de reatância, como mostrado na figura 4.

Figura 4: Impedância respiratória de entrada de um camundongo sujeito à FOT, cujo sinal de entrada é uma composição de senóides com frequências entre 1 e 20,5 $\mathrm{Hz}$.

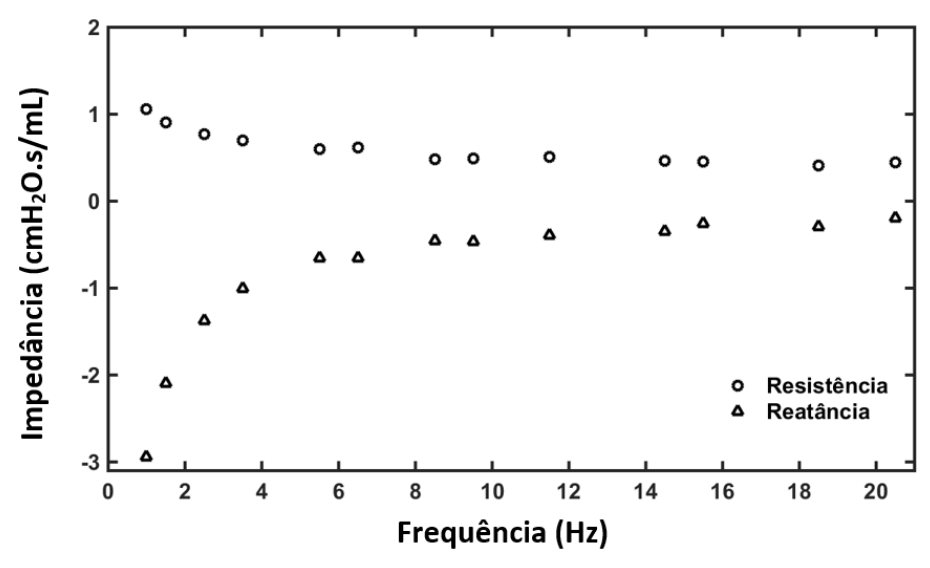

Fonte: Próprio Autor

Enquanto a parte real da impedância é ligada aos componentes dissipativos do sistema respiratório como a resistência mecânica das vias aéreas e o amortecimento mecânico no parênquima pulmonar, a parte imaginária se relaciona com componentes conservativos, como a complacência parenquimal e a inércia dos gases nas vias aéreas (BATES, 2009). A banda de frequência na qual a FOT é realizada e, consequentemente, a impedância é determinada, é de crucial importância para a avaliação do sistema respiratório. Enquanto a resposta em baixas frequências $(<3 \mathrm{~Hz}$ ) possui a capacidade de caracterizar componentes ligados ao parênquima pulmonar, a avaliação em frequências altas $(>3 \mathrm{~Hz})$ permite a avaliação de vias aéreas principais (HANTOS et al., 1992).

Para a estimação da impedância respiratória, vamos considerar o sistema respiratório como linear e invariante no tempo, sujeito à um sinal de entrada de fluxo no tempo $(\dot{v}(t))$ e um sinal de saída de pressão no tempo $(p(t))$. A função de autocorrelação do processo $\dot{v}(t)$ é definida por (LATHI, 2017):

$$
R_{\dot{v} \dot{v}}(t)=\int_{-\infty}^{+\infty} \dot{v}(t-\tau) \cdot \dot{v}(\tau) d \tau
$$


Seja $z(t)$ a resposta do sistema à um impulso unitário. Podemos então escrever o sinal de pressão na saída do sistema respiratório como (LATHI, 2017):

$$
p(t)=\int_{-\infty}^{+\infty} \dot{v}(t-\tau) \cdot z(\tau) d \tau
$$

De maneira que a função de correlação cruzada dos processos $\dot{v}(t)$ e $p(t)$ é dada por (LATHI, 2017):

$$
R_{p \dot{v}}(t)=\int_{-\infty}^{+\infty} p(t-\tau) \cdot \dot{v}(\tau) d \tau=\int_{-\infty}^{+\infty} z(t-\tau) \cdot R_{\dot{v} \dot{v}}(\tau) d \tau
$$

Analisando a equação 2.2 no domínio da frequência com o auxílio da Transformada de Fourier, obtemos a densidade espectral de potência (MANOLAKIS; INGLE, 2011):

$$
S_{\dot{v} \dot{v}}(\omega)=\int_{-\infty}^{+\infty} R_{\dot{v} \dot{v}}(t) \cdot e^{-j \omega t} d t
$$

Analogamente, podemos analisar a equação 2.4 no domínio da frequência, obtendo a densidade espectral de potência cruzada:

$$
S_{p \dot{v}}(\omega)=\int_{-\infty}^{+\infty} R_{p \dot{v}}(t) \cdot e^{-j \omega t} d t=Z(\omega) \cdot S_{\dot{v} \dot{v}}(\omega)
$$

onde $Z(\omega)$ é a transformada de Fourier da resposta do sistema à um pulso unitário.

Por fim, a estimação da função de transferência $(\hat{Z}(\omega))$ pode ser determinada a partir da razão entre a estimação da densidade espectral de potência cruzada $\left(\hat{S}_{p \dot{v}}(\omega)\right)$ e a estimação da densidade espectral de potência $\left(\hat{S}_{\dot{v} \dot{v}}(\omega)\right)$ (PEEBLES; READ; READ, 2001):

$$
\hat{Z}(\omega)=\frac{\hat{S}_{p \dot{v}}(\omega)}{\hat{S}_{\dot{v} \dot{v}}(\omega)}
$$

Sendo esta a equação mais empregada na avaliação da impedância respiratória.

\subsection{O Modelo de Fase Constante $(C P M)$}

A modelagem matemática do sistema respiratório é um passo fundamental na sua análise mecânica, uma vez que permite traduzir em parâmetros fisiológicos a impedância estimada. Modelos matemáticos para o sistema respiratório podem ser trabalhados tanto 
no domínio do tempo quanto no domínio da frequência e podem possuir graus de complexidade bastante diversos. Vale ressaltar que, na modelagem de um sistema biológico, é de extrema importância que os parâmetros possuam interpretação fisiológica. Além disso, um limitante para o grau de complexidade de modelos para o sistema respiratório é o pequeno número de variáveis que podem ser medidos, como fluxo, volume e pressão (SIMILOWSKI; BATES, 1991).

Talvez o modelo mais simples e mais utilizado no domínio do tempo é o chamado modelo de compartimento único viscoelástico, que se baseia no conceito intuitivo de que o sistema respiratório pode ser simplificado a um balão, representando os pulmões e caixa torácica, com uma elastância $E$ e uma dissipação de energia no parênquima descrita por $R_{t}$, com um tubo na sua entrada, representando as vias aéreas, com uma resistência newtoniana $R_{a w}$, como mostra a figura 5:

Figura 5: O modelo de compartimento único viscoelástico.

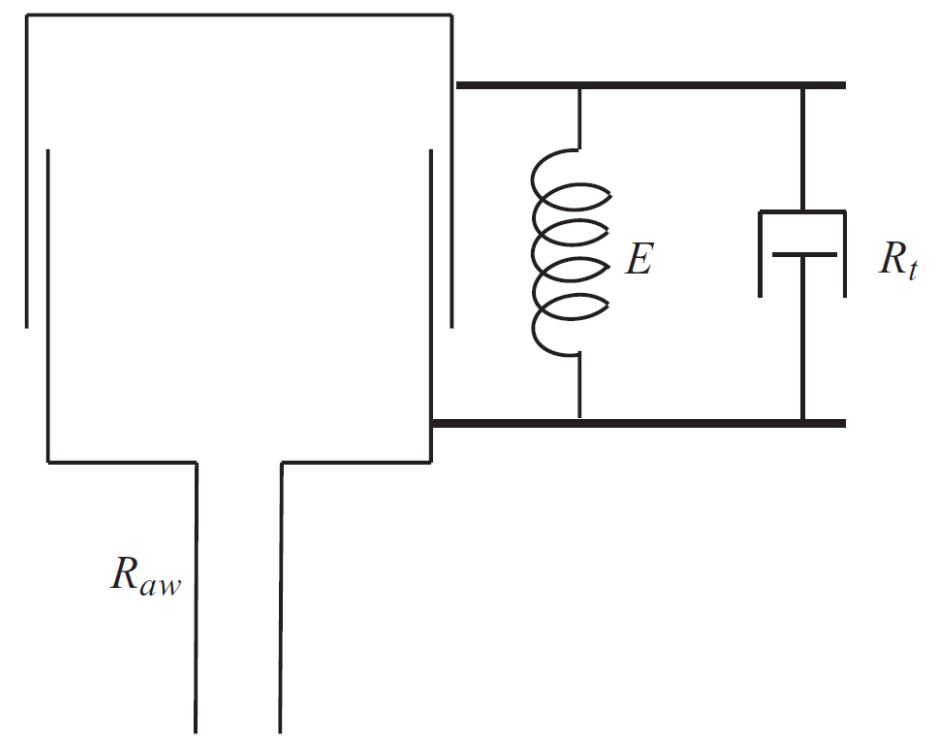

Fonte: Bates (2009)

No domínio do tempo, sendo $v(t)$ o volume de gás deslocado para dentro do sistema respiratório com o seu fluxo correspondente $\dot{v}(t), p(t)$ a pressão na saída do sistema e $p_{0}$ a pressão atmosférica externa, o modelo de compartimento único viscoelástico pode ser equacionado como (BATES, 2009):

$$
p(t)=p_{0}+\left(R_{a w}+R_{t}\right) \cdot \dot{v}(t)+E \cdot v(t)
$$

Apesar de sua simplicidade, tal modelo é capaz de capturar os aspectos mais importantes da respiração apresentando um ótimo ajuste aos dados experimentais, como 
mostrado na figura 6 :

Figura 6: De cima para baixo, sinal de fluxo em função do tempo, sinal de volume em função do tempo, sinal de pressão adquirido e ajuste do modelos de compartimento único viscoelástico, e resíduos do modelo.

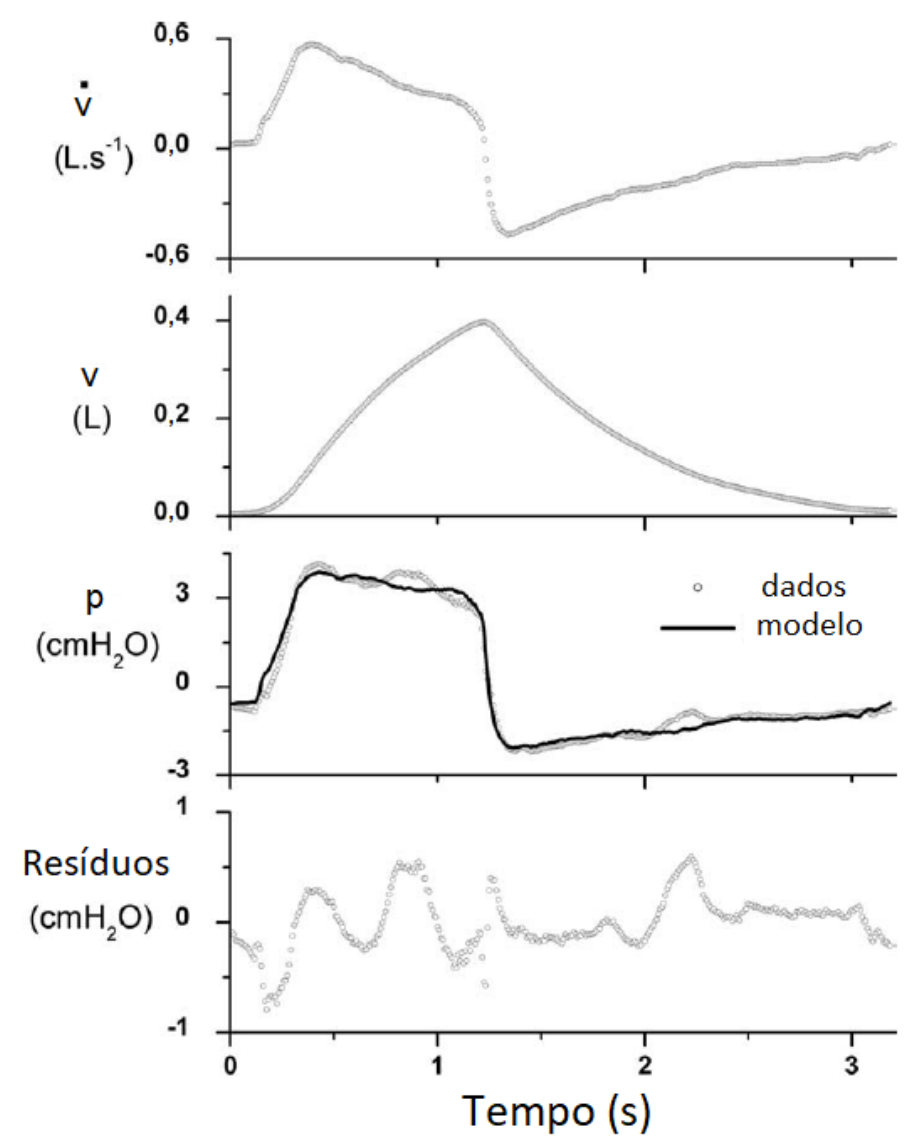

Fonte: adaptado de Bates (2009)

Todavia, uma considerável quantidade de evidências experimentais sugerem que, tanto as resistências, quanto a elastância descritos na equação 2.8 possuem uma dependência em relação à frequência que não são previstas no modelo de compartimento único viscoelástico, principalmente em regiões de baixa frequência (HANTOS et al., 1986; HANTOS; DAROCZY; SUKI; NAGY, 1987). Apesar de tal problema ter como possível solução a adição de mais corpos no modelo representado na figura 5, isso aumenta consideravelmente a complexidade da álgebra envolvida sem necessariamente refletir em uma melhor compreensão da mecânica do sistema respiratório.

A utilização de modelos com amortecedores e molas associados em série e paralelo possui uma interpretação fisiológica bastante intuitiva. Contudo, essa associação direta de parâmetros com fenômenos físicos pode ser superficial. Dessa maneira, Hantos e colaboradores (1992) desenvolveram o Modelo de Fase Constante (CPM, do inglês Constant Phase 
Model) como uma resposta à observações experimentais que reportaram a adaptação a tensões em tiras do tecido pulmonar como uma função de potência no tempo (HANTOS et al., 1992). Atualmente o $C P M$ é o modelo no domínio da frequência mais aceito e utilizado na literatura para a descrição do comportamento da impedância respiratória de entrada (BATES; LUTCHEN, 2005).

Observa-se experimentalmente que, para um tecido submetido à um tensão inicial $y_{0}$, o decaimento da mesma no tempo se dá por:

$$
y(t)=y_{0} \cdot t^{-k}
$$

sendo $y_{0}$ e $k$ constantes.

No caso de estudos realizados num pulmão isolado, temos que a queda de pressão depois de uma insuflação também decai como uma função de potência no tempo, ou seja (HANTOS et al., 1992):

$$
p(t)=p_{0} \cdot t^{-k}
$$

sendo $p_{0}$ e $k$ constantes.

De acordo com a teoria de sistemas lineares, uma função de potência no tempo é a resposta de um sistema a uma entrada impulsiva. No caso do sistema respiratório, a insuflação do pulmão se deve a uma entrada aproximadamente em degrau de fluxo. Dessa forma, a impedância do sistema respiratório pode ser calculada a partir da Transformada de Fourier da equação 2.10 (BATES, 2009):

$$
\begin{array}{r}
Z(\omega)=\mathfrak{F}\left(p_{0} \cdot t^{-k}\right)=\left(p_{0} \cdot \sqrt{\frac{2}{\pi}}\right) \cdot \Gamma(1-k) \cdot\left(\frac{\cos \left[(1-k) \cdot \frac{\pi}{2}\right]-j \cdot \operatorname{sen}\left[(1-k) \cdot \frac{\pi}{2}\right]}{\omega^{1-k}}\right)= \\
=\frac{G-j \cdot H}{\omega^{\alpha}} \quad(2.11)
\end{array}
$$

sendo $\Gamma$ a função gama e:

$$
\begin{aligned}
& G=\left(p_{0} \cdot \sqrt{\frac{2}{\pi}}\right) \cdot \Gamma(1-k) \cdot \cos \left[(1-k) \cdot \frac{\pi}{2}\right] \\
& H=\left(p_{0} \cdot \sqrt{\frac{2}{\pi}}\right) \cdot \Gamma(1-k) \cdot \operatorname{sen}\left[(1-k) \cdot \frac{\pi}{2}\right]
\end{aligned}
$$




$$
\alpha=1-k
$$

de maneira que:

$$
\alpha=\frac{2}{\pi} \cdot \tan ^{-1}\left(\frac{H}{G}\right)
$$

O nome "Modelo de Fase Constante"se origina das equações 2.12 e 2.13. A fase da componente parenquimal da impedância pode ser calculada a partir de:

$$
\phi=\tan ^{-1}\left(\frac{H}{G}\right)=(1-k) \cdot \frac{\pi}{2}
$$

que é independente da frequência de excitação do sistema.

Vale ressaltar que tal modelagem se desenvolveu a partir de propriedades do tecido pulmonar de forma que uma modelagem completa do sistema respiratório necessitaria a adição de termos ligados às vias aéreas. Para tal, Hantos et al. (1992) acrescentaram ao modelo a resistência das vias aéreas $R_{N}$ e a inércia do gás nas vias aéreas $(I)$, emergindo com a expressão completa do Modelo de Fase Constante:

$$
Z(\omega)=R_{N}+j \omega I+\frac{G-j \cdot H}{\omega^{\alpha}}
$$

A interpretação fisiológica dos parâmetros do $C P M$ é razoavelmente mais complexa do que no caso de modelos compartimentais. A viscância $(G)$ e a elastância $(H)$ não possuem um análogo físico direto, uma vez que o tecido pulmonar é um complexo sistema de células, fibras, biomoléculas e fluídos que interferem de maneira conjunta no comportamento mecânico do parênquima. Modelos de corpos e molas se mostraram demasiadamente limitados para explicar esse fenômeno que, ainda é pouco compreendido pelos pesquisadores da área (BATES, 2009).

No caso do $C P M$, a viscância pode ser relacionada à dissipação de energia no tecido pulmonar enquanto a elastância ao armazenamento de energia elástica na porção parenquimal. Os componentes ligados à vias aéreas possuem análogos físicos diretos sendo a $R_{N}$ a resistências newtoniana ligada à vias aéreas e $I$ a inércia do gás nas vias aéreas.

Em resumo, o $C P M$ é um modelo matematicamente simples com a capacidade de discernir não só componentes dissipativos e conservativos do sistema respiratório como também tem a habilidade de separar parcialmente componentes ligados à vias aéreas e 
parênquima. Uma vez que a componente parenquimal da equação 2.17 é dividida pela frequência de excitação externa, quando a frequência é próxima de zero a impedância do sistema respiratório é dominada quase que em sua totalidade pela resposta parenquimal. Caso contrário, quando a frequência tende a infinito, a resposta dos tecidos vai a zero, sendo dominada pelo comportamento das vias aéreas (HANTOS et al., 1992).

\subsection{O Ventilador Para Pequenos Animais $(S A V)$}

A realização da FOT em pequenos animais é fortemente condicionada a presença de um equipamento que permita a estimulação do sistema com um sinal de entrada com volume condizente ao tamanho dos pulmões desses animais e a aquisição do respectivo sinal de saída, de baixa amplitude, propriamente acondicionado. Tais requisitos se mostravam um grande desafio técnico dadas as tecnologias disponíveis nos anos 1960, 1970 e 1980, fazendo com que a maior parte dos experimentos fossem realizados em humanos (PESLIN; JARDIN; DUVIVIER; BEGIN, 1984; LANDSER et al., 1976; FISHER; DUBOIS; HYDE, 1968) com alto falantes gerando o sinal perturbatório de entrada.

No final dos anos 1980 e início dos anos 1990, o desenvolvimento de novas tecnologias permitiu a popularização da utilização da FOT em animais de médio porte como cães devido, principalmente, ao trabalho do grupo de pesquisa do professor Zoltan Hantos na Universidade de Szeged na Hungria, que desenvolveu um equipamento para a realização da FOT pelo método do wavetube (HANTOS et al., 1992; HANTOS et al., 1986).

Já em meados dos anos 90, Schuessler e Bates (1995) desenvolveram o primeiro protótipo do "Ventilador Para Pequenos Animais" (SAV, do inglês Small Animals Ventilator). A principal evolução adicionada era a utilização de um pistão servo controlado para a geração do sinal de fluxo de entrada, no lugar de um alto falante. Dessa forma, a partir da área de seção transversal do pistão, do seu deslocamento horizontal e da aplicação de uma derivada em tempo discreto, era possível estimar o sinal de fluxo de entrada sem a necessidade de um pneumotacógrafo que, por possuir um alto volume morto, não permite a aquisição de um sinal de fluxo de amplitude baixa com uma alta relação sinal por ruído, como no caso de experimentos em pequenos animais (BATES; IRVIN, 2003). Uma esquematização dos componentes do $S A V$ pode ser observada na figura 7 .

O sinal multifrequencial de fluxo é gerado em um computador sendo encaminhado para um conversor digital-analógico (DAC, do inglês Digital-to-Analog Converter). Em seguida, tal sinal é levado ao motor linear acoplado a um pistão que se encontra dentro 
Figura 7: Diagrama do $S A V$.

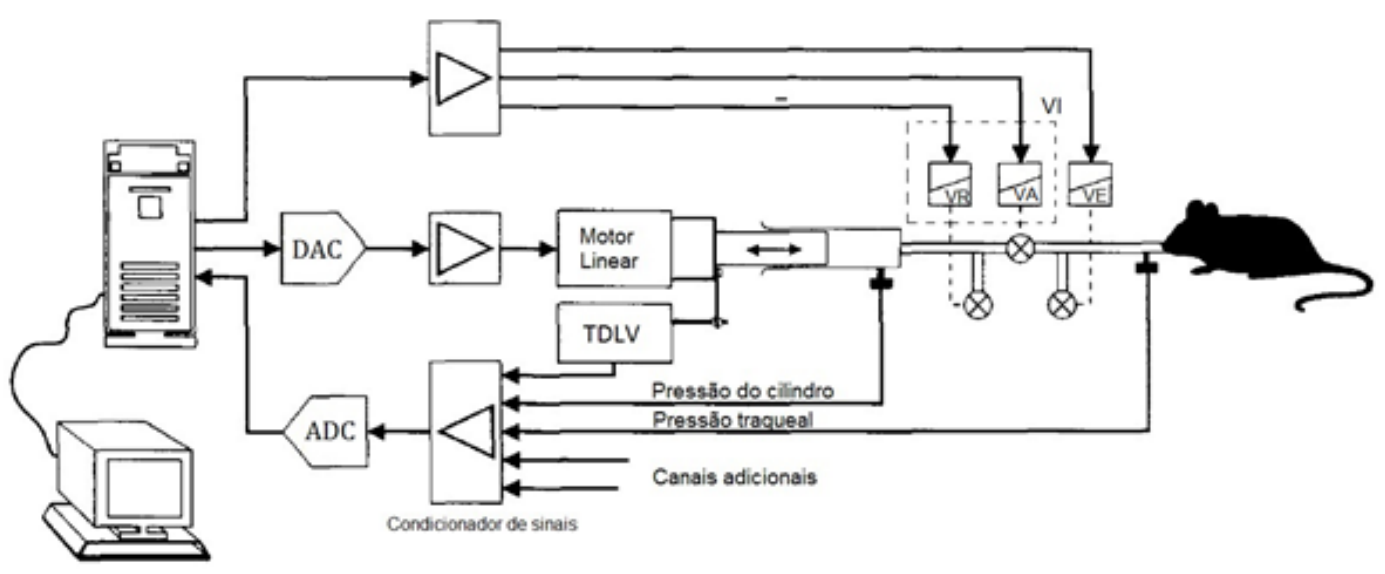

Fonte: adaptado de Schuessler e Bates (1995)

de uma câmara cilíndrica de vidro hermeticamente vedada. Vale ressaltar que a posição do pistão é servo-controlada por um transformador diferencial linear variável (LVDT, do inglês Linear Variable Differential Transformer). Dessa forma, o fluxo de ar pode ser estimado a partir da derivada discreta do volume de ar deslocado, calculado a partir do produto entre a área de seção transversal do pistão e seu deslocamento horizontal (BATES; SCHUESSLER; DOLMAN; EIDELMAN, 1997).

O deslocamento de ar gerado é encaminhado por meio de tubos até o sistema respiratório do animal, passando por uma sequência de válvulas que controlam a inspiração e a expiração do animal. Durante a inspiração, a válvula animal (VA) se mantém aberta enquanto a válvula refil (VR) e a válvula expiratória (VE) permanecem fechadas. Dessa forma, o ar fresco vindo do cilindro é direcionado até o sistema respiratório do animal. Já na expiração, o animal expira passivamente com a VE aberta, direcionando o ar para uma coluna de água que aplica uma pressão hidrostática no sistema respiratório do animal, também conhecida como pressão positiva expiratória final ( $P E E P$, do inglês Positive End-Expiratory Pressure). Ao mesmo tempo, a VA permanece fechada e a VR é aberta, introduzindo ar fresco externo para dentro do cilindro hermeticamente vedado (SCHUESSLER; BATES, 1995).

No $S A V$, o animal se encontra no final da tubulação que contém as válvulas. A conexão do animal com o equipamento se dá por meio da introdução de uma cânula metálica propriamente fixada na traqueia do animal. Vale ressaltar também que o $S A V$ funciona não só como um ventilador mecânico, que mantém o animal respirando quando o mesmo se encontra sob efeito de anestésicos e paralisante muscular, mas também como um gerador de perturbações multifrequenciais para a realização da FOT. 
A partir do modelo original do $S A V$ proposto por Schuessler e Bates (1995) foi desenvolvido o flexiVent (SCIREQ, Montreal, Canadá), equipamento comercial para a realização da FOT em pequenos animais de fácil manuseio e manutenção. Devido a isso não só o $S A V$ mas a própria $F O T$ se tornaram mais acessíveis a diversos grupos de pesquisa fazendo com que a técnica se popularizasse e viesse a ser uma das mais importantes ferramentas de avaliação da mecânica respiratória em pequenos animais. Vale ressaltar que, apesar das importantes evoluções tecnológicas ocorridas de 1995 para os dias atuais, a estrutura geral de funcionamento do $S A V$ não foi alterada de forma que somente as partes que o compõem foram substituídas por versões mais modernas, como por exemplo, transdutores, sistemas de aquisição de dados e o sistema servo-controlado que controla a movimentação do pistão.

\subsection{Processamento Digital de Sinais no $S A V$}

Uma vez que os sinais de fluxo e de pressão são aquisitados no $S A V$, uma sequência de técnicas de processamento digital de sinais é aplicada para a estimação da função de transferência ou, da impedância respiratória de entrada.

O sinal de fluxo de entrada, também chamado de QuickPrime-3, possui duração de 3 segundos e é composto por senóides com os primeiros 13 múltiplos primos da frequência fundamental $0,5 \mathrm{~Hz}(1,1,5,2,5,3,5$ 5,5, 6,5 8,5, 9,5 11,5, 14,5 15,5, 18,5 e 20,5 Hz). Tal sinal possui período de 2 segundos, dessa forma, a sua composição final de 3 segundos é a junção de 1 período completo de 2 segundos seguido por metade do sinal completo, ou seja, um trecho de 1 segundo. Uma forma alternativa de enxergar essa composição é a junção de 2 períodos completos com sobreposição de 50\% (figura 8-A). Para garantir que os espectros de todas as frequências tenham a mesma energia no sinal de fluxo a amplitude de senóide no sinal de volume é proporcional ao inverso do valor da frequência (BATES, 2009) (figura 8-B).

Já o sinal de pressão, também com 3 segundos de duração, é aquisitado por um transdutor de pressão devidamente calibrado. Em ambos os casos, os sinais são discretizados com uma frequência de amostragem de $256 \mathrm{~Hz}$. Para a estimação das densidades espectrais de potência e de potência cruzada (equações 2.5 e 2.6) é utilizada a técnica do periodograma (MANOLAKIS; INGLE, 2011), uma vez que os sinais apresentam redundância.

Para a aplicação do periodograma, primeiramente os sinais de fluxo e pressão, ambos 
Figura 8: A) Sinal multifrequencial de volume no domínio do tempo (QuickPrime-3) gerado pelo $S A V$. Entre as linhas verticais cheias temos o primeiro período completo (0-2 s). Já entre as linhas verticais não preenchidas temos o segundo período completo. Entre as linhas não preenchidas e preenchidas (1-2 s) temos a sobreposição de $50 \%$ do sinal. B) Sinal multifrequencial de volume no domínio da frequência contendo raias nos 13 primeiros múltiplos inteiros primos de $0,5 \mathrm{~Hz}$ e com amplitude proporcional ao inverso da frequência.

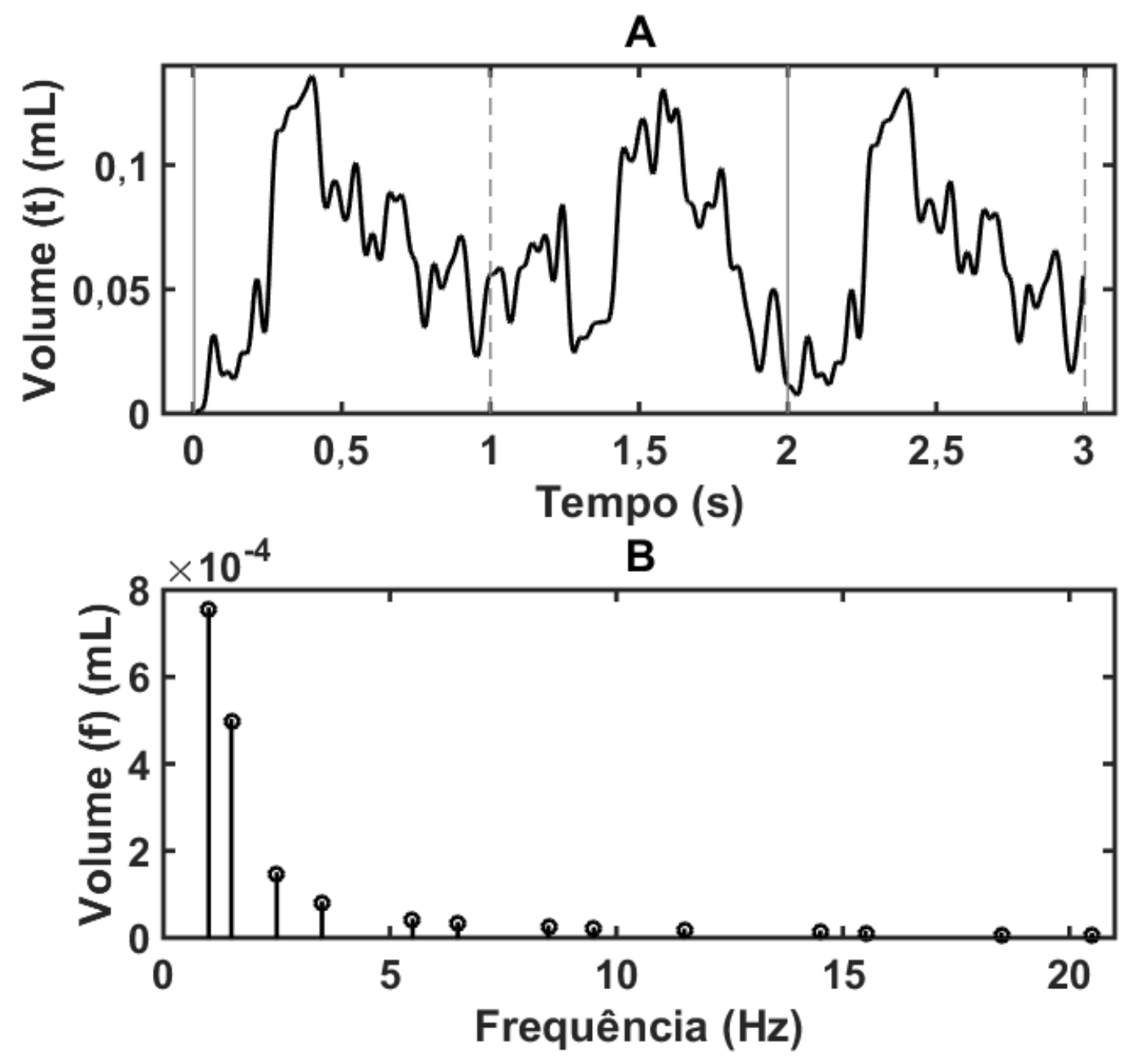

Fonte: Próprio Autor 
com 3 segundos de duração, são separados em trechos de 2 segundos (0-2 s e 1-3 s). Em seguida, cada trecho é convoluído por uma janela que apresenta queda suave a zero nas extremidades e um lóbulo central (janela de Hanning), visando mitigar efeitos de borda (figura 9).

Figura 9: A) Sinal de pressão de saída no domínio do tempo adquirido por um transdutor de pressão. B) Sinal de pressão de saída no domínio do tempo convoluído por uma janela de Hanning, que possui queda suave a zero nas extremidades.
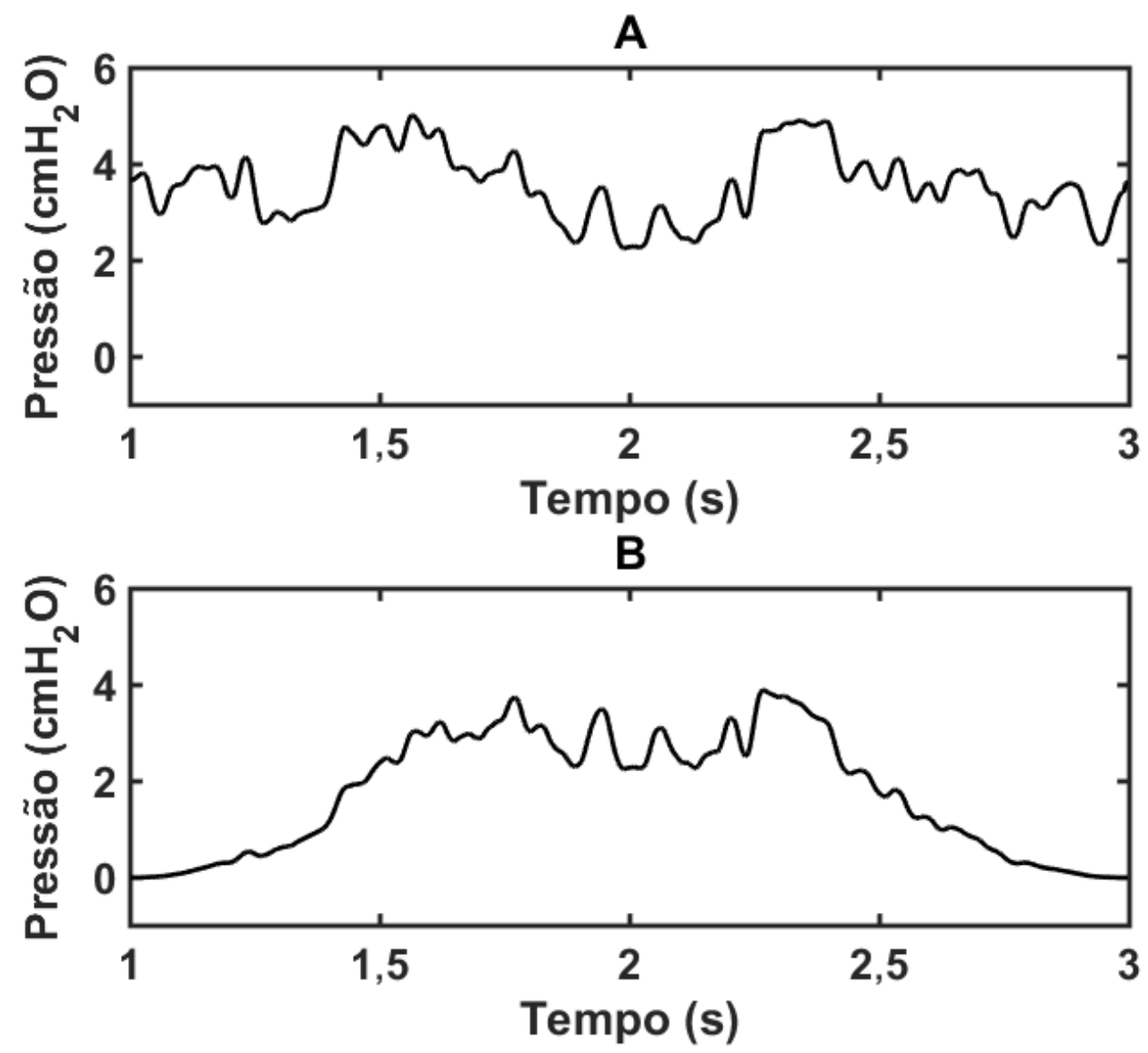

Fonte: Próprio Autor

Em seguida, as densidades espectrais de potência para cada trecho são estimadas em todas as frequências presentes no sinal de entrada. Adiante, é efetuada a média das densidades espectrais obtidas para cada trecho, com o intuito de limpar possíveis contribuições espúrias causadas por ruídos ou vazamentos fazendo com que as raias espectrais sejam mais estreitas. Por fim, a impedância respiratória de entrada é estimada a partir da equação 2.7 (figura 10).

Uma vez estimada tanto a parte real quanto a parte imaginária da impedância, realizamos o ajuste das curvas ao $C P M$ (equação 2.17) a partir da minimização de uma 
Figura 10: A) Parte real da impedância respiratória de entrada. B) Parte imaginária da impedância respiratória de entrada.
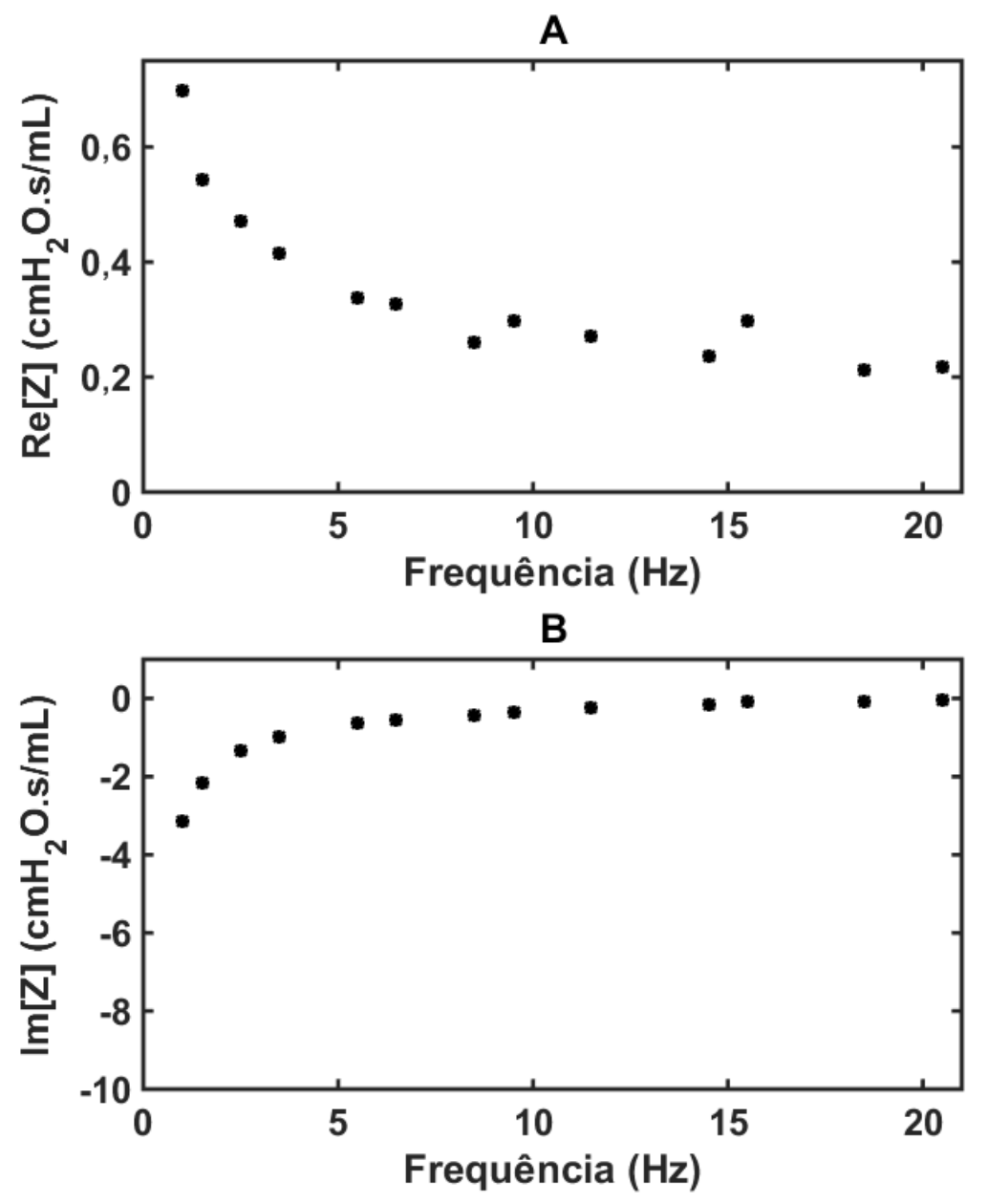

Fonte: Próprio Autor

função custo dada por (THAMRIN et al., 2004):

$$
\Phi=\sqrt{\frac{1}{N} \sum_{i=1}^{N}\left|Z_{d}\left(f_{1}\right)-Z_{m}\left(f_{i}\right)\right|^{2}}
$$

onde $N$ é o número de frequências presentes no sinal de entrada, $Z_{d}$ é a impedância estimada a partir dos sinais de entrada e saída e $Z_{m}$ é a impedância modelala pelo $C P M$ (equação 2.17). Dessa forma, é possível obter não só a estimação dos parâmetros do modelo como também da qualidade do ajuste, através do $C O D$, parâmetro utilizado como critério de aceitabilidade do ajuste ao CPM (VITORASSO, 2016), dado por (BATES, 2009): 


$$
C O D=1-\frac{n \Phi^{2}}{\sum_{i=1}^{n}\left|Z_{d}\left(f_{1}\right)-\overline{Z_{d}}\right|^{2}}
$$

\subsection{Não Linearidades No Sistema Respiratório}

Apesar de uma primeira aproximação do sistema respiratório como tendo um comportamento linear e invariante no tempo para pequenas deformações ser válida e bastante útil para a aplicação da FOT, tanto na utilização do conceito de função de transferência como para a aplicação do CPM (BATES, 2009), o comportamento do sistema respiratório é intrinsicamente não linear (SUKI, 1993). Além disso, uma das origens do recrudescimento de tal comportamento é a presença de patologias como, por exemplo, modelos animais de asma sujeitos à broncoconstrições severas (WAGERS et al., 2002; LUTCHEN et al., 1994; BATES; IRVIN; FARRÉ; HANTOS, 2011) ou a lesão pulmonar induzida por ventilação, que leva ao derecrutamento de unidades pulmonares e, consequentemente, à hiperinflação de unidades ativas (SMITH; BATES, 2013; SMITH; GRANT; BATES, 2013).

Apesar de fenômenos não lineares serem, em geral, bastante complexos e de modelagem geralmente individualizada, tecidos biológicos moles como ligamentos e válvulas cardíacas podem ser modelados como viscoelásticos quasi-lineares (FUNK; HALL; CRANDALL; PILKEY, 2000; DOEHRING; FREED; CAREW; VESELY, 2005), o que significa ser possível separar o comportamento estático não linear do comportamento dinâmico linear (FUNG, 2013). Dessa forma, uma maneira útil de analisar o sistema respiratório é utilizando uma estrutura de blocos em série, com um bloco estático não linear seguido de um bloco dinâmico linear (modelo de Hammerstein) ou com um bloco dinâmico linear seguido de um bloco estático não linear (modelo de Wiener) (MAKSYM; BATES, 1997; SUKI, 1993) (figura 11).

Tanto no modelo de Wiener como de Hammerstein, o sistema linear é simplesmente a resposta impulsiva do sistema, enquanto o sistema não linear é descrito como uma função polinomial (SUKI; ZHANG; LUTCHEN, 1995). Com relação a modelagem do sistema não linear, um polinômio de terceira ordem apresentou o balanceamento ideal entre a qualidade do ajuste e o número de parâmetros livres, garantindo a presença de significado fisiológico para tais parâmetros (SUKI; YUAN; ZHANG; LUTCHEN, 1997). Vale ressaltar que, apesar de Fung (2013) ter proposto o modelo de Hammerstein para a viscoelasticidade quase estática de tecidos moles, o modelo de Wiener apresenta resultados ligeiramente superiores para o sistema respiratório (SUKI; ZHANG; LUTCHEN, 1995). 
Figura 11: Modelos não lineares de Wiener e Hammerstein para o sistema respiratório com um sinal de fluxo de entrada $(\dot{v}(t))$ e um sinal de pressão de saída $(p(t))$.

Modelo de Wiener

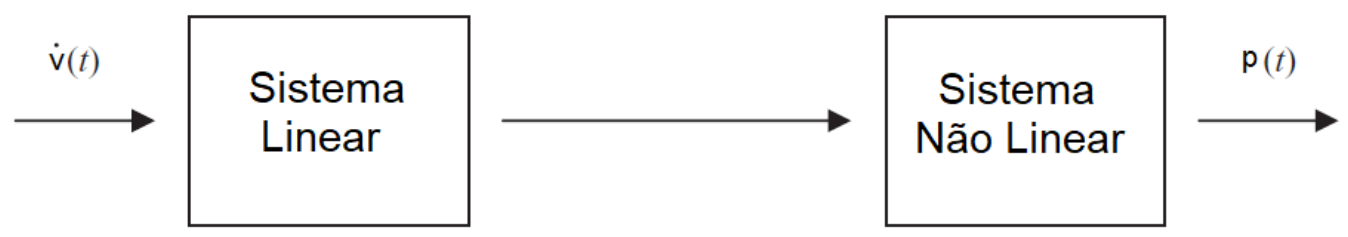

\section{Modelo de Hammerstein}

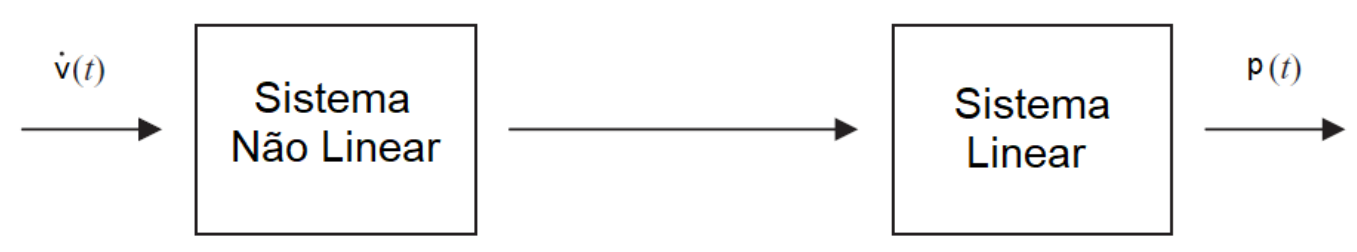

Fonte: adaptado de Bates (2009)

Em termos práticos, para a estimação da impedância respiratória de entrada, a principal consequência da presença de não linearidades no sistema respiratório quando um sinal excitatório composto por senóides de múltiplas frequências é aplicado, é a presença de raias espectrais espúrias quando o sinal de saída é analisado, com contribuições posicionadas em múltiplos inteiros de frequências presentes no sinal de entrada (distorção harmônica) e em combinações lineares de frequências de entrada (intermodulação) (BATES, 2009).

Dado um sinal de entrada $x(t)$, o sinal de saída $y(t)$ do sistema não linear invariante no tempo pode ser descrito no domínio do tempo a partir da série de Volterra (CHUA; NG, 1979; ICHIKAWA; GOTO, 1992):

$$
y(t)=h_{0}+\sum_{n=1}^{\infty} \underbrace{\int_{-\infty}^{\infty} \ldots \int_{-\infty}^{\infty}}_{n} h_{n}\left(\tau_{1}, \tau_{2}, \ldots, \tau_{n}\right) \prod_{k=1}^{n} x\left(t-\tau_{k}\right) d \tau_{k}
$$

onde $h_{n}$ é o $n$-ésimo cerne da série de Volterra. Vale ressaltar que quando $n=1$ temos um sistema com comportamento linear.

No caso de uma entrada composta pela sobreposição de $M$ senóides, ou seja: 


$$
x(t)=\sum_{n=1}^{M} a_{n} e^{\left(j \cdot 2 \pi f_{n} t+\phi_{n}\right)}
$$

Temos que a saída do sistema não linear pode ser descrito no domínio da frequência a partir da transformada de Fourier da equação 2.20 (SUKI; LUTCHEN, 1992):

$$
Y(f)=\sum_{n=1}^{\infty}(\underbrace{\sum_{i_{1}=-M}^{M} \ldots \sum_{i_{n}=-M}^{M}}_{n} H_{n}\left(f_{i_{1}}, f_{i_{2}}, \ldots, f_{i_{n}}\right) \delta\left(f-f_{i_{1}}-\ldots-f_{i_{n}}\right) \prod_{k=1}^{n} A_{i_{k}})
$$

onde $H_{n}$ é a transformada de Fourier do $n$-ésimo cerne da série de Volterra apresentado na equação $2.20, \delta$ é a função delta de Dirac e $A_{i_{k}}=\frac{a_{i_{k}} e^{j \phi_{i_{k}}}}{2}$. Além disso, como $f_{-k}=-f_{k}$, $A_{i_{-k}}=A_{i_{k}}^{*}$.

Analisando a equação 2.22, observamos que, no domínio da frequência, a contribuição não linear de $n$-ésima ordem apresentará raias espectrais em todas as $\left(\begin{array}{c}2 M \\ n\end{array}\right)$ combinações de frequências presentes no sinal de entrada, já considerando as frequências negativas $-f_{k}$ (figura 12). Classificamos a contribuição não linear como distorção harmônica o caso particular onde as $n$ frequências escolhidas são iguais, de maneira que a distorção harmônica de $n$-ésima ordem ocorrerá na frequência $n f_{k}$. Caso pelo menos uma das frequências escolhidas seja diferente, temos a intermodulação (BATES, 2009).

O problema da não linearidade no sistema respiratório se torna delicado quando uma contribuição não linear se manifesta na mesma raia de uma frequência presente no sinal de entrada, tornando impossível separar a mesma da transferência linear de energia e, consequentemente, enviesando a estimação da impedância respiratória de entrada (SUKI; LUTCHEN, 1992; SUKI, 1993; ZHANG; SUKI; LUTCHEN, 1995; BATES, 2009). A escolha das frequências presentes no sinal de entrada podem atenuar tal efeito, porém é impossível eliminar todas as sobreposições de contribuições lineares e não lineares.

Uma possível estratégia para a escolha do conjunto de frequências no sinal de entrada, é a utilização de sinais do tipo prime, que consiste em múltiplos inteiros primos de uma frequência fundamental, como por exemplo, o sinal QuickPrime-3 do SAV (flexiVent, SCIREQ, Montreal, Canadá). Tal sinal consiste nos primeiros 13 números naturais primos multiplicados pela frequência fundamental de $0,5 \mathrm{~Hz}$. Dessa forma, todas as contribuições não lineares se manifestarão em múltiplos inteiros da mesma frequência fundamental e, 
Figura 12: Sinal de fluxo na entrada do sistema respiratório no domínio da frequência (gráfico superior) e sinal de pressão na saída do sistema respiratório (gráfico inferior). Em A, observamos a ausência de raia espectral no sinal de entrada e a presença no sinal de saída, indicando a presença de uma contribuição não linear. Já em B temos a superposição de uma contribuição linear e de uma contribuição não linear.
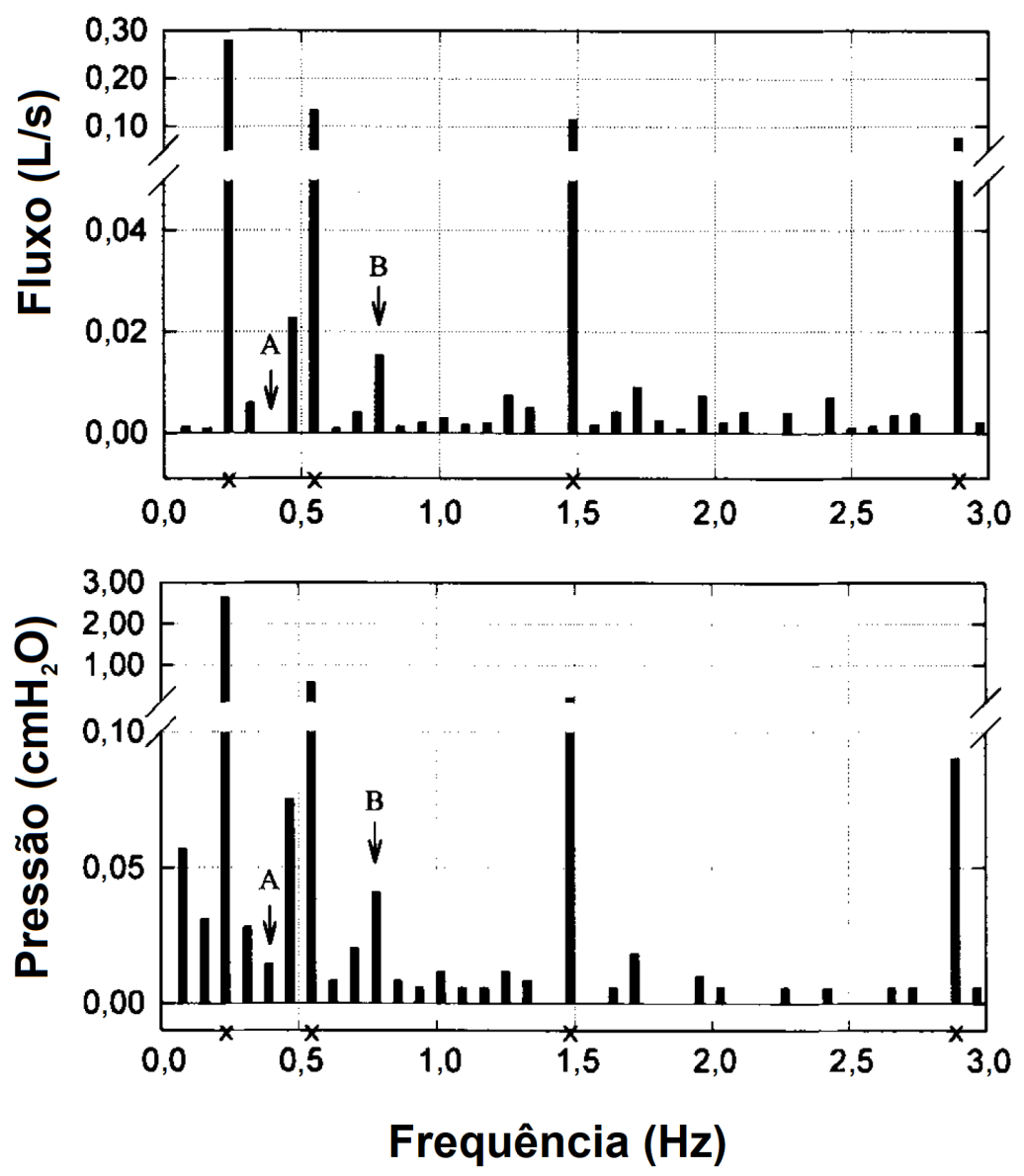

Fonte: adaptado de Zhang, Suki e Lutchen (1995)

mais do que isso, não haverá superposição entre efeitos da distorção harmônica (não linearidades em múltiplos inteiros de frequências presentes no sinal de entrada) e contribuições lineares. No entanto, efeitos da intermodulação ainda serão possíveis como, por exemplo, intermodulação de segunda ordem na frequência $2,5 \mathrm{~Hz}$ devido a contribuição das frequências $1 \mathrm{~Hz}$ e 1,5 Hz (BATES, 2009; SUKI; LUTCHEN, 1992).

Outra alternativa é a escolha dos sinais do tipo NSND (non-sum non-difference). Da mesma forma, tal sinal também é composto por múltiplos primos de uma frequência fundamental, porém, possuem a especificidade de que a combinação de $N$ frequências nunca irá coincidir com uma frequência presente no sinal de entrada, evitando-se assim a presença tanto de distorção harmônica como de intermodulação até a $N$-ésima ordem. Suki e Lutchen (1992) propuseram os sinais $N S N D-2$, que evita efeitos não lineares de 
$2^{\text {a }}$ ordem e $N S N D-4$, que evita contribuições de até $4^{\mathrm{a}}$ ordem, porém, concluíram que as contribuições não lineares possuem maior relevância até a $2^{\mathrm{a}}$ ordem, de forma que o sinal NSND-2 é suficiente para os propósitos almejados (SUKI; LUTCHEN, 1992; SUKI, 1993; BATES, 2009).

Por último, apesar da maior sobreposição de contribuições lineares e não lineares, a versão comercial do SAV (flexiVent, SCIREQ, Montreal, Canadá) se utiliza de sinais do tipo prime devido à presença de um maior número de raias espectrais em regiões de interesse para a avaliação fisiológica.

\subsection{O Índice de Distorção Harmônica}

Para quantificar os efeitos de contribuições não lineares quando um sinal multifrequencial composto por múltiplos inteiros de uma frequência fundamental $\left(f_{0}\right)$ é aplicado, Zhang, Suki e Lutchen (1995) propuseram o índice de distorção harmônica $\left(k_{d}\right)$, uma extensão da proposta de Suki et al. (1991), que definiu um índice para um entrada composta por uma única senóide.

A principal consequência da presença de não linearidades no sistema é a emergência de raias espectrais em frequências espúrias no sinal de saída. Dessa forma, a quantificação da contribuição não linear pode ser feita a partir da razão entre a potência do sinal de saída em frequências diferentes das frequências de entrada $\left(P_{N I}\right)$ pela potência total do sinal $\left(P_{T}\right)$ :

$$
k_{d}=\sqrt{\frac{P_{N I}}{P_{T}}}
$$

A avaliação não-enviesada do índice de distorção harmônica envolve uma série de suposições e correções que serão brevemente descritas nessa seção. O primeiro passo é a estimação da tranferência linear de energia em frequências espúrias que eventualmente estejam presentes no próprio sinal de entrada.

Seja $f_{N I}$ o conjunto de frequências espúrias múltiplas de $f_{0}$ entre a menor e a maior frequência de entrada. Dessa forma, $X\left(f_{N I}\right)$ é a entrada espúria, ou seja, componente do sinal de entrada constituída a partir da sobreposição de senóides com todas as frequências $f_{N I}$. Seja também $Z_{\text {lin }}$ a função de transferência do subsistema linear, ou seja, uma aproximação para da série de Volterra até primeira ordem. Dessa forma, a transferência linear de energia para a entrada espúria $X\left(f_{N I}\right)$ é dada por: 


$$
Y_{l i n}\left(f_{N I}\right)=Z_{l i n}\left(f_{N I}\right) \cdot X\left(f_{N I}\right)
$$

E, consequentemente:

$$
P_{N I}=\sum_{f \neq f_{I}}\left|Y(f)-Y_{\text {lin }}(f)\right|^{2}
$$

onde $Y(f)$ é o sinal de saída aquisitado, no domínio da frequência, $f_{I}$ é o conjunto das frequências de entrada e $f$ é a união entre os conjuntos de frequências $f_{I}$ e $f_{N I}$.

Uma vez que $Z_{\text {lin }}(f)$ não é conhecido a priori, considera-se que em $f_{I}$ o sistema apresenta comportamento quasi-linear. Dessa forma, dos sinais de pressão de saída, de fluxo de entrada e da equação 2.7 estima-se uma impedância aproximadamente linear em $f_{I}\left(Z_{\text {app }}\right)$ e os parâmetros do $C P M$ através da minimização da função custo descrita na equação 2.18. Então, a partir dos parâmetros obtidos em $f_{I}$, extrapola-se a impedância para todo o conjunto de frequências $f$ com o intuito de se obter a impedância modelada $Z_{m}(f)$. Por fim, por considerar o sistema respiratório quasi-linear em $f_{I}$, temos que $Z_{m}(f)=Z_{\text {lin }}(f)$ (ZHANG; SUKI; LUTCHEN, 1995).

Uma vez que a determinação da impedância se dá a partir do ajuste de um modelo, uma correção devido ao erro no ajuste do modelo aos dados $(\epsilon)$ é fundamental para a estimação de $Y_{l i n}(f)$ :

$$
\epsilon=\sqrt{\frac{1}{N} \sum_{f=f_{I}}\left(\operatorname{Re}\left(Z_{\text {app }}(f)\right)-\operatorname{Re}\left(Z_{m}(f)\right)\right)^{2}+\left(\operatorname{Im}\left(Z_{\text {app }}(f)\right)-\operatorname{Im}\left(Z_{m}(f)\right)\right)^{2}}
$$

onde $N$ é a quantidade de valores de $f_{I}$.

Dessa forma, o erro do modelo linear numa frequência qualquer $\left(\delta Z_{m}(f)\right)$ é obtido considerando uma igual contribuição das partes real e imaginária:

$$
\delta Z_{m}(f)= \pm \frac{1}{\sqrt{2}} \epsilon \pm j \cdot \frac{1}{\sqrt{2}} \epsilon
$$

A partir de $\delta Z_{m}(f)$ pode-se calcular o desvio na aproximação linear do sinal de saída devido ao ajuste do modelo $\left(\delta Y_{\text {lin }}(f)\right)$ : 


$$
\delta Y_{\text {lin }}(f)=X(f) \cdot \delta Z_{m}(f)= \pm \frac{\epsilon}{\sqrt{2}}(\operatorname{Re}[X(f)]-\operatorname{Im}[X(f)]+j \cdot[\operatorname{Re}[X(f)]+\operatorname{Im}[X(f)]])
$$

Consequentemente, o erro máximo das componentes reais e imaginárias de $Y_{\text {lin }}(f)$ são:

$$
\left|\operatorname{Re}\left[\delta Y_{\text {lin }}(f)\right]\right|=\left|\operatorname{Im}\left[\delta Y_{\text {lin }}(f)\right]\right|=\frac{\epsilon}{\sqrt{2}}(|\operatorname{Re}[X(f)]|+|\operatorname{Im}[X(f)]|)
$$

Dessa forma, $P_{N I}$ com a correção devido a aproximação do cerne de Volterra de primeira ordem pelo Modelo de Fase Constante a partir da função de transferência nas frequências de entrada é dado por (ZHANG; SUKI; LUTCHEN, 1995):

$$
P_{N I}=\sum_{f \neq f_{I}}\left(\left(\operatorname{Re}[Y(f)]-\operatorname{Re}\left[Y_{\text {lin }}(f)\right]\right)^{2} g_{R e}(f)+\left(\operatorname{Im}[Y(f)]-\operatorname{Im}\left[Y_{\text {lin }}(f)\right]\right)^{2} g_{\operatorname{Im}}(f)\right)
$$

onde:

$$
\begin{gathered}
g_{R e}(f)=\left\{\begin{array}{l}
1, \text { se }\left|\operatorname{Re}[Y(f)]-\operatorname{Re}\left[Y_{\text {lin }}(f)\right]\right|>\left|\operatorname{Re}\left[\delta Y_{\text {lin }}(f)\right]\right| \\
0, \text { se }\left|\operatorname{Re}[Y(f)]-\operatorname{Re}\left[Y_{\text {lin }}(f)\right]\right| \leq\left|\operatorname{Re}\left[\delta Y_{\text {lin }}(f)\right]\right|
\end{array}\right. \\
g_{\operatorname{Im}}(f)=\left\{\begin{array}{l}
1, \text { se }\left|\operatorname{Im}[Y(f)]-\operatorname{Im}\left[Y_{\text {lin }}(f)\right]\right|>\left|\operatorname{Im}\left[\delta Y_{\text {lin }}(f)\right]\right| \\
0, \text { se }\left|\operatorname{Im}[Y(f)]-\operatorname{Im}\left[Y_{\text {lin }}(f)\right]\right| \leq\left|\operatorname{Im}\left[\delta Y_{\text {lin }}(f)\right]\right|
\end{array}\right.
\end{gathered}
$$

Por último, efetua-se uma correção para o ruído branco no sinal de entrada, que também pode levar ao aparecimento de frequências espúrias no sinal de saída do sistema sem qualquer tipo de relação com os fenômenos não-lineares supracitados (distorção harmônica e intermodulação). Considerando que o ruído branco contribui igualmente em todas as frequências, inclusive naquelas distantes do valor máximo presente no conjunto $f_{I}$, podemos estimar a potência média do ruído em cada raia espectral $(N P)$. Dessa forma, podemos remover a influência do ruído na estimação de $P_{N I}$ :

$$
P_{N I}=\left(P_{N I}-N P \cdot L\right) \cdot u\left(P_{N I}-N P \cdot L\right)
$$

onde $L$ é o número de frequências diferentes, múltiplos da frequência fundamental dentro 
do intervalo entre o menor e o maior valor de $f_{I}$ e a funcão degrau unitário é utilizado para evitar valores negativos da potência. Corrigindo também a potência total do sinal de pressão de saída:

$$
P_{T O T}=\sum_{f}|Y(f)|^{2}-N P \cdot(L+N)
$$

onde também se inclui as $N$ frequências de $f_{I}$.

A partir das Eq. 2.34, 2.33 e 2.23 podemos, por fim, determinar o índice de distorção harmônica do sistema. 


\section{MATERIAIS E MÉTODOS}

Nesse capítulo detalharemos os procedimentos matemáticos e computacionais referentes ao processamento digital de sinais da FOT, a metodologia aplicada para a realização de experimentos com animais e a metodologia para análise dos dados obtidos.

\subsection{A Presença de Ruído Na Estimação da Impedância Respiratória de Entrada}

A presença de ruídos provenientes de esforços de respiração espontânea se manifestam como quedas abruptas no nível da pressão para valores entre 0 e $-1 \mathrm{cmH}_{2} \mathrm{O}$ no sinal de saída num curto intervalo de tempo (0,2-0,4 s). Dessa forma, simulamos o surgimento desse fenômeno computacionalmente (MATLAB R2015a, The Mathworks, Natick, EUA) a partir de sinais de pressão previamente coletados por outro estudo (VITORASSO, 2016) (figura 13), uma vez que um dos principais nortes desse trabalho é o desenvolvimento de uma técnica que permita a redução no descarte de dados e, consequentemente, no número de animais sacrificados.

Além disso, como a respiração espontânea se apresenta como um disrupção bastante breve no sinal de pressão no domínio do tempo e, como o sinal QuickPrime-3 apresenta dois períodos completos com sobreposição de $50 \%$, caso tal manifestação ocorra nos intervalos $0-1$ s ou 2-3 s, ainda assim teríamos um período completo do sinal multifrequencial sem ruído, que nos permite a análise da impedância, o ajuste ao $C P M$, a análise dos parâmetros do modelos e a avaliação da não linearidade do sistema a partir do índice de distorção harmônica. Então, geramos, aleatoriamente uma queda na pressão para níveis entre 0 e - $1 \mathrm{~cm} \mathrm{H}_{2} \mathrm{O}$ num intervalo de tempo entre 0,2 e 0,4 s no primeiro ou no último segundo do sinal (figura 13). Por fim, removemos o trecho de 1 segundo de duração que contenha a disrupção ficando apenas com o período completo sem a presença de contribuições espúrias.

Uma vez munidos dos 3 sinais (sinal de 3 segundos sem a presença de ruído, sinal de 3 
Figura 13: Sinal de pressão de saída no domínio do tempo coletado na realização da FOT em um camundongo com a adição computacional de ruído simulando a respiração espontânea do animal entre 2-3 s.

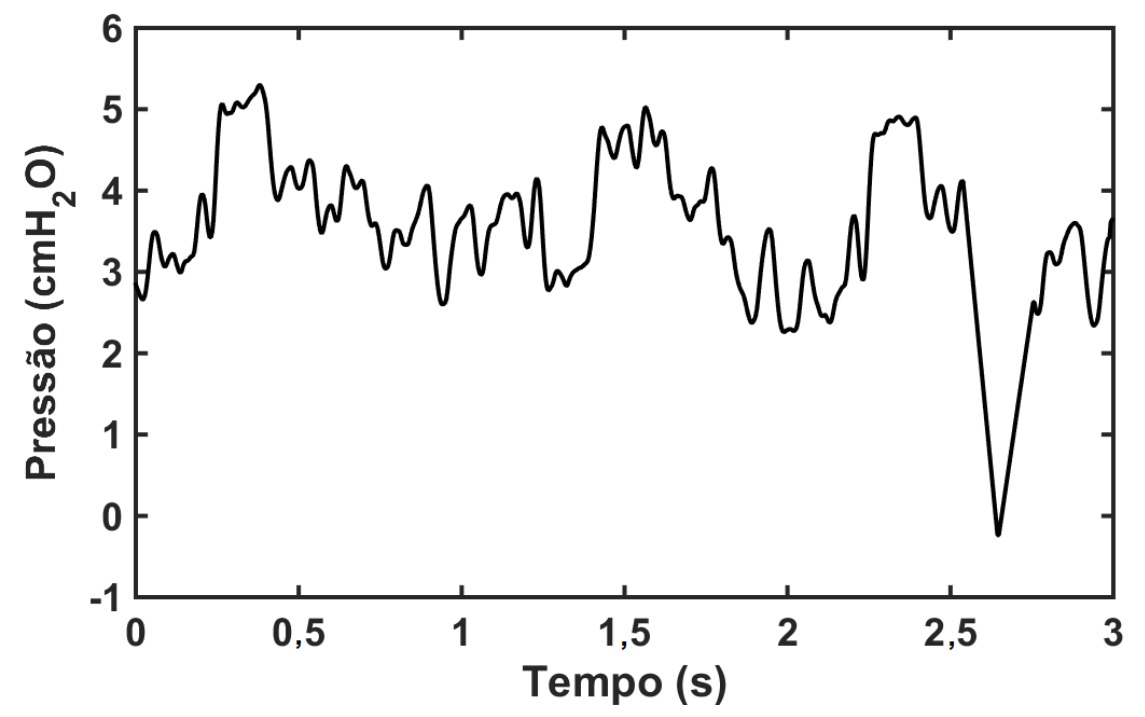

Fonte: Próprio Autor

segundos com o ruído e sinal de 2 segundos sem ruído), estimamos a impedância a partir dos sinais de pressão e de fluxo (equação 2.7), ajustamos o $C P M$ a partir da minimização da função custo (equação 2.18) e obtemos não só os parâmetros do modelo (equação 2.17) como também o COD (equação 2.19). Por fim, efetuamos a avaliação da não linearidade do sistema a partir do índice de distorção harmônica (equação 2.23).

A análise e manipulação dos sinais, a estimação da impedância, o ajuste ao modelo e a estimação do coeficiente de distorção harmônica foram realizados por meio de algoritmos próprios desenvolvidos em uma plataforma de programação matemática (MATLAB R2015a, The Mathworks, Natick, EUA).

\subsection{A Correção do Índice de Distorção Harmônica na Presença de Ruído}

O cálculo do índice de distorção harmônica envolve a estimação do espectro de potência do sinal de saída em frequências diferentes das presentes no sinal de entrada. No entanto, uma sequência de procedimentos devem ser feitos para que transferências lineares de energia em frequências espúrias do sinal de entrada e flutuações naturais devido ao ajuste do modelo não sejam contabilizadas como manifestações não lineares.

Para tal uma sequência de considerações são feitas, sendo a principal a aproximação do 
comportamento do sistema respiratório como quasi-linear nas frequências de entrada $\left(f_{I}\right)$ (ZHANG; SUKI; LUTCHEN, 1995). A partir disso, estimou-se uma impedância aproximadamente linear $\left(Z_{a p p}\right)$ e, consequentemente, parâmetros do $C P M$ que nos fornecem uma extrapolação da impedância em todo o espectro entre a maior e a menor frequência presente no sinal de entrada $\left(Z_{m}\right.$ e $\left.Z_{\text {lin }}\right)$.

No caso da estimação do índice de distorção harmônica com a presença de ruído devido a esforços de respiração espontânea, observa-se um ajuste ruim do $C P M$ à impedância, caracterizado pelo baixo valor do COD, levando a um maior valor do erro do ajuste, representado pela equação 2.26 .

Um maior valor desse erro $(\epsilon)$ faz com que a impedância, quando a extrapolação a partir do parâmetros do modelo é efetuada, apresente uma zona de tolerância $\left(\delta Z_{m}\right)$ maior (equação 2.27). Isso também implica numa maior flutuação do espectro de potência do sinal de pressão no domínio da frequência $\left(\delta Y_{\text {lin }}\right)$ (equação 2.28). A partir das equações 2.31 e 2.32, temos que um ajuste ruim do $C P M$ aos dados e o consequente aumento do erro no ajuste faz com que eventuais manifestações não lineares não sejam contabilizadas como tal mas sim como desvios devido ao ajuste do modelo.

Para analisar o efeito do aumento do erro, propomos uma correção ao cálculo do índice de distorção harmônico. Uma vez que temos a disposição o sinal de pressão antes da adição do ruído, consideraremos que $Z_{a p p}$ é a função de transferência entre o sinal de fluxo de entrada e o sinal de pressão original (3 segundos de duração). Em seguida, a partir de $Z_{\text {app }}$ ajustamos o $C P M$ obtendo assim os parâmetros do modelo, $Z_{\text {lin }}$ e $\epsilon$, fazendo com que $\delta Y_{\text {lin }}$ possua um valor menor.

A partir dos resultados obtidos considerando $Z_{a p p}$ como a função de transferência do sinal corrompido ( $C P M$ corrompido) e do sinal original ( $C P M$ real), avaliaremos o impacto das aproximações efetuadas tanto na aplicação de metacolina por injeções em bolus (figura 25) quanto para infusão contínua (figura 26).

\subsection{Experimentos com Animais}

Todos os experimentos com animais foram aprovados pelo Comitê de Ética para Uso de Animais do Instituto de Ciências Biomédicas da Universidade de São Paulo (n. 15 na página 16 do livro 3, 27/03/2014) e estão de acordo com a Lei Brasileira que regulamenta todas as atividades de pesquisa que envolvam uso de animais (lei n. 11794 de 10/08/2008).

25 amostras de modelos murinos de senescência acelerada (SAMR1) de 3 meses de 
idade do tipo naïve foram divididos em dois diferentes grupos que receberam o broncoconstritor metacolina $(\mathrm{MCh})$ em diferentes doses pela via intravenosa (IV) através de injeções em bolus (15 animais) ou pela via intravenosa através de infusão contínua (10 animais). Os animais foram sedados a partir de uma injeção pela via intraperitonial de uma solução de Cetamina (120 mg/kg) e Xilazina (12 mg/kg). A musculatura respiratória foi bloqueada através da administração intraperitonial do paralisante neuromuscular brometo de pancurônio $(1 \mathrm{mg} / \mathrm{kg})$.

Em seguida, os animais foram traqueostomizados e a canulação foi realizada com uma cânula metálica de tamanho 18G (BD Company, São Paulo, Brasil). Uma vez canulados os animais foram levados ao flexiVent (SCIREQ, Montreal, Canadá) e ventilados por 7 minutos com um volume de $10 \mathrm{~mL} / \mathrm{kg}$, numa frequência respiratória de 150 respirações por minuto e uma $\mathrm{PEEP}$ de $3 \mathrm{~cm} \mathrm{H}_{2} \mathrm{O}$. Após o intervalo de tempo inicial sob ventilação, foram realizadas duas manobras de recrutamento, cada uma consistindo numa inflação de 3 segundos em rampa seguido de 3 segundos com o pistão parado, totalizando uma manobra de 6 segundos, dos pulmões do animal, até que a pressão na entrada das vias aéreas alcançasse o valor de $30 \mathrm{cmH}_{2} \mathrm{O}$.

Para o grupo que recebe o broncoconstritor através de injeções em bolus, imediatamente após as manobras de recrutamento, uma solução salina tamponada de fosfato (PBS) foi administrada através de uma injeção com o auxílio de uma agulha inserida na veia jugular direita, anexada a um tubo flexível de PVC e a uma seringa. Em seguida, foi executado o protocolo de realização da FOT, que consiste em 15 realizações da FOT (cada realização com duração de 3 segundos e consistindo na aplicação do sinal QuickPrime-3), com um intervalo de 5 segundos entre cada realização. Uma vez concluído o protocolo pós administração de PBS diferentes doses de metacolina foram administradas por meio de injeções em bolus através da veia jugular direita $(0,03,0,1,0,3$ e $1 \mathrm{mg} / \mathrm{kg})$ e o protocolo de realização da FOT previamente descrito foi executado para cada dose injetada, totalizando 75 realizações da FOT (figura 14).

De maneira análoga, para a infusão contínua, tanto o PBS quanto as doses de metacolina (por meio de uma solução de metacolina de concentração $320 \mathrm{mg} / \mathrm{ml}$ em taxas de infusão de 48, 96 e $192 \mu \mathrm{g} /(\mathrm{kg} \cdot \min ))$ foram administradas com o auxílio de uma bomba de infusão contínua (11 Plus, Harvard Apparatus, Holliston, EUA) no lugar do tubo de PVC acoplado à seringa. O broncoconstritor foi administrado durante 5 minutos para cada taxa de infusão e a FOT foi efetuada 15 vezes com intervalo de 17 s entre cada realização, para cada taxa de infusão, totalizando 60 realizações (figura 15). 
Figura 14: Protocolo para realização da FOT em camundongos com administração de broncoconstritor por injeções em bolus.

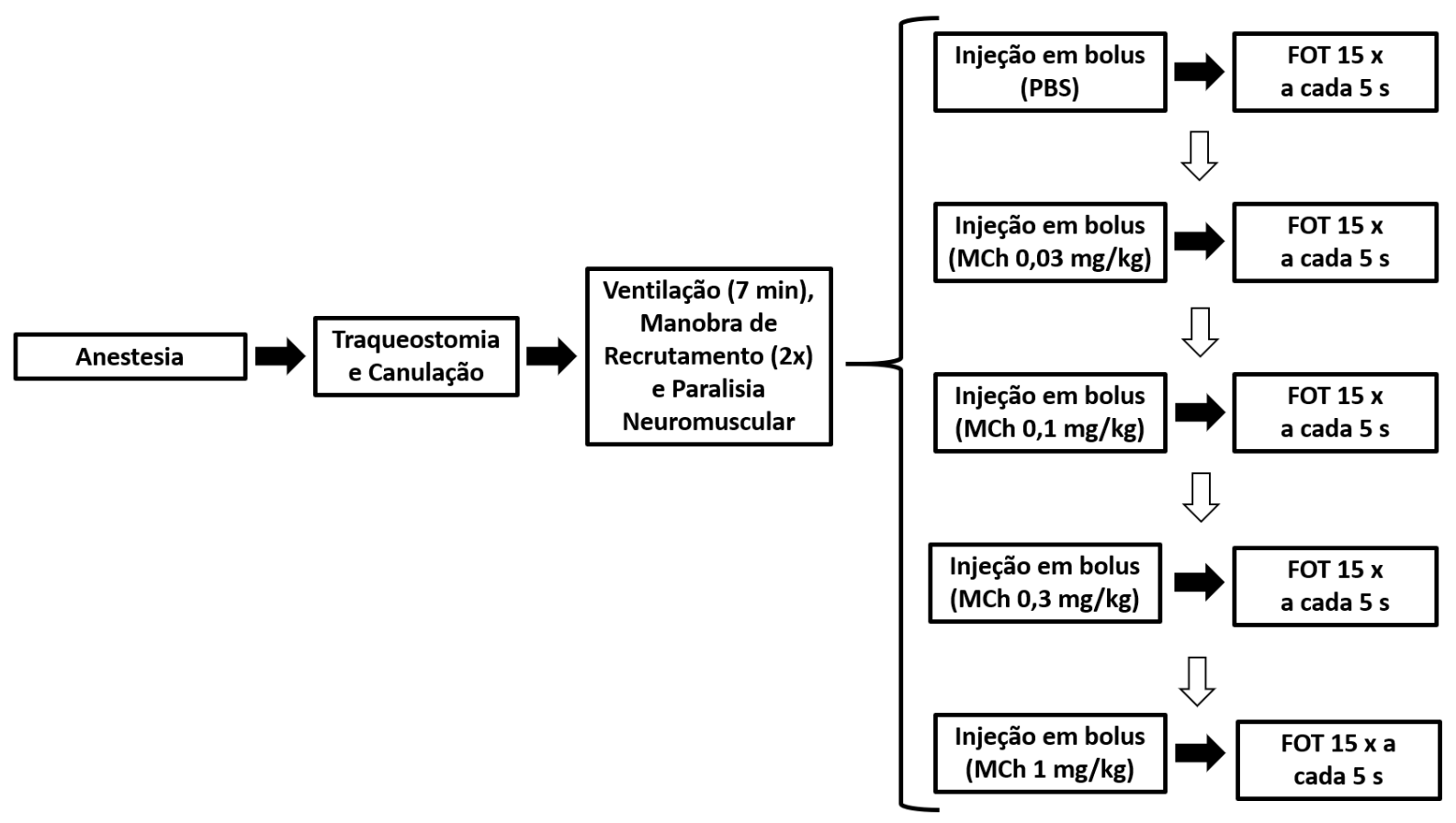

Fonte: Próprio Autor

\subsection{Análise dos Dados}

Foram analisados os valores de $C O D$, os parâmetros do $C P M$ e o índice de distorção harmônica tanto para a administração de broncoconstritor por injeções em bolus quanto para infusão contínua, para os 3 tipos de sinais de pressão de saída: 1) sinal de 3 segundos sem a presença de ruído (Original), 2) sinal de 3 segundos com a presença de ruído (Corrompido) e 3) sinal de 2 segundos tendo sido excluído o trecho de 1 segundo que contenha a simulação da disrupção por respiração espontânea (Janelado).

Para todas as comparações estatísticas feitas, os resultados foram primeiramente submetidos ao teste de normalidade de Shapiro-Wilk. Já as comparação entre grupos foram feitas através do teste $\mathrm{T}$ de Student, caso ambos os grupos apresentassem distribuição normal ou através do teste U de Mann-Whitney caso pelo menos um conjunto rejeitasse a hipótese de distribuição normal. Todos os testes foram realizados por meio de algoritmos próprios construídos em uma plataforma de programação matemática (MATLAB R2015a, The Mathworks, Natick, EUA). 
Figura 15: Protocolo para realização da FOT em camundongos com administração de broncoconstritor por infusão contínua.

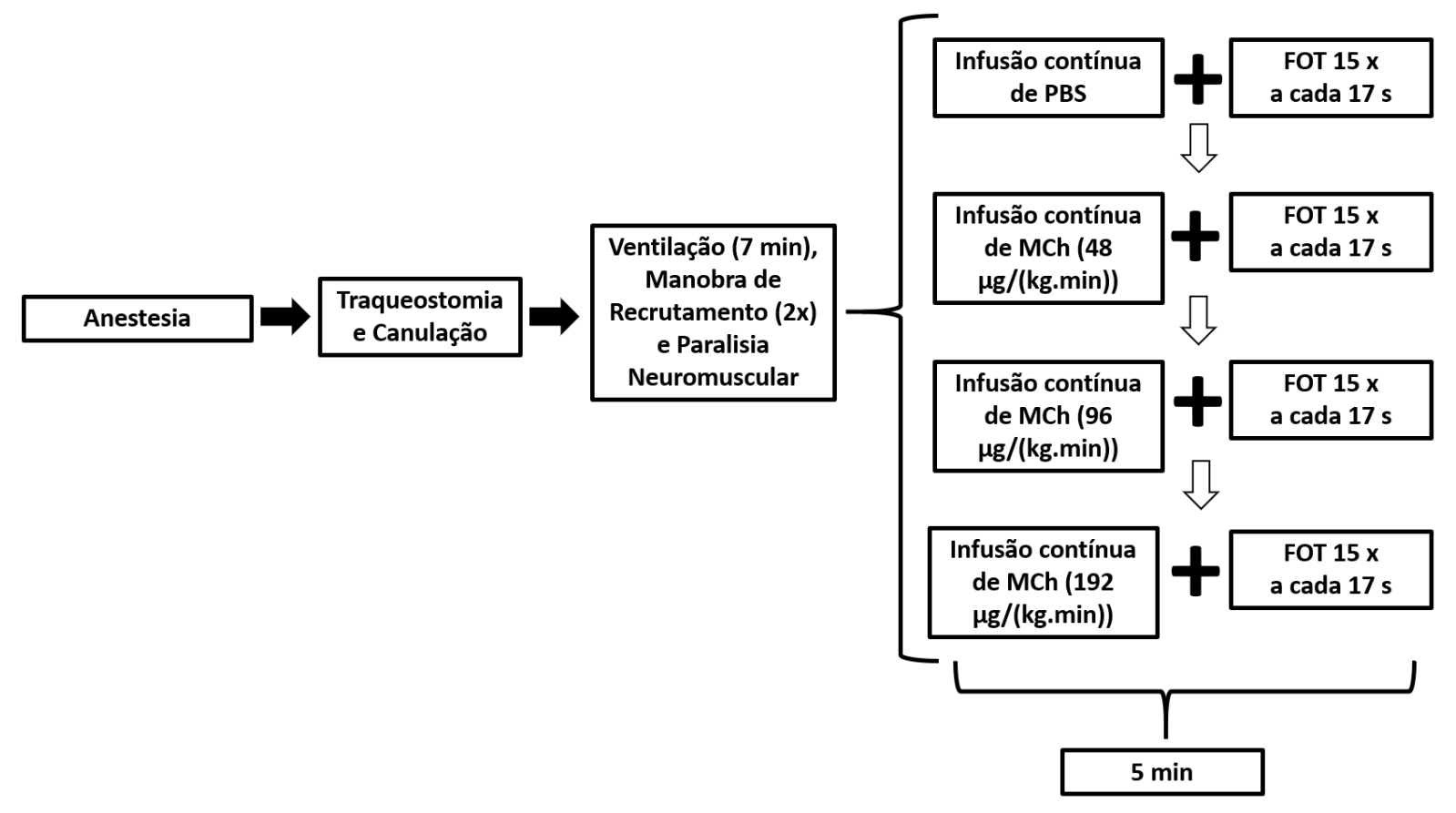

Fonte: Próprio Autor 


\section{RESULTADOS}

Nesse capítulo apresentaremos os resultados obtidos a partir da metodologia descrita no capítulo anterior.

\subsection{Análise do Ruído Simulado}

Para analisar o comportamento da queda de pressão devido a esforços de respiração espontânea no domínio da frequência, efetuamos a FFT de 100 ruídos gerados computacionalmente (MATLAB R2015a, The Mathworks, Natick, EUA) a partir das regras citadas no capítulo anterior e efetuamos a média do espectro gerado em múltiplos inteiros da frequência fundamental, entre a menor e a maior frequência presente no sinal de entrada (0,5 e 20,5 Hz respectivamente) (figura 16).

Como observado na figura 16, a maior parte da contribuição do ruído no espectro de potência do sinal de pressão ocorre entre 0 e $5 \mathrm{~Hz}$, com pico em $0,5 \mathrm{~Hz}$.

\subsection{Coeficientes de Determinação}

Primeiramente apresentamos os gráficos com os valores médios mais ou menos dois erros médios padrões do $C O D$ para as 75 realizações da FOT nas quais o broncoconstritor foi administrado em diferentes doses via injeções em bolus (15 animais) (figura 17) e para as 60 realizações da FOT nas quais a metacolina foi aplicada por infusão contínua com diferentes taxas de infusão (10 animais) (figura 18). Por fim foi efetuada a comparação entre os grupos Janelado e Corrompido com relação ao grupo Original.

No gráfico A de ambas as figuras temos os resultados para os sinais Original (quadrados cinzas) e Janelado (triângulos pretos), e a linha pontilhada preta que representa o valor de threshold de 0,9 do COD. Já no gráfico B de ambas as figuras temos os valores do $C O D$ para o sinal corrompido (círculos pretos). 
Figura 16: Média \pm 2 SEM de 100 simulações computacionais do ruído no domínio da frequência.

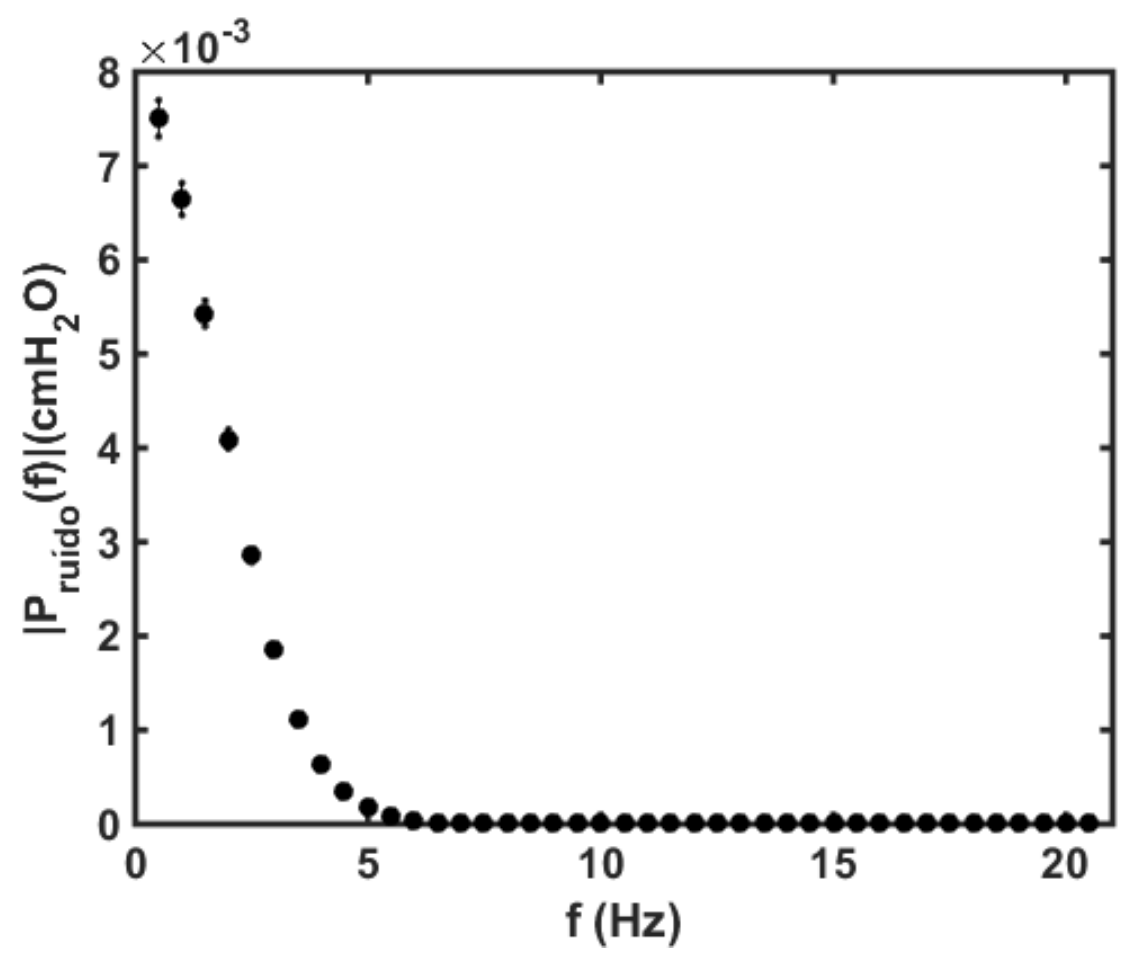

Fonte: Próprio Autor

Nos gráficos A de ambas as figuras observa-se que tanto para o sinal Original quanto para o sinal Janelado o valor do COD diminui a medida que doses ou taxas de infusão maiores de metacolina são administrados. Além disso, na comparação entre os sinais Janelado e Original, todos os testes estatísticos para injeções em bolus e 57 das 60 comparações para infusão contínua mostraram diferenças significantes com valores consistentemente menores do que os apresentados pelo sinal Original.

\subsection{Parâmetros do $C P M$}

A partir do ajuste da impedância ao $C P M$ apresentamos o valor médio mais ou menos dois erros padrões da média dos 3 parâmetros do modelo (resistência das vias aéreas, viscância e elastância) para os sinais Original e Janelado (figura 19) e para o sinal Corrompido (figura 20) a partir da administração de metacolina por injeções em bolus e para os sinais Original e Janelado (figura 21) e para o sinal corrompido (figura 22) após a administração de metacolina por infusão contínua. Igualmente comparamos os grupos Janelado e Corrompido com o grupo Original.

A resistência das vias aéreas $(R)$, viscância $(G)$ e elastância $(H)$ são apresentados nos 
Figura 17: Média \pm 2 SEM do COD de 15 animais obtidos a partir do ajuste do $C P M$ à impedância respiratória de entrada estimada após a administração de broncoconstritor por injeções em bolus em 75 realizações da FOT utilizando o sinal A) Original (quadrado cinza) e Janelado (triângulo preto) B) Corrompido (círculo preto). ${ }^{*} p<0,05,{ }^{\times} p<0,01 \mathrm{e}^{+} p<0,001$.

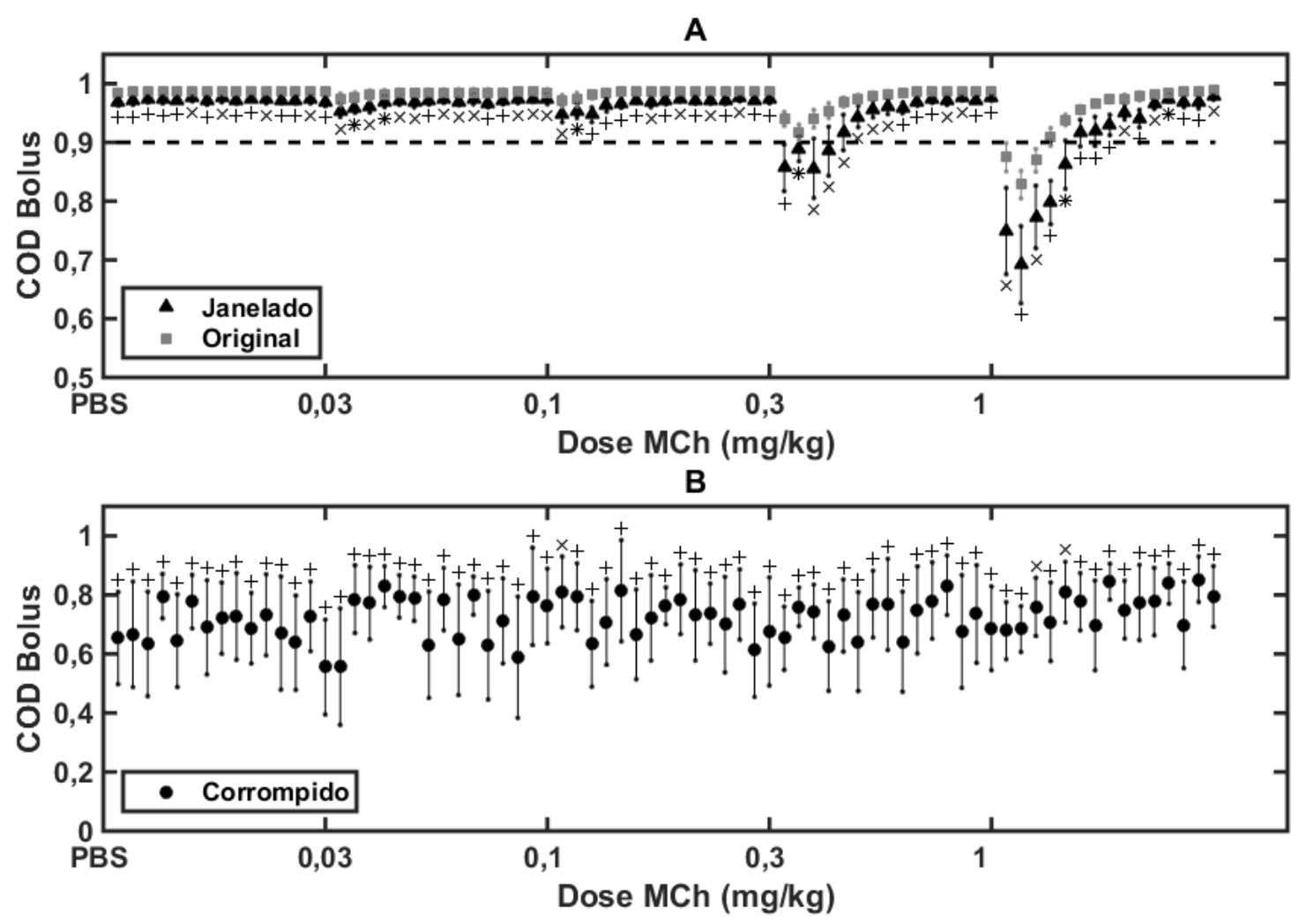

Fonte: Próprio Autor

gráficos A, B e C, respectivamente, das figuras 19, 20, 21 e 22. Nas figuras 19 e 20 temos os parâmetros obtidos após a administração de metacolina por injeções em bolus para os sinais Original (quadrados cinzas) e Janelado (triângulos pretos) (figura 19) e para o sinal Corrompido (triângulos cinzas) (figura 20). Já os resultados para a infusão contínua foram apresentados na figura 21 para os sinais Original (quadrados cinzas) e Janelado (triângulos pretos) e na figura 22 para o sinal Corrompido (triângulos cinzas).

Curiosamente, diferenças estatisticamente significantes não foram observadas na comparação entre todos os parâmetros obtidos a partir dos sinais Original e Janelado tanto para infusão contínua quanto para bolus. Já para a comparação entre os sinais Original e Corrompido, observa-se que para bolus diferenças se mostram presentes em $72 \%$ das realizações para $R$ e $71 \%$ das realizações para $H$ enquanto para $G$, observou-se diferenças em apenas 9 das 75 realizações, principalmente na dose de $0,1 \mathrm{mg} / \mathrm{kg}$. 
Figura 18: Média \pm 2 SEM do $C O D$ de 10 animais obtidos a partir do ajuste do $C P M$ à impedância respiratória de entrada estimada após a administração de broncoconstritor por infusão contínua em 60 realizações da FOT utilizando o sinal A) Original (quadrado cinza) e Janelado (triângulo preto) B) Corrompido (círculo preto). ${ }^{*} p<0,05,{ }^{\times} p<0,01 \mathrm{e}^{+} p<0,001$.

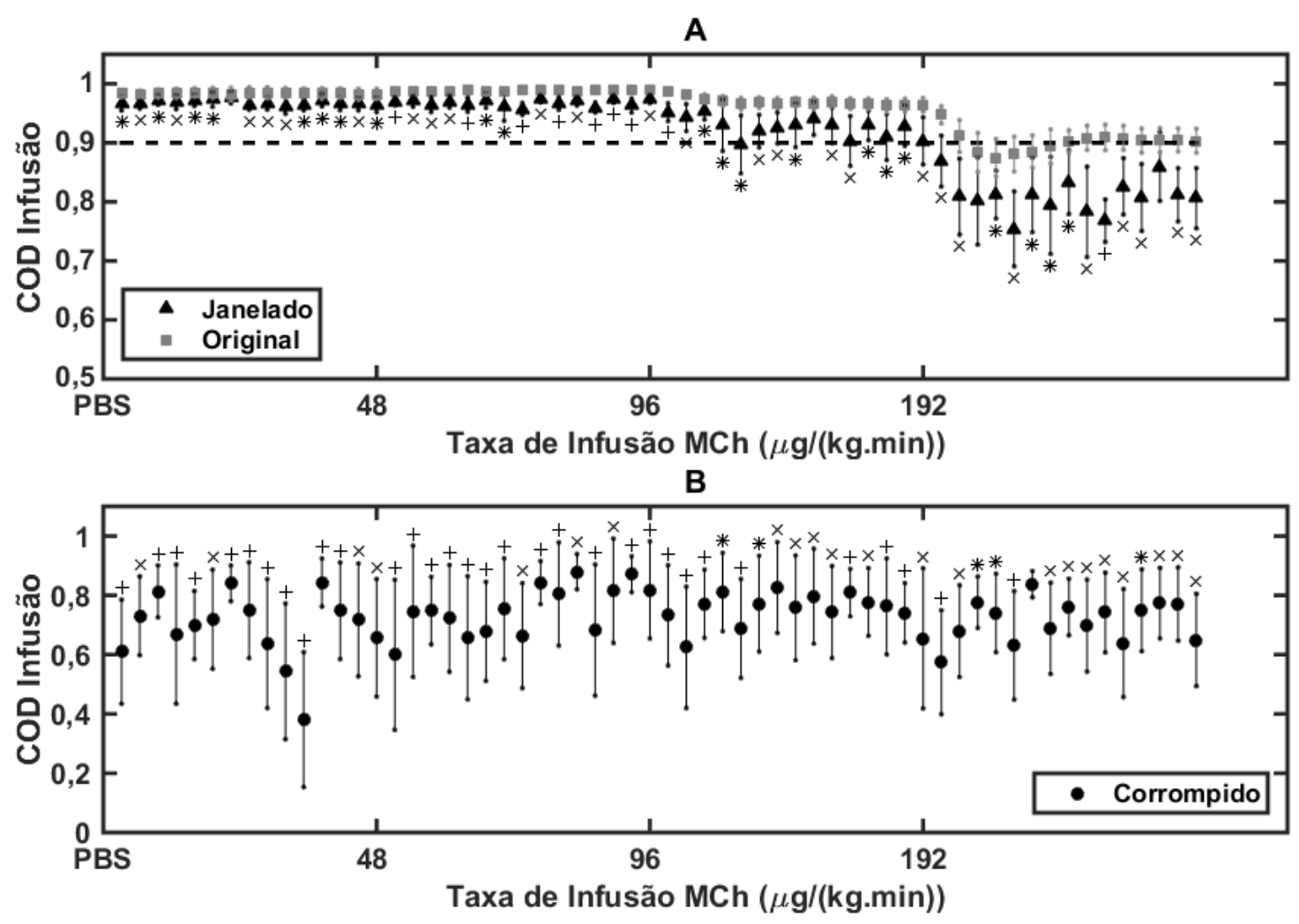

Fonte: Próprio Autor

A comparação entre os sinais Original e Corrompido para infusão contínua mostra diferenças estatísticas apenas no valor basal e na taxa de infusão mais baixa tanto para $R$ (18\% das realizações) quanto para $H$ (20\% das realizações), enquanto para $G$ apenas 4 das 60 realizações apresentaram $p<0,05$.

\section{4 Índices de Distorção Harmônica}

Com relação ao índice de distorção harmônica, primeiramente apresentamos os resultados dos 3 sinais seguindo os passos descritos na seção 2.7, após administração de metacolina por injeções em bolus (figura 23) ou infusão contínua (figura 24) para diferentes doses ou taxas de infusão. Em seguida, comparamos os sinais Janelado (triângulos pretos nos gráficos A) e Corrompido (triângulos cinzas nos gráficos B) com o sinal Original 
(quadrados cinzas nos gráficos A).

Observa-se que tanto para bolus quanto para infusão contínua o índice é maior para o sinal Corrompido do que para o sinal Original, com diferenças estatísticas siginifcantes. Já na comparação entre os sinais Janelado e Original, em $69 \%$ das realizações da FOT após adminsitração de metacolina por bolus se observou diferenças estatísticas. Por outro lado, para a infusão contínua, as diferenças se concentraram principalmente após administração de solução salina e da primeira taxa de infusão de metacolina com $30 \%$ das realizações apresentando diferenças estatísticas.

\subsection{Correção do Índice de Distorção Harmônica}

Nas figuras 25 e 26 apresentamos, tanto para a administração de metacolina por bolus como por infusão contínua, o índice de distorção harmônica para o sinal corrompido calculado a partir da metodologia descrita na seção 2.7, ou seja ajustando o $C P M$ ao sinal corrompido (triângulos cinzas), e a partir da correção proposta na seção 3.2, utilizando o valor do CPM ajustado ao sinal não corrompido (triângulos pretos), ambos no gráfico A. Além disso, no gráfico B, apresentamos as diferenças entre os índices obtidos pelas duas metodologias.

Observa-se que, para a administração de broncoconstritor em ambos os casos diferenças estatísticas entre o índice obtido pelas duas metodologias são observadas em poucas realizações experimentais da FOT (20\% das realizações em bolus e $12 \%$ em infusão contínua). Além disso, o índice calculado a partir dos parâmetros obtidos no sinal não corrompido apresentam valores consistentemente maiores. No entanto, essa diferença vai diminuindo a medida que a dose do broncoconstritor aumenta, chegando a valores muito próximos nas últimas doses.

\subsection{Variação do Índice de Distorção Harmônica com Relação ao Valor Basal}

Por último, avaliamos a diferença entre os valores obtidos após a administração de cada dose do broncoconstritor para a adminsitração em bolus (figura 27) e infusão contínua (figura 28) com relação ao valor basal, ou seja, o valor médio do índice após a administração da solução salina de maneira a avaliar se as flutuações no valor do índice de distorção harmônica se devem unicamente a adição de um offset. 
Apresentamos os resultados tanto para bolus (figura 27) quanto para infusão (figura 28) no caso dos sinais Original (quadrados cinzas no gráfico A), Janelado (triângulos pretos no gráfico A) e Corrompido (triângulos cinzas no gráfico B). Observa-se que apenas em 3 realizaçõs por bolus e 5 por infusão existem diferenças estatisticamente significante entre as variações do índice com relação ao nível basal na comparação entre os sinais Original e Janelado. 
Figura 19: Média \pm 2 SEM dos parâmetros do $C P M$ de 15 animais após a administração de broncoconstritor por injeções em bolus em 75 realizações da FOT com os sinais Original (quadrado cinza) e Janelado (triângulo preto) A) Resistência de vias aéreas $(R)$ B) Viscância $(G)$ e C) Elastância $(H) .{ }^{*} p<0,05,{ }^{\times} p<0,01 \mathrm{e}^{+}$ $p<0,001$.
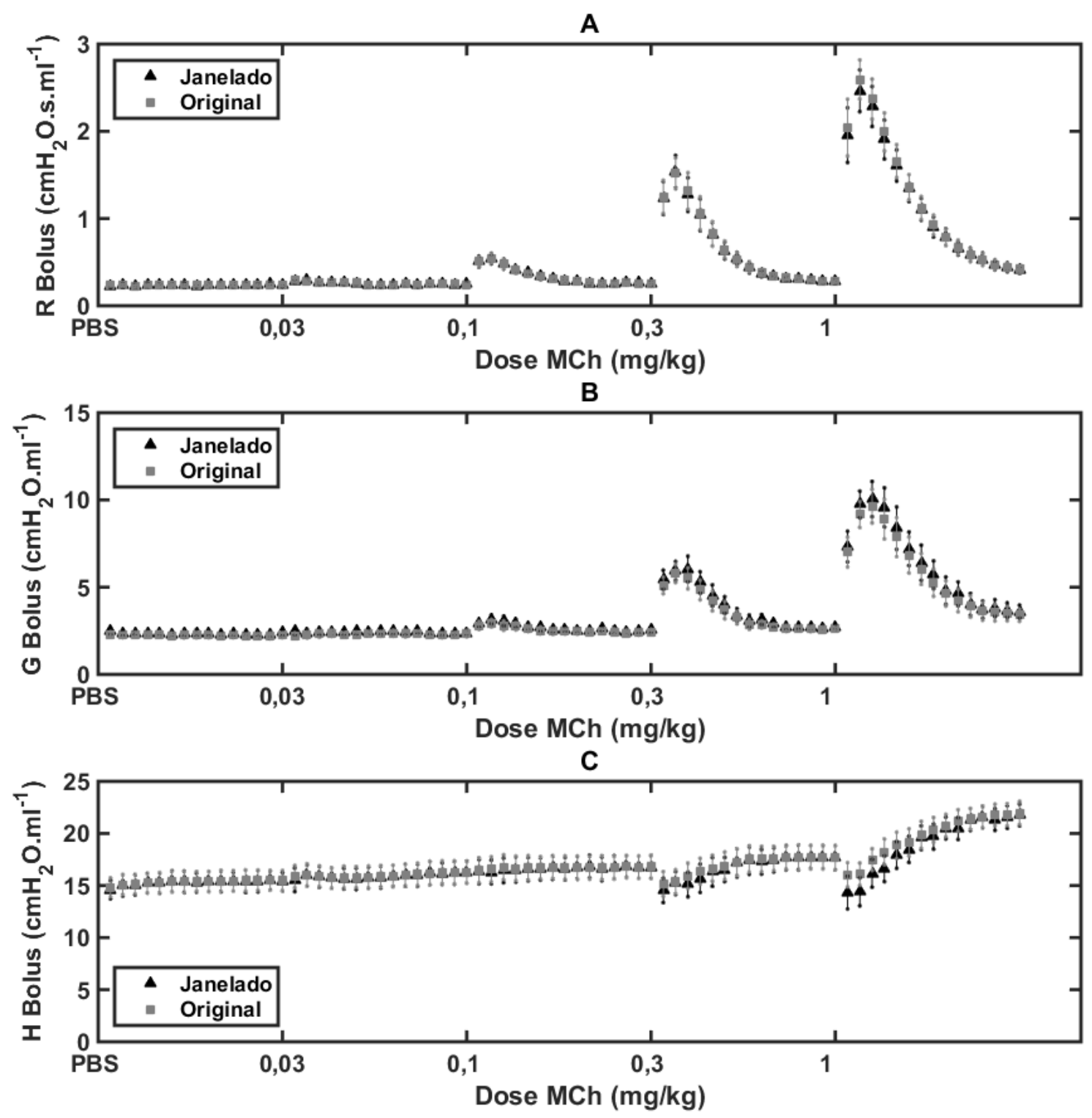

Fonte: Próprio Autor 
Figura 20: Média \pm 2 SEM dos parâmetros do $C P M$ de 15 animais após a administração de broncoconstritor por injeções em bolus em 75 realizações da FOT com o sinal Corrompido (triângulo cinza) A) Resistência de vias aéreas $(R)$ B) Viscância $(G)$ e C) Elastância $(H) .{ }^{*} p<0,05,{ }^{\times} p<0,01$ e ${ }^{+} p<0,001$.
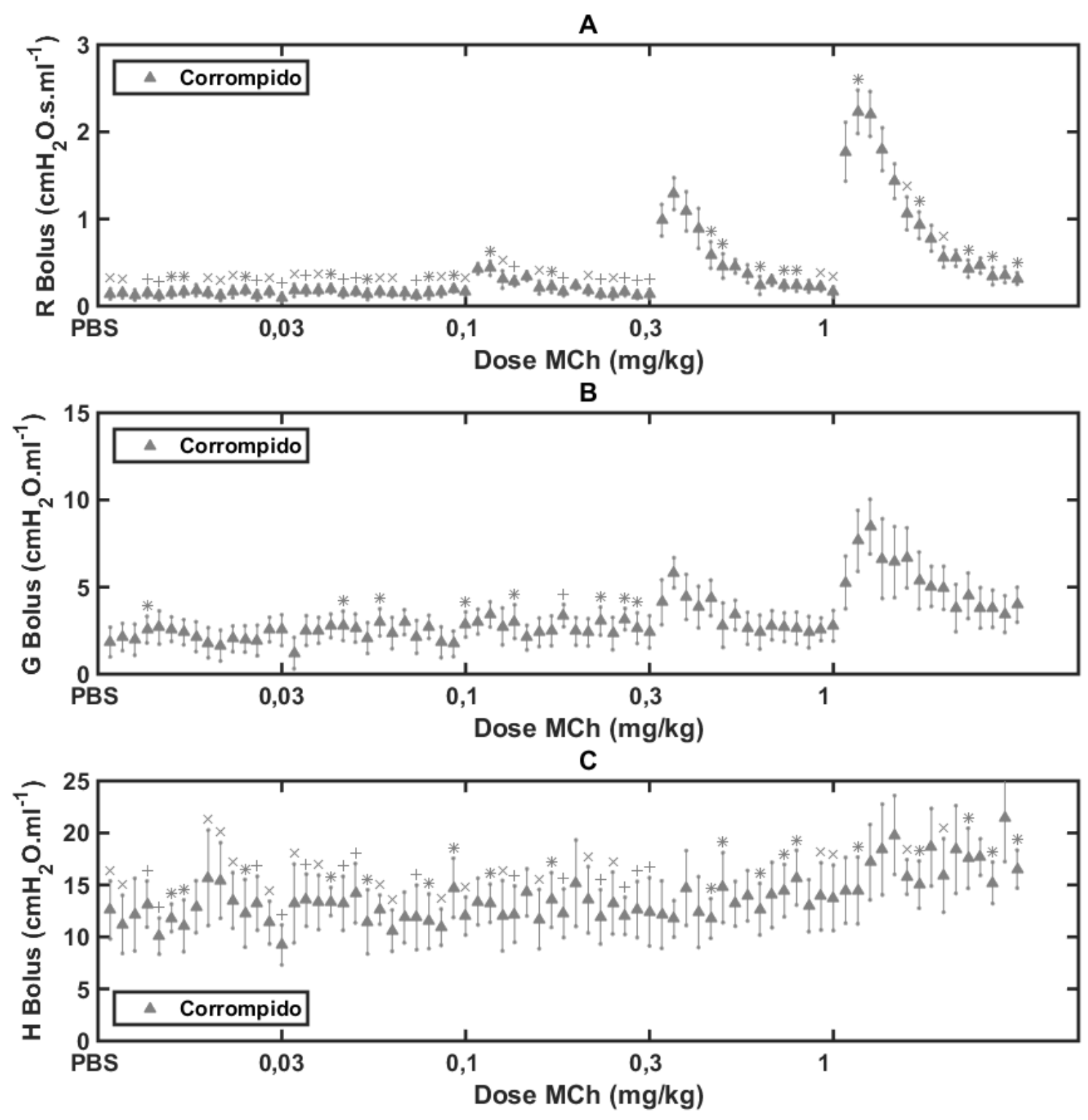

Fonte: Próprio Autor 
Figura 21: Média \pm 2 SEM dos parâmetros do $C P M$ de 10 animais após a administração de broncoconstritor por infusão contínua em 60 realizações da FOT com os sinais Original (quadrado cinza) e Janelado (triângulo preto) A) Resistência de vias aéreas $(R)$ B) Viscância $(G)$ e C) Elastância $(H) .{ }^{*} p<0,05,{ }^{\times} p<0,01 \mathrm{e}^{+}$ $p<0,001$.
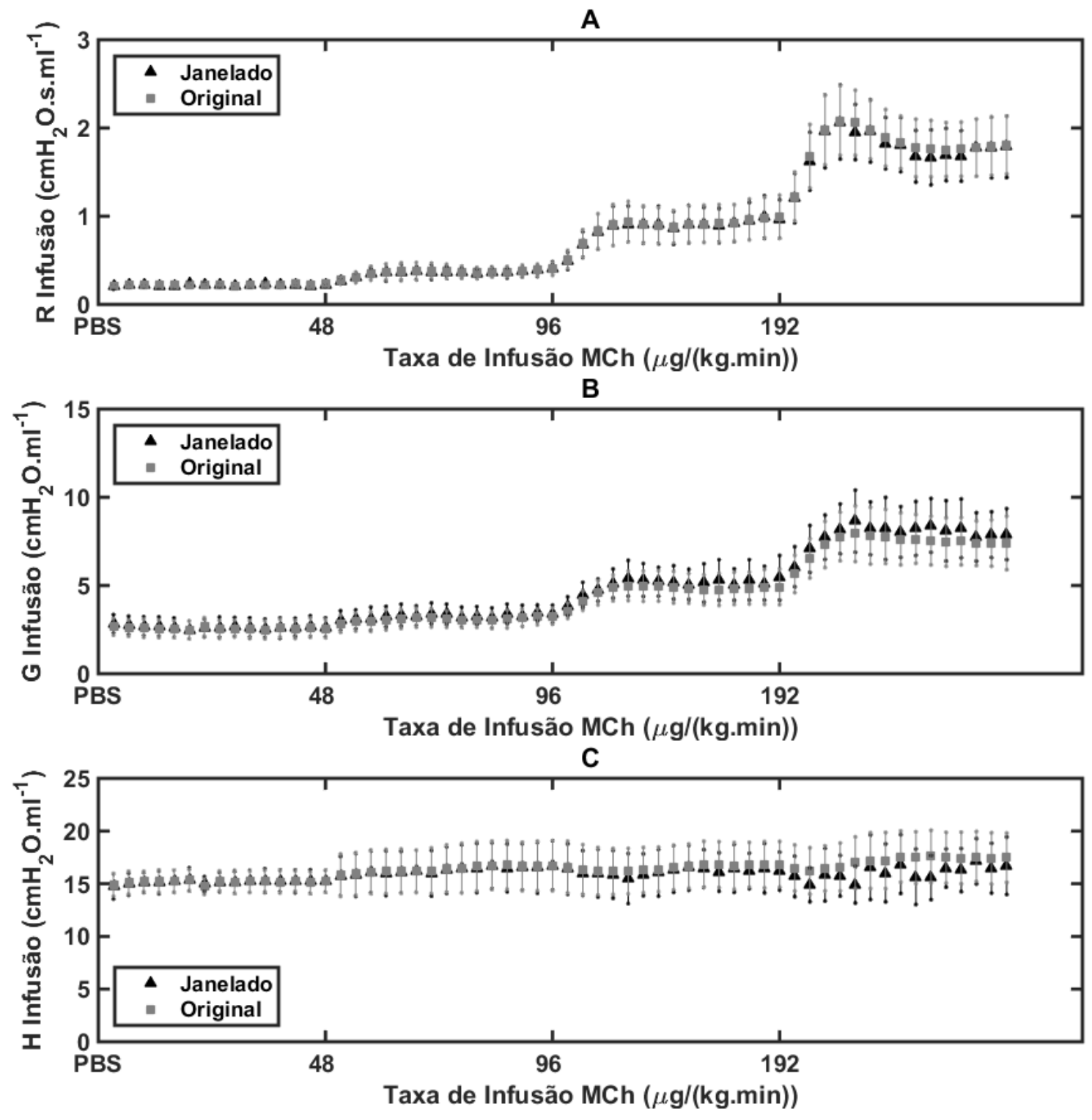

Fonte: Próprio Autor 
Figura 22: Média \pm 2 SEM dos parâmetros do $C P M$ de 10 animais após a administração de broncoconstritor por infusão contínua em 60 realizações da $F O T$ com o sinal Corrompido (triângulo cinza) A) Resistência de vias aéreas $(R)$ B) Viscância $(G)$ e C) Elastância $(H) .{ }^{*} p<0,05,{ }^{\times} p<0,01$ e ${ }^{+} p<0,001$.
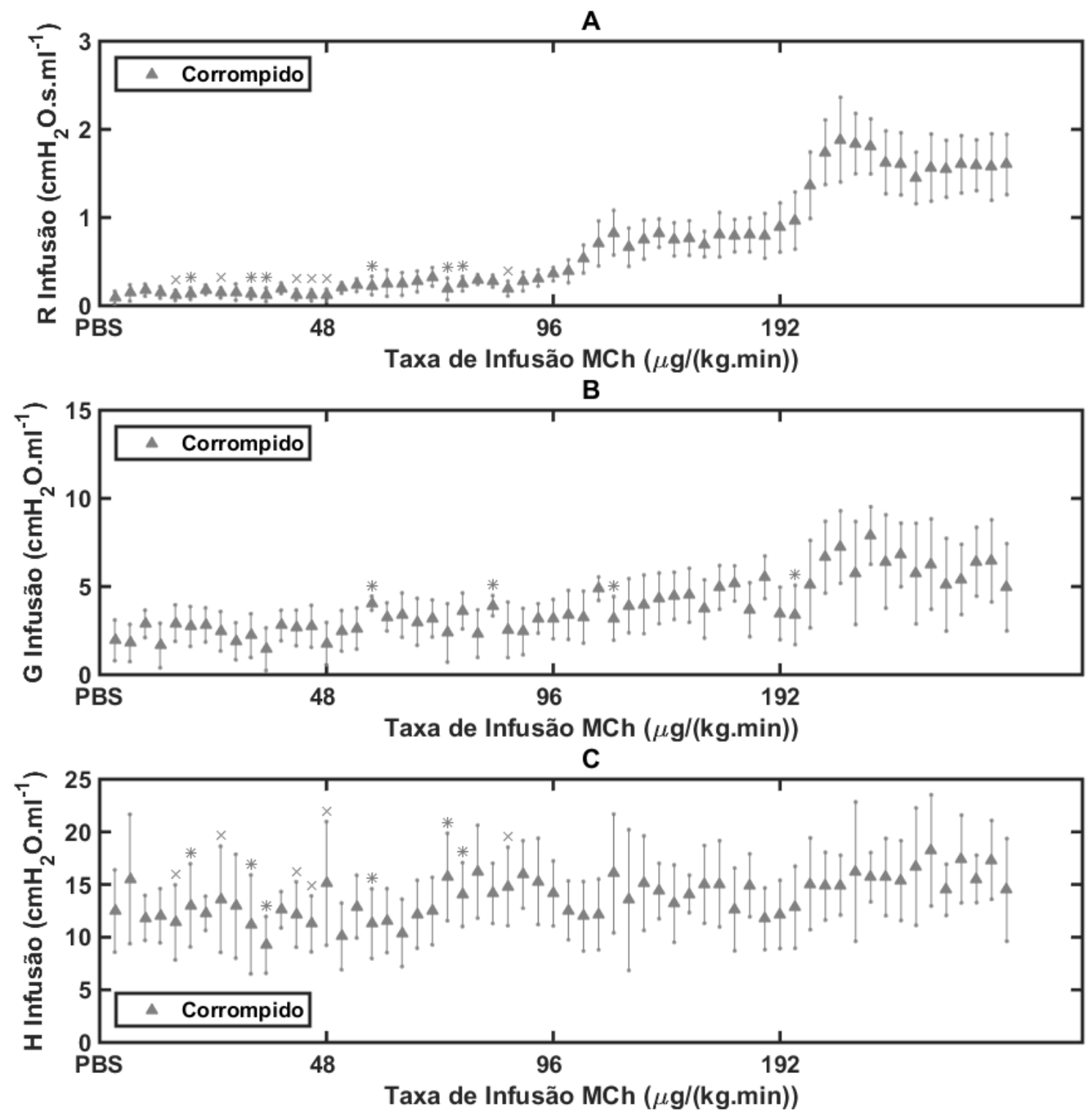

Fonte: Próprio Autor 
Figura 23: Média \pm 2 SEM do índice de distorção harmônica de 15 animais obtidos a partir da metodologia descrita na seção 2.7, após a administração de broncoconstritor por injeções em bolus em 75 realizações da FOT utilizando o sinal A) Original (quadrado cinza) e Janelado (triângulo preto) B) Corrompido (triângulo cinza). * $p<0,05,{ }^{\times} p<0,01 \mathrm{e}^{+} p<0,001$.
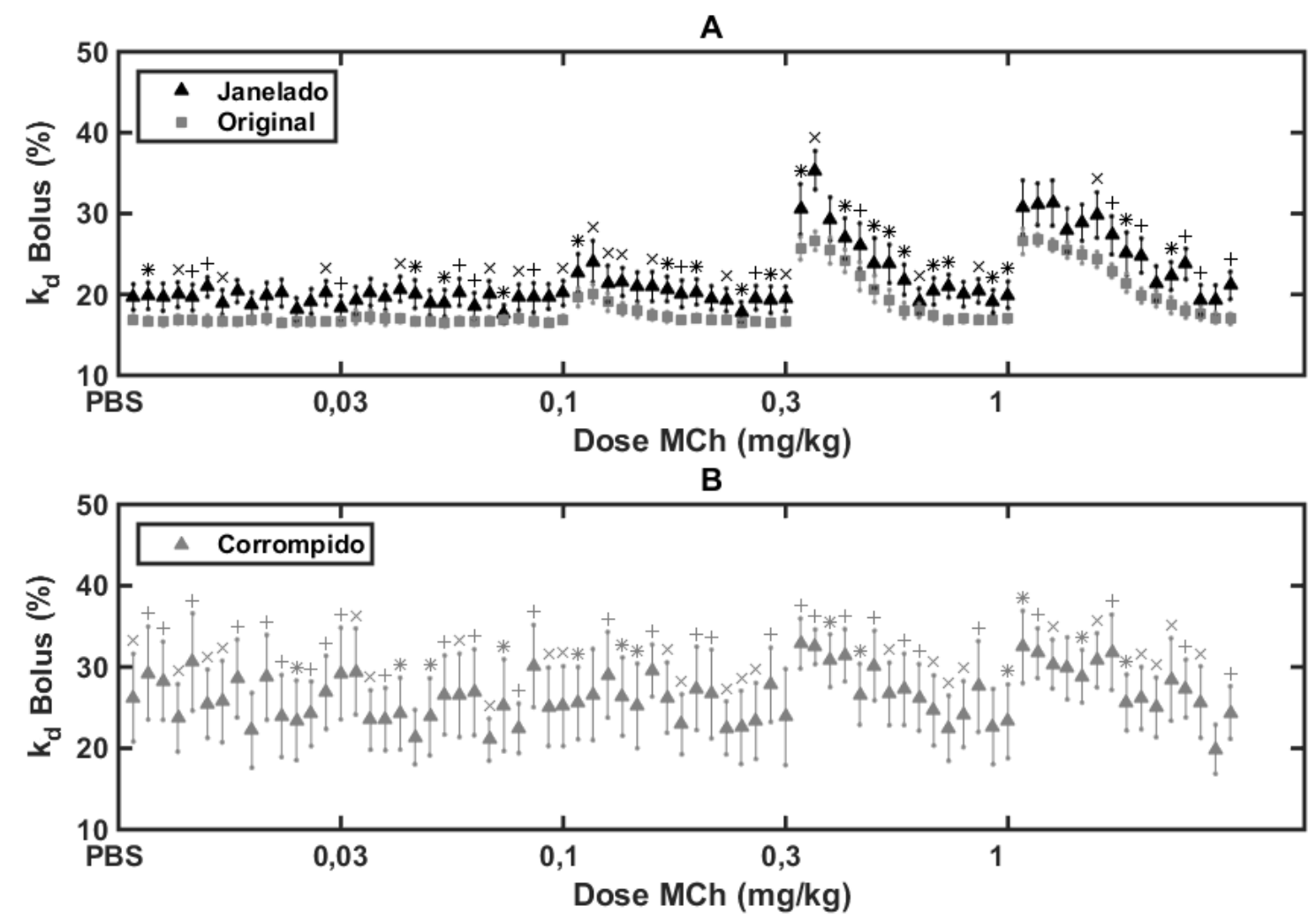

Fonte: Próprio Autor 
Figura 24: Média \pm 2 SEM do índice de distorção harmônica de 10 animais obtidos a partir da metodologia descrita na seção 2.7, após a administração de broncoconstritor por infusão contínua em 60 realizações da FOT utilizando o sinal A) Original (quadrado cinza) e Janelado (triângulo preto) B) Corrompido (triângulo cinza). * $p<0,05,{ }^{\times} p<0,01 \mathrm{e}^{+} p<0,001$.
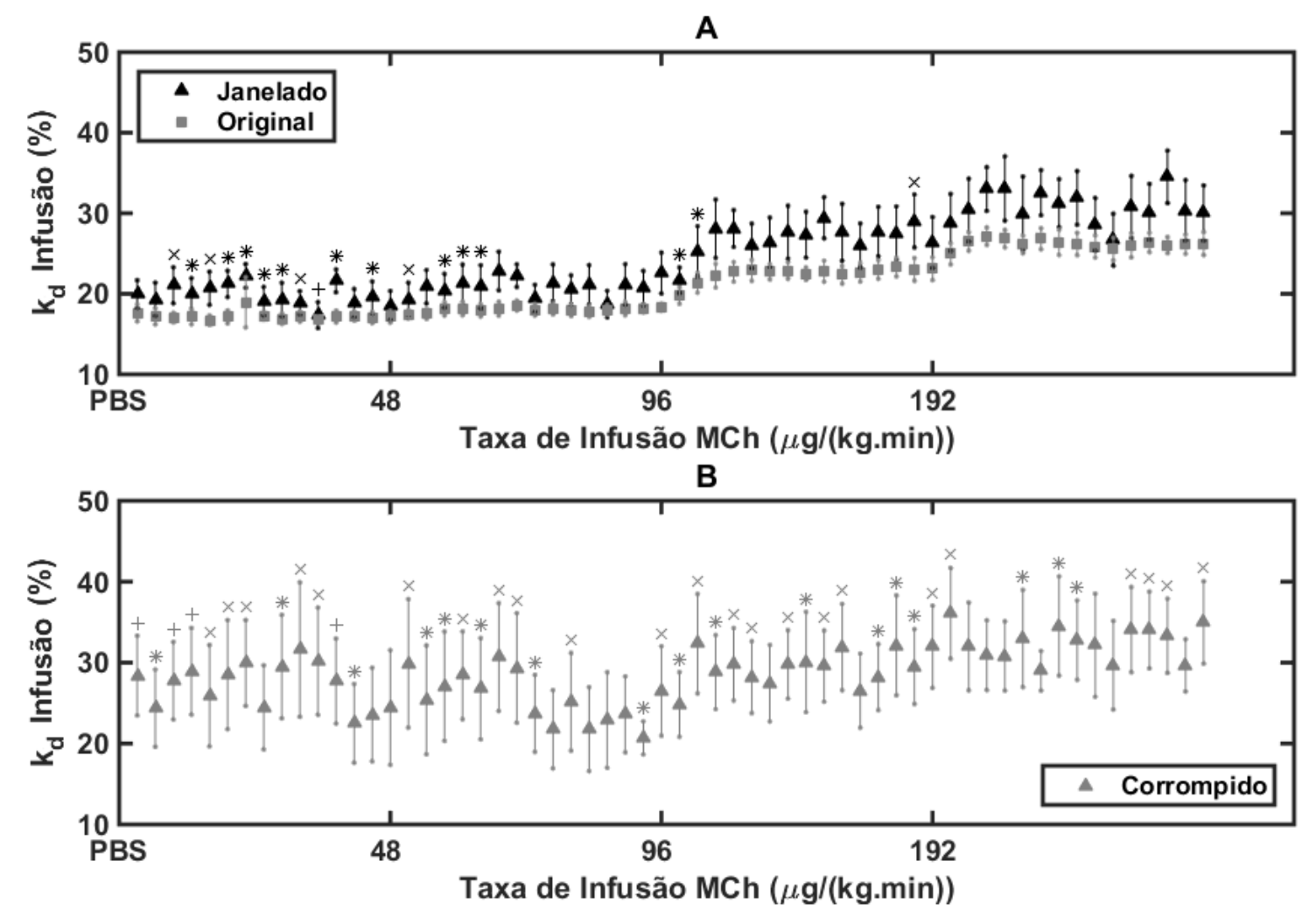

Fonte: Próprio Autor 
Figura 25: A) Média \pm 2 SEM do índice de distorção harmônica de 15 animais obtidos a partir da metodologia descrita na seção 3.2 (triângulo preto) e na seção 2.7 (triângulo cinza), após a administração de broncoconstritor por injeções em bolus em 75 realizações da FOT e B) Diferença entre o índice obtido pelas seções 3.2 e 2.7. ${ }^{*} p<0,05,{ }^{\times} p<0,01 \mathrm{e}^{+} p<0,001$.
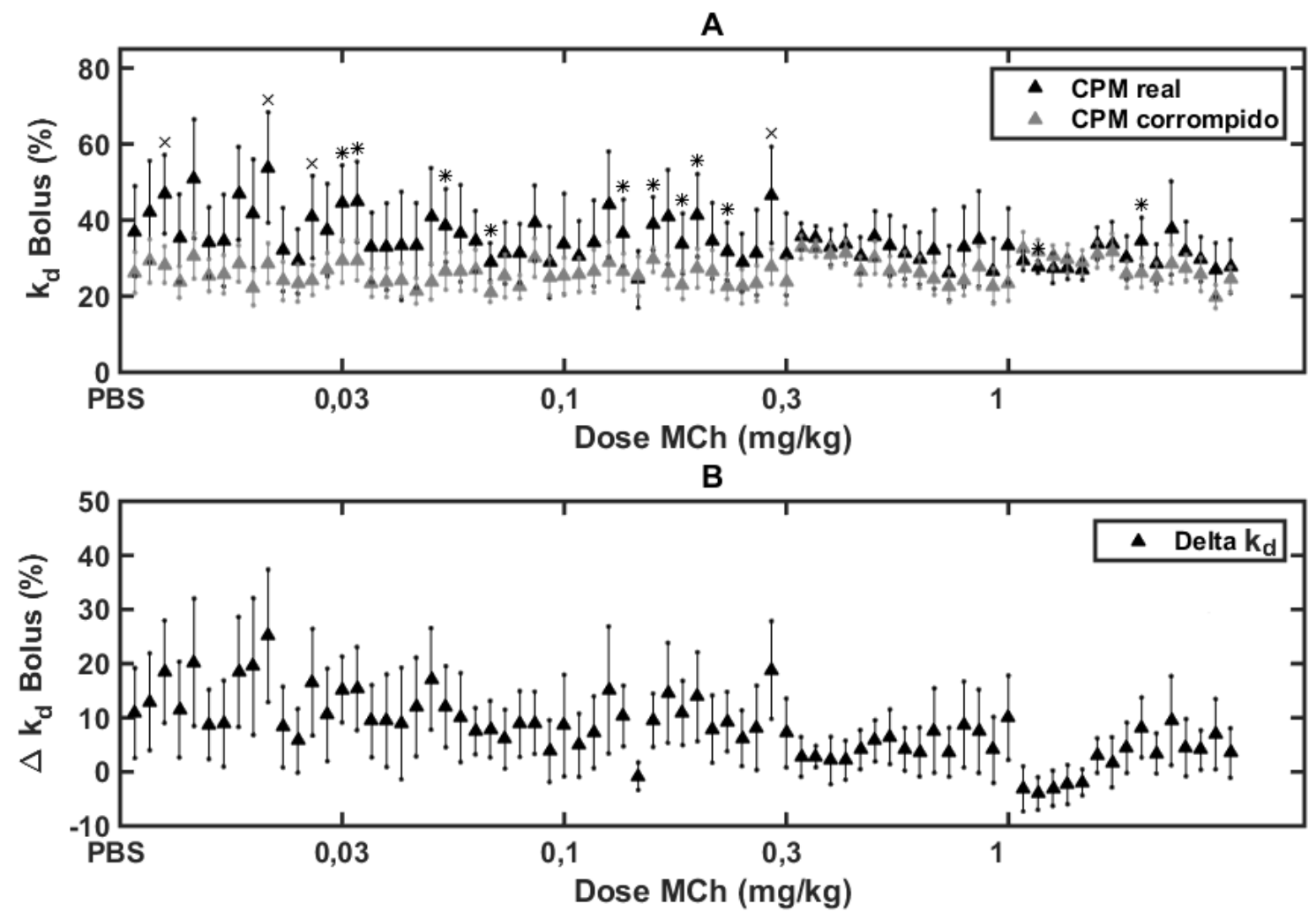

Fonte: Próprio Autor 
Figura 26: A) Média \pm 2 SEM do índice de distorção harmônica de 10 animais obtidos a partir da metodologia descrita na seção 3.2 (triângulo preto) e na seção 2.7 (triângulo cinza), após a administração de broncoconstritor por infusão contínua em 60 realizações da FOT e B) Diferença entre o índice obtido pelas seções 3.2 e 2.7. ${ }^{*} p<0,05,{ }^{\times} p<0,01 \mathrm{e}^{+} p<0,001$.
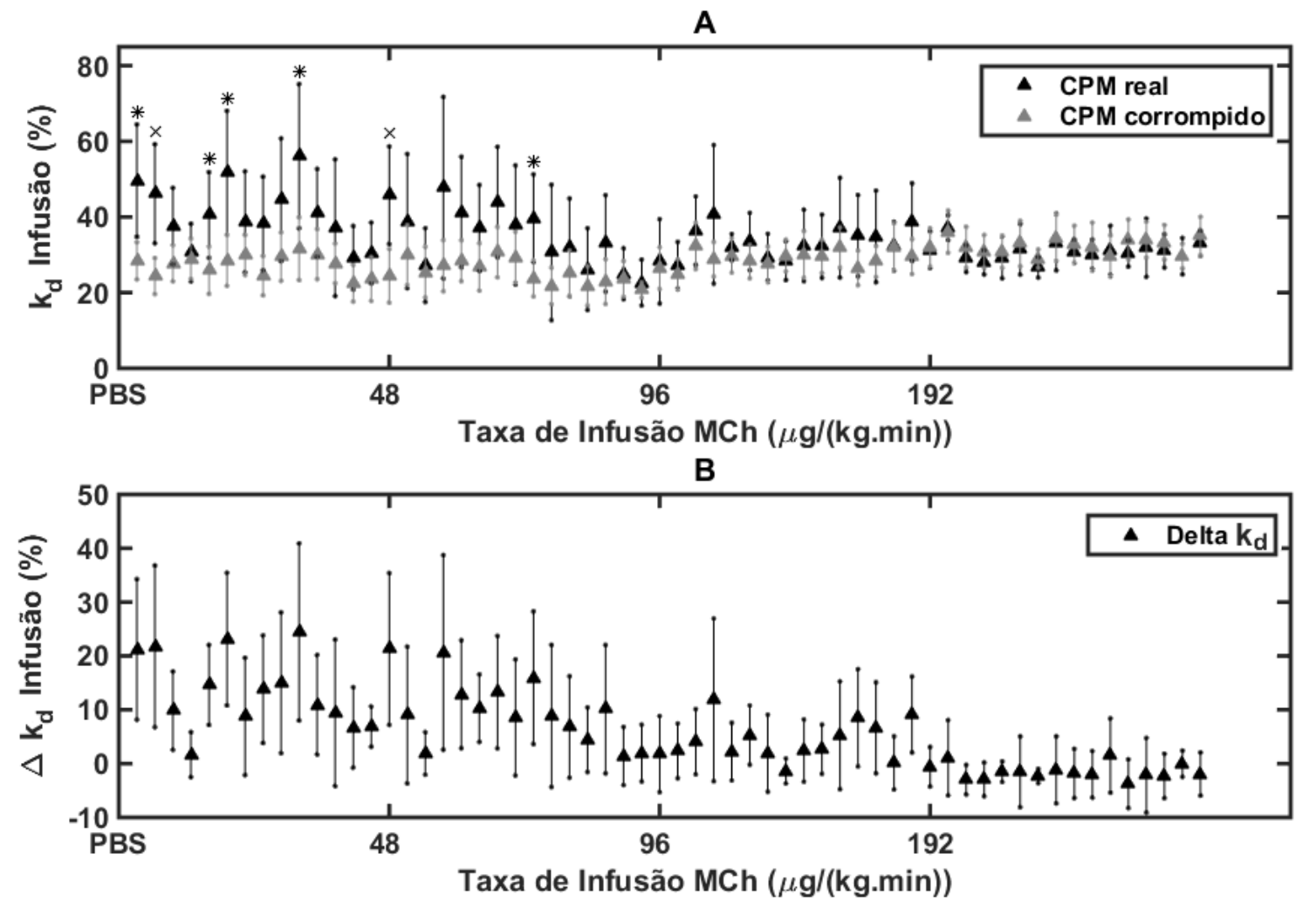

Fonte: Próprio Autor 
Figura 27: Média \pm 2 SEM do índice de distorção harmônica de 15 animais obtidos a partir da metodologia descrita na seção 2.7 após a administração de broncoconstritor por injeções em bolus em 60 realizações da FOT subtraído do valor médio do índice nas 15 realizações da FOT após administração de solução salina utilizando o sinal A) Original (quadrado cinza) e Janelado (triângulo preto) B) Corrompido (triângulo cinza). ${ }^{*} p<0,05,{ }^{\times} p<0,01 \mathrm{e}^{+} p<0,001$.
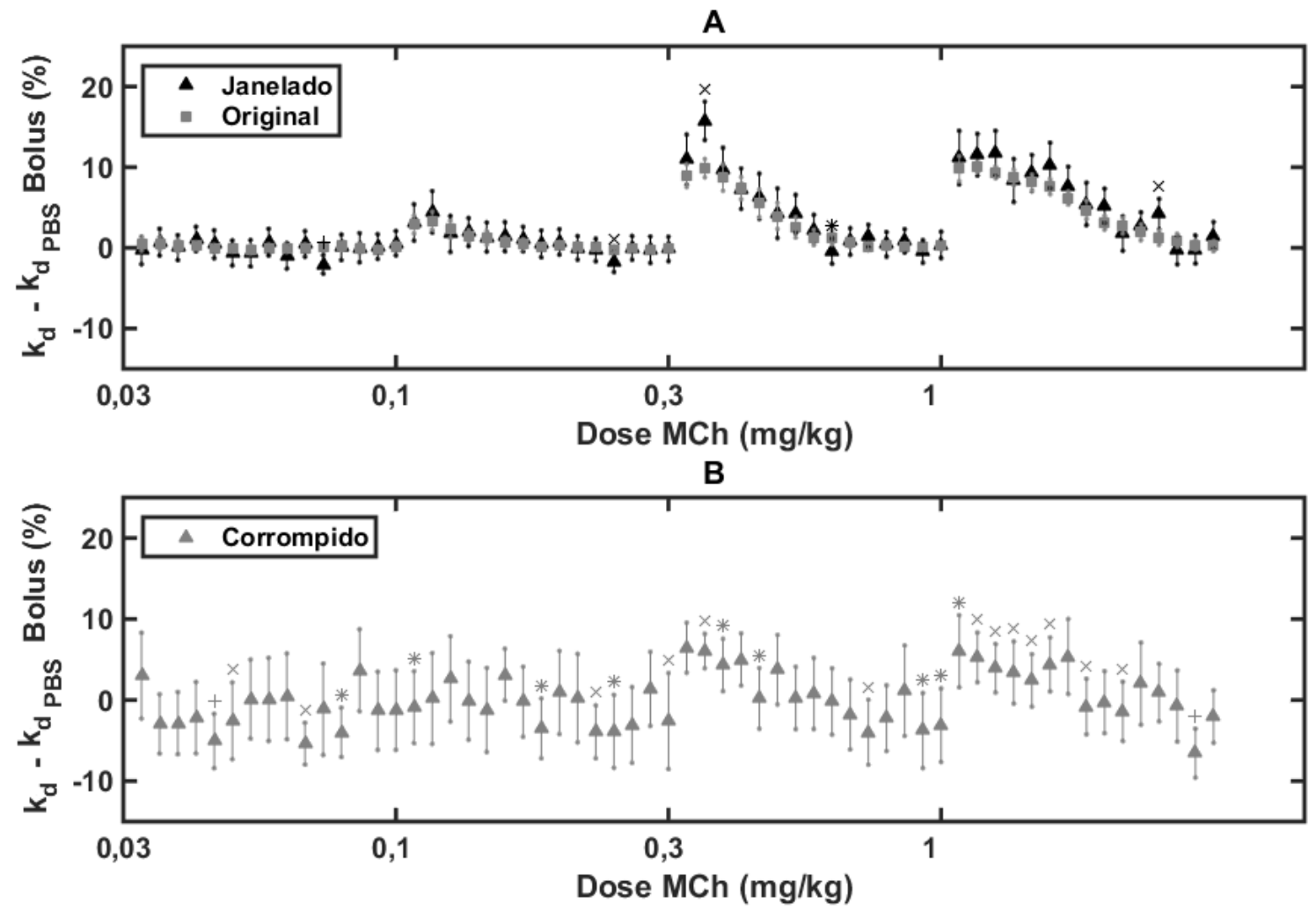

Fonte: Próprio Autor 
Figura 28: Média \pm 2 SEM do índice de distorção harmônica de 10 animais obtidos a partir da metodologia descrita na seção 2.7 após a administração de broncoconstritor por infusão contínua em 45 realizações da FOT subtraído do valor médio do índice nas 15 realizações da FOT após administração de solução salina utilizando o sinal A) Original (quadrado cinza) e Janelado (triângulo preto) B) Corrompido (triângulo cinza). ${ }^{*} p<0,05,{ }^{\times} p<0,01 \mathrm{e}^{+} p<0,001$.

A
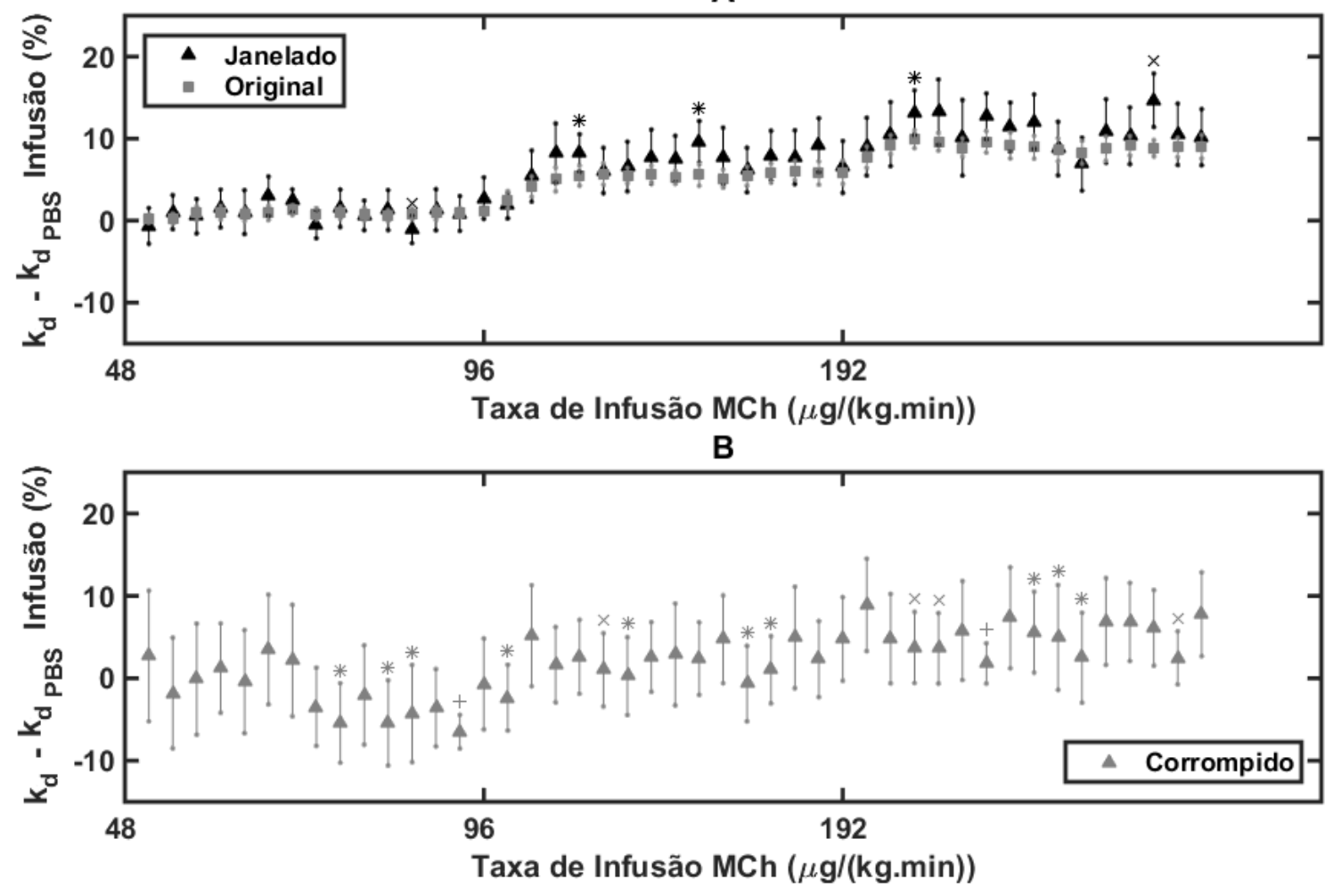

Fonte: Próprio Autor 


\section{DISCUSSÃO}

Nesse trabalho avaliamos os efeitos da presença de disrupções devido a esforços de respiração espontânea no sinal de pressão de saída quando a FOT é realizada em camundongos e propusemos alternativas para que informações fisiológicas ainda possam ser extraídas tendo como objetivo a redução no desperdício de dados provenientes de animais, seguindo o princípio dos 3 R's (redução, refinamento e reposição) (GUHAD, 2005; FLECKNELL, 2002).

Para tal, avaliamos uma nova abordagem no processamento de sinais na realização da FOT pelo flexiVent (SCIREQ, Montreal, Candá). Uma vez que o sinal multifrequencial mais utilizado nesse equipamento (QuickPrime-3) é formado a partir da junção de 2 períodos completos de 2 segundos com sobreposição de 1 segundo, gerando um sinal de 3 segundos, caso o ruído se manifeste entre 0-1 s ou entre 2-3 s, ainda assim teríamos um período completo para análise, do qual poderíamos extrair informações do comportamento fisiológico do animal. Dessa maneira, partindo de uma base de dados previamente coletada da realização da FOT em camundongos sob diferentes níveis de broncoconstrição, simulamos computacionalmente o ruído para testar essa hipótese. Efetuamos comparações em diversos parâmetros provenientes da FOT entre três sinais: o Original, referente ao sinal de 3 segundos sem disrupção, o Corrompido, referente ao sinal de 3 segundos com a presença de ruído no primeiro ou no último segundo e o sinal Janelado, referente ao período completo de 2 segundos que não contenha o ruído, após a administração de broncoconstritor por meio de injeções em bolus ou por infusão contínua, em diferentes doses ou diferentes taxas de infusão.

Primeiramente, através de simulações computacionais, avaliamos o ruído gerado computacionalmente no domínio da frequência (figura 16) visando compreender seu impacto na impedância respiratória de entrada no domínio da frequência. Tal análise indicou que a disrupção afeta especialmente a banda de baixas frequências, podendo enviesar a estimação da impedância nessa região. Tal resultado sugere que os parâmetros do $C P M$ ligados ao parênquima pulmonar (viscância e elastância) podem ser especialmente 
afetados uma vez que eles têm um papel dominante na impedância na faixa de baixas frequências. Dessa maneira, temos que o perfil da impedância estimada quando a respiração espontânea se manifesta pode não seguir o comportamento descrito pelo $C P M$ (HANTOS et al., 1992) levando a um ajuste ruim do modelo, um baixo valor de COD (equação 2.19) e, consequentemente, ao descarte dos dados obtidos.

Em seguida, avaliamos o Coeficiente de Determinação $(C O D)$ que indica a qualidade do ajuste do Modelo de Fase Constante $(C P M)$ aos dados da impedância respiratória de entrada obtida através dos sinais multifrequenciais de fluxo de entrada e de pressão de saída (BATES, 2009). Os resultados foram apresentados nas figuras 17, para administração de metacolina por injeções em bolus em diferentes doses, e 18, para a administração de metacolina por infusão contínua em diferentes taxas de infusão.

Observa-se que, tanto para bolus quanto para infusão (gráficos B), os resultados no sinal Corrompido apresentam níveis consistentemente mais baixos do que para o sinal Original, com valores médios flutuando, em sua maioria, entre 0,6 e 0,8, com barras de erro (2 erros padrões da média) bastante grandes e com diferenças estatisticamente significantes para todos os casos testados. Tal resultado se encontra dentro do esperado uma vez que uma disrupção no sinal de saída tende a afastar o comportamento do sistema respiratório do previsto pelo modelo, piorando a qualidade do ajuste. Já a geração aleatória do ruído dentro de alguns limites pré estabelecidos (duração entre 0,2 e 0,4 s e queda de pico entre 0 e $-1 \mathrm{~cm} \mathrm{H}_{2} \mathrm{O}$ ) eleva o tamanho das barras de erro, calculadas a partir de um grupo de 15 animais para bolus e 10 animais para infusão contínua.

Já na comparação entre os sinais Original e Janelado, tanto para bolus quanto para infusão contínua, são observadas diferenças estatísticas entre quase todas as realizações da FOT, com os valores do sinal Janelado menores. Entretanto, uma semelhança qualitativa no perfil das curvas é observada, com a presença de quedas acentuadas no valor do COD imediatamente após a administração de metacolina por bolus, principalmente em doses maiores, e com uma queda de patamar, mantendo o nível aproximadamente constante, a medida que taxas de infusão maiores de broncoconstritor são administradas. Tal resultado também era esperado uma vez que a presença de 2 períodos completos e, consequentemente, a utilização do periodograma tende a diminuir o impacto de ruídos e vazamentos espectrais, fazendo com que as raias FFT sejam mais bem definidos, levando a valores mais consistentes da impedância na frequência de entrada e, consequentemente a um valor de COD mais baixo e com menos flutuações (MANOLAKIS; INGLE, 2011).

O $C O D$ possui grande valor prático sendo usado como um critério de aceitabilidade 
simples e objetivo para a realização da FOT (VITORASSO, 2016), uma vez que é um parâmetro disponível no equipamento comercial para realização da FOT em pequenos animais (flexiVent, SCIREQ, Montreal, Canadá). Apesar de, usualmente, realizações da FOT com COD abaixo de 0,9 serem descartadas, o perfil qualitativo das curvas apresentadas nas figuras 17 e 18, bastante similares ao observado para o sinal Original, nos sugere que, mesmo quando o $C O D$ vai para valores abaixo do threshold, informações fisiológicas ainda podem ser extraídas.

Em seguida efetuamos a avaliação dos parâmetros do $C P M$ (resistência de vias aéreas, viscância e elastância). Os resultados foram apresentados nas figuras 19 e 20 para administração de metacolina por injeções em bolus e nas figuras 21 e 22 para administração por infusão contínua.

As figuras 19 e 21 contém o que talvez seja o resultado mais interessante desse trabalho: a comparação entre os sinais Original e Janelado não apresentou diferenças estatisticamente significantes em nenhum parâmetro do $C P M$, em nenhum dos dois diferentes métodos de administração de metacolina e em nenhuma dose ou taxa de infusão. Apesar de efeitos claramente benéficos de um segundo período com sobreposição de $50 \%$ no processamento digital de sinais, como por exemplo valores de $C O D$ mais próximos de 1 e mais consistentes, ou seja, com barras de incerteza menores, a utilização de apenas um período completo não aparenta enviesar o valor médio dos parâmetros do $C P M$, mesmo quando o $C O D$ cai abaixo de 0,9 .

Com relação aos resultados obtidos após administração de metacolina por injeções em bolus, observamos que, mesmo nas realizações experimentais mais críticas (imediatamente após a administração do broncoconstritor), o sinal Janelado oferece resultados de acordo com o esperado sem a presença de disrupções. No entanto, numa análise qualitativa, a partir da última dose $(1 \mathrm{mg} / \mathrm{kg})$ temos que pequenas diferenças, principalmente na resistência e na elastância, são observadas no pico de resposta do fármaco o que levanta o questionamento se tais congruências entre os sinais Janelado e Original continuarão a ser observadas para doses maiores.

Analogamente, apesar de não observarmos diferenças estatísticas no caso de infusão contínua, a maior taxa de infusão mostra pequenas variações do resultado com relação ao valor do sinal Original, reforçando a hipótese de que em níveis mais intensos de broncoconstrição, discrepâncias poderão surgir. No entanto, vale ressaltar que tanto a última dose de bolus quando a última taxa de infusão estão em níveis consideravelmente mais altos daqueles que são usualmente utilizados em biologia experimental de forma que 
valores mais altos podem elevar drasticamente o nível de não linearidades no sistema, comprometendo a confiabilidade das realizações experimentais.

Por outro lado, a comparação entre os sinais Original e Corrompido para administração em bolus (figura 20) mostra diferenças estatisticamente significantes em praticamente todas as realizações experimentais para a elastância. Já a viscância parece não ser severamente comprometida pela presença de ruído enquanto para a resistência, apenas nos picos de resposta das doses mais altas não foram observadas diferenças. A administração de metacolina tende a aumentar significativamente a resistência das vias aéreas devido a redução do lúmen das vias aéreas. Especula-se que, nas doses maiores, os efeitos da broncoconstrição são bastante severos de forma que a presença de ruído se torna apenas uma contribuição marginal.

Para a administração de metacolina por infusão contínua praticamente não houve diferença em nenhum dos parâmetros nas duas taxas mais altas de infusão. No caso da infusão contínua os efeitos do fármaco se manifestam de maneira aproximadamente constante durante todas as realizações experimentais ao invés de um pico acentuado de resposta, ou seja, seria como se estivéssemos observando o que acontece no pico de metacolina por injeções em bolus em todas as realizações. Isso pode explicar os resultados observados, que estão em concordância com as observações nos picos de resposta na administração por injeções em bolus, especialmente para a resistência.

Os níveis de não linearidades no sistema foram quantificados a partir do índice de distorção harmônica apresentado na seção 2.7. A estimação foi efetuada tanto para bolus (figura 23) quanto para infusão contínua (figura 24) para os sinais Original (quadrados cinzas no gráfico A), Janelado (triângulos pretos no gráfico A) e Corrompido (triângulos cinzas no gráfico B). Na comparação entre os sinais Original e Janelado observou-se a presença de diferenças estatisticamente significantes em praticamente todas as realizações em bolus com valores do índice consistentemente maiores para o sinal Janelado. Já para a infusão contínua, apesar de uma considerável quantidade de realizações não refutarem a hipótese nula do teste estatístico, observa-se qualitativamente valores mais altos para o sinal Janelado.

Levando em consideração o fato do sinal Original apresentar dois períodos completos sobrepostos, é natural que se observe um índice de distorção harmônica menor. Acreditamos que isso se deve a forma como o índice é estimado, englobando todo e qualquer aumento no espectro de potência do sinal de pressão de saída no domínio da frequência para além do esperado a partir do $C P M$, a menos de uma série de correções, e ao fato das 
raias espectrais do sinal de pressão no domínio da frequência serem mais estreitas no sinal Original, devido ao cálculo da média dos espectros dos dois períodos. Uma discussão mais aprofundada com relação a forma como o índice é calculado será levada a cabo em parágrafos subsequentes.

Apesar de valores consistentemente maiores do índice de distorção harmônica do sinal Janelado em comparação com o sinal Original, nos questionamos se tais diferenças não emergem unicamente da presença de um offset devido à ausência da utilização do periodograma, ou seja, o aumento no índice se manifesta igualmente em todas as realizações sem que haja um fenômeno fisiológico. Para testar essa hipótese, efetuamos a diferença entre o índice de distorção harmônica obtido em diferentes doses ou taxas de infusão de broncoconstritor com relação a média do valor obtido após a adminstração de solução salina, ou seja, comparado ao nível basal dos animais.

As figuras 27, para injeções em bolus, e 28 para infusão contínua nos mostram que, na maior parte das realizações experimentais, não existem diferenças estatísticas significantes quando avaliamos a variação do índice de distorção harmônica com relação a um valor basal, referente a aplicação de solução salina. Esse resultado é bastante interessante pois reforça a tese de que os aumentos do índice no sinal Janelado observados nos gráficos A das figuras 23 e 24 não possuem origem fisiológica mas apenas de especificidades das técnicas de processamento de sinais utilizadas em diferentes situações.

Isso nos leva a concluir que mesmo com a ausência de um segundo período completo ainda conseguimos detectar o aumento de manifestações não lineares no sistema respiratório devido à efeitos de broncoconstrição sem grandes enviesamentos com relação ao sinal Original. Tal resultado junto com o observado para os parâmetros do $C P M$ (figuras 19 e 21) demonstram que apesar do método proposto ser extremamente simples ele é robusto a ponto de manter resultados consistentes não só na observação dos parâmetros como também em uma análise mais aprofundada que leva em conta níveis estimados de não linearidade, até mesmo quando o valor do $C O D$ cai para menos de 0,9 .

Apesar de fugir do objetivo principal do estudo, que consiste em avaliar técnicas de processamento digital de sinais para potencialmente reduzir o número de animais sacrificados, também avaliamos a metodologia utilizada para a estimação do índice de distorção harmônica e discutimos possíveis problemas visando atingir um dos objetivos secundários propostos inicialmente por esse trabalho.

O cerne principal do índice, seguindo a metodologia proposta na seção 2.7, é a hipótese de que o sistema respiratório possui comportamento quasi-linear, ou seja, o comporta- 
mento não linear não possui manifestação dominante, sendo apenas uma perturbação do sistema linear. Dessa forma, uma vez que as linhas espectrais de frequências presentes no sinal de entrada são bastante proeminentes, nesse conjunto de frequências, a estimação da impedância e dos parâmetros do $C P M$ não possui enviesamento e, consequentemente, a extrapolação da impedância em todos os múltiplos inteiros da frequência fundamental entre a menor e a maior frequência presente no sinal de entrada a partir dos parâmetros do $C P M$ pode ser considerada a impedância linear (equação 2.24).

A partir dessa impedância linear, obtém-se o sinal de pressão de saída devido unicamente a transferência linear de energia através do produto dessa impedância estimada a partir dos parâmetros do modelo (equação 2.17) com o sinal de fluxo no domínio da frequência em todo o espectro de frequências. Uma vez que fenômenos não lineares se manifestam em combinações lineares de frequências presentes no sinal de entrada, o índice de distorção harmônica contabiliza o somatório da diferença entre o espectro de potência no domínio da frequência observado e o previsto pela impedância linear em múltiplos inteiros da frequência fundamental, entre a maior e a menor frequência presente no sinal de entrada (equação 2.25).

No entanto uma correção é feita levando em conta a qualidade do ajuste da impedância ao modelo. Define-se uma região de tolerância ligado ao erro do ajuste ao modelo de forma que, somente diferenças entre o espectro de potência do sinal de pressão adquirido e linear, a partir dos parâmetros do $C P M$, acima dessa tolerância são contabilizadas como não linearidades (equação 2.29). Ocorre que, quanto maior o grau de broncoconstrição e, consequentemente, o de não linearidade, pior é o ajuste dos dados, aumentando a zona de tolerância, o que pode levar a uma subestimação dos efeitos da não linearidade no sistema. O problema se torna ainda maior quando efetuamos o cálculo do índice usando o sinal Corrompido, onde até mesmo os parâmetros obtidos pelo $C P M$ possuem valores pouco confiáveis.

Para avaliar os efeitos do fenômeno descrito acima, calculamos o índice de distorção harmônica do sinal Corrompido a partir da metodologia mostrada na seção 2.7 e a partir da correção proposta na seção 3.2, tanto para bolus (figura 25) quanto para infusão contínua (figura 26). Nos respectivos gráficos A foram apresentados os valores do índice utilizando a metodologia da seção 2.7, ou seja, com os parâmetros do $C P M$ estimados a partir do próprio sinal Corrompido (triângulos cinzas) e a partir da medologia da seção 3.2, ou seja, a partir dos parâmetros estimados no sinal Original (triângulos pretos). Já nos gráficos B foi apresentada a diferença entre os dois índices. 
Observa-se que, para as duas vias de administração do broncoconstritor, a utilização dos parâmetros do $C P M$ a partir do sinal Original tende a fornecer valores mais altos do índice, principalmente nas doses menores, ou seja, uma quantidade significativa de energia espúria ultrapassa a zona de tolerância definida a partir do ajuste do modelo à impedância. Evidentemente, grandes flutuações são observadas uma vez que o ruído do sinal Corrompido é gerado de forma aleatória dentro de algumas condições pré-definidas.

A medida que a dose ou a taxa de infusão de broncoconstritor é aumentada, observase uma redução na diferença entre os os métodos para estimação do índice de distorção harmônica, indo até valores muito próximos de zero. Uma possível justificativa para esse resultado é o fato de que altos níveis de broncoconstrição adicionam uma alta quantidade de energia no sinal de maneira que a contribuição do ruído devido a esforços de respiração espontânea vai diminuindo, aproximando os resultados obtidos pelos sinais Original e Corrompido, como observado também nas figuras 19 e 21.

Os resultados mostrados nas figuras 25 e 26 indicam que, apesar do índice de distorção harmônica ser a técnica mais robusta para quantificar a presença de não linearidades, ele possui limitações importantes. Para sua utilização é crucial que a condição de quasilinearidade do sistema seja respeitada de forma que os parâmetros ajustados do $C P M$ não sejam enviesados e que o erro no ajuste do modelo possua um valor baixo. No entanto, vale ressaltar que uma alternativa mais precisa para quantificar fenômenos não lineares seja improvável dado o baixo grau de invasividade da FOT e, consequentemente, a profundidade das informações fisiológicas nela presente. Isso leva ao dilema de que quanto maior a presença de não linearidades maior a tendência em subestimar seus efeitos. Novamente relembramos que a grande maioria dos experimentos realizados com a utilização de broncoconstritores na FOT utilizam doses ou taxas de infusão muito menores dos que as usadas nesse trabalho de maneira que a condição de quasi-linearidade é bastante razoável nesses casos.

Apesar da alternativa proposta nessa tese ser bem sucedida não só na estimação dos parâmetros do $C P M$ a partir de um único período de 2 segundos do sinal mas também das variações no índice de distorção harmônica de diferentes doses ou taxas de infusão de broncoconstritor com relação ao valor basal, é importante que joguemos luz nas limitações presentes nesse estudo.

Primeiramente é importante frisar que nossa hipótese foi testada apenas na condição específica em que a disrupção do sinal é composta por um ruído proveniente de respiração espontânea, ou seja, uma queda abrupta no sinal de pressão em um intervalo de tempo 
bastante curto. Além disso, a simulação do ruído foi feita computacionalmente de forma que é possível discernir com exatidão o ruído do sinal Original, situação que por vezes se mostra bastante difícil na prática e requer relativa experiência com dados da FOT. Dessa maneira, a utilização dessa técnica quando não se há grande convicção de que o único efeito disruptivo do sinal provém da respiração espontânea pode se mostrar falha e não é recomendada. Outra limitação evidente é quando o ruído se apresenta entre 1-2 segundos do sinal. Nesse caso, nossa proposta não se aplica e recomenda-se o descarte da realização experimental.

Também vale ressaltar que, além do comportamento não linear, o sistema respiratório também apresenta comportamento não estacionário durante a realização da $F O T$, principalmente no pico de resposta de metacolina quando a mesma é administrada por injeções em bolus. Dessa forma, os períodos de 0-2 s ou de 1-3 s podem possuir informações fisiológicas diferentes. No entanto, não acreditamos que tal comportamento distancie consideravelmente os resultados obtidos nos sinais Original e Janelado visto que devido a efetuação da média entre os dois períodos, as informações presentes em ambos os trechos acabam sendo misturadas. 


\section{CONCLUSÃO}

Nesse trabalho propomos uma ferramenta para reaproveitar dados experimentais da FOT no caso específico em que um ruído devido a esforços de respiração espontânea estão presentes em animais submetidos ao sinal QuickPrime-3 do flexiVent (SCIREQ, Montreal, Canadá). Tal sinal multifrequencial é composto por dois períodos completos de 2 segundos com sobreposição de 50\%, dessa forma, quando o ruído se manifesta entre 0-1 s ou entre 2-3 s ainda é possível a utilização do período completo que não contenha o ruído para o processamento do sinal e consequente análise da impedância respiratória de entrada, parâmetros do $C P M$ e índice de distorção harmônica.

Reforçamos que tal trabalho possui diversas limitações tais como: 1) O fato de havermos testado-o apenas em casos onde a disrupção provém única e exclusivamente da respiração espontânea, não sendo recomendada sua utilização em casos alheios aos testados, 2) a utilização da técnica só pode ser feita quando a perturbação acontece no primeiro ou no último segundo do sinal de saída e 3) caso o sistema apresente comportamento não estacionário as informações fisiológicas presentes entre os períodos de 0-2 s e de 1-3 s podem ser diferentes.

Apesar de ser uma técnica extremamente simples e de fácil aplicação observou-se uma considerável robustez na comparação do sinal completo com o sinal de 2 segundos. Quando animais foram sujeitos a administração de metacolina por injeções em bolus ou por infusão contínua, em diversas doses ou taxas de infusão, observou-se grande convergência nos valores dos parâmetros do $C P M$, sem a presença de diferenças estatisticamente significantes em todos os casos testados, inclusive naqueles em que o $C O D$ falha em atingir o nível de 0,9. Mais do que isso, também se observou uma convergência entre as variações do índice de distorção harmônica com relação ao valor basal, indicando que nos dois níveis de análise desse trabalho, a utilização de apenas um período completo de 2 segundos não mostrou perdas ou enviesamentos nas informações fisiológicas presentes no sistema respiratório dos animais obtidos através da FOT. 


\section{REFERÊNCIAS BIBLIOGRÁFICAS}

BATES, J. H. Lung mechanics: an inverse modeling approach. [S.l.]: Cambridge University Press, 2009.

BATES, J. H.; IRVIN, C. G. Measuring lung function in mice: the phenotyping uncertainty principle. Journal of applied physiology, American Physiological Society Bethesda, MD, v. 94, n. 4, p. 1297-1306, 2003.

BATES, J. H.; IRVIN, C. G.; FARRÉ, R.; HANTOS, Z. Oscillation mechanics of the respiratory system. Comprehensive Physiology, Wiley Online Library, 2011.

BATES, J. H.; LUTCHEN, K. R. The interface between measurement and modeling of peripheral lung mechanics. Respiratory physiology \& neurobiology, Elsevier, v. 148, n. $1-2$, p. $153-164,2005$.

BATES, J. H.; SCHUESSlER, T. F.; DOLMAN, C.; EIDELMAN, D. H. Temporal dynamics of acute isovolume bronchoconstriction in the rat. Journal of Applied Physiology, American Physiological Society Bethesda, MD, v. 82, n. 1, p. 55-62, 1997.

CHUA, L. O.; NG, C.-Y. Frequency domain analysis of nonlinear systems: general theory. IEE Journal on Electronic Circuits and Systems, IET, v. 3, n. 4, p. 165-185, 1979.

DOEHRING, T. C.; FREED, A. D.; CAREW, E. O.; VESELY, I. Fractional order viscoelasticity of the aortic valve cusp: an alternative to quasilinear viscoelasticity. Journal of biomechanical engineering, American Society of Mechanical Engineers, v. 127, n. 4 , p. 700-708, 2005.

DUBOIS, A. B.; BRODY, A. W.; LEWIS, D. H.; JR, B. F. B. Oscillation mechanics of lungs and chest in man. Journal of applied physiology, Am Physiological Soc, v. 8, n. 6 , p. $587-594,1956$.

FARRÉ, R.; NAVAJAS, D. Forced oscillation: A poorly exploited tool for simply assessing respiratory function in children. Respirology, Wiley Online Library, v. 21, n. 6, p. 982-983, 2016.

FISHER, A. B.; DUBOIS, A. B.; HYDE, R. W. Evaluation of the forced oscillation technique for the determination of resistance to breathing. The Journal of clinical investigation, Am Soc Clin Investig, v. 47, n. 9, p. 2045-2057, 1968.

FLECKNELL, P. Replacement, reduction and refinement. Altex, v. 19, n. 2, p. 73-78, 2002. 
FUNG, Y.-c. Biomechanics: mechanical properties of living tissues. [S.l.]: Springer Science \& Business Media, 2013.

FUNK, J.; HALL, G.; CRANDALL, J.; PILKEY, W. Linear and quasi-linear viscoelastic characterization of ankle ligaments. Journal of biomechanical engineering, American Society of Mechanical Engineers, v. 122, n. 1, p. 15-22, 2000.

GUHAD, F. Introduction to the 3rs (refinement, reduction and replacement). Journal of the American Association for Laboratory Animal Science, American Association for Laboratory Animal Science, v. 44, n. 2, p. 58-59, 2005.

HAMLINGTON, K. L.; BATES, J. H.; ROY, G. S.; JULIANELLE, A. J.; CHARLEBOIS, C.; SUKI, B.; SMITH, B. J. Alveolar leak develops by a rich-get-richer process in ventilator-induced lung injury. PloS one, Public Library of Science, v. 13, n. 3, p. e0193934, 2018.

HANTOS, Z.; CZÖVEK, D.; GYURKOVITS, Z.; SZABÓ, H.; MAÁR, B. A.; RADICS, B.; VIRÁG, K.; MAKAN, G.; ORVOS, H.; GINGL, Z. et al. Assessment of respiratory mechanics with forced oscillations in healthy newborns. Pediatric pulmonology, Wiley Online Library, v. 50, n. 4, p. 344-352, 2015.

HANTOS, Z.; DAROCZY, B.; SUKI, B.; GALGOCZY, G.; CSENDES, T. Forced oscillatory impedance of the respiratory system at low frequencies. Journal of Applied Physiology, Am Physiological Soc, v. 60, n. 1, p. 123-132, 1986.

HANTOS, Z.; DAROCZY, B.; SUKI, B.; NAGY, S. Low-frequency respiratory mechanical impedance in the rat. Journal of Applied Physiology, Am Physiological Soc, v. 63, n. 1, p. 36-43, 1987.

HANTOS, Z.; DAROCZY, B.; SUKI, B.; NAGY, S.; FREDBERG, J. Input impedance and peripheral inhomogeneity of dog lungs. Journal of Applied Physiology, Am Physiological Soc, v. 72, n. 1, p. 168-178, 1992.

HARTNEY, J. M.; ROBICHAUD, A. Assessment of airway hyperresponsiveness in mouse models of allergic lung disease using detailed measurements of respiratory mechanics. In: Mouse Models of Allergic Disease. [S.1.]: Springer, 2013. p. 205-217.

ICHIKAWA, S.; GOTO, T. An analysis for steady-state response of nonlinear systems with sinusoidal inputs. Electronics and Communications in Japan (Part III: Fundamental Electronic Science), Wiley Online Library, v. 75, n. 6, p. 35-45, 1992.

KACZKA, D. W.; DELLACÁ, R. L. Oscillation mechanics of the respiratory system: applications to lung disease. Critical Reviews ${ }^{\text {TM }}$ in Biomedical Engineering, Begel House Inc., v. 39, n. 4, 2011.

LANDSER, F.; NAGLES, J.; DEMEDTS, M.; BILLIET, L.; WOESTIJNE, K. Van de. A new method to determine frequency characteristics of the respiratory system. Journal of Applied Physiology, Am Physiological Soc, v. 41, n. 1, p. 101-106, 1976.

LATHI, B. P. Principles of Linear Systems and Signals. [S.1.]: Oxford University Press, 2017. 
LORX, A.; CZÖVEK, D.; GINGL, Z.; MAKAN, G.; RADICS, B.; BARTUSEK, D.; SZIGETI, S.; GÁL, J.; LOSONCZY, G.; SLY, P. D. et al. Airway dynamics in copd patients by within-breath impedance tracking: effects of continuous positive airway pressure. European Respiratory Journal, Eur Respiratory Soc, v. 49, n. 2, p. 1601270, 2017.

LUNDBLAD, L.; PIITULAINEN, E.; WOLLMER, P. C80-b multi-modality assessment of copd, asthma, and asthma-copd overlap syndrome: Ccomparison of the forced oscillation technique and spirometry in copd and alpha-1-antitrypsin deficient patients. American Journal of Respiratory and Critical Care Medicine, American Thoracic Society, v. 195, 2017.

LUTCHEN, K. R.; SUKI, B.; ZHANG, Q.; PETAK, F.; DAROCZY, B.; HANTOS, Z. Airway and tissue mechanics during physiological breathing and bronchoconstriction in dogs. Journal of Applied Physiology, Am Physiological Soc, v. 77, n. 1, p. 373-385, 1994.

MAKSYM, G. N.; BATES, J. H. Nonparametric block-structured modeling of rat lung mechanics. Annals of biomedical engineering, Springer, v. 25, n. 6, p. 1000-1008, 1997.

MANOLAKIS, D. G.; INGLE, V. K. Applied digital signal processing: theory and practice. [S.l.]: Cambridge University Press, 2011.

MCGOVERN, T. K.; ROBICHAUD, A.; FEREYDOONZAD, L.; SCHUESSLER, T. F.; MARTIN, J. G. Evaluation of respiratory system mechanics in mice using the forced oscillation technique. Journal of visualized experiments: JoVE, MyJoVE Corporation, n. 75, 2013.

MEAD, J. Control of respiratory frequency. Journal of Applied Physiology, Am Physiological Soc, v. 15, n. 3, p. 325-336, 1960.

MORI, V.; OLIVEIRA, M.; VARGAS, M.; CUNHA, A. da; SOUZA, R. de; PITREZ, P.; MORIYA, H. Input respiratory impedance in mice: comparison between the flow-based and the wavetube method to perform the forced oscillation technique. Physiological measurement, IOP Publishing, v. 38, n. 6, p. 992, 2017.

MORI, V.; SMITH, B. J.; SUKI, B.; BATES, J. H. T. Linking physiological biomarkers of ventilator-induced lung injury to a rich-get-richer mechanism of injury progression.

Annals of Biomedical Engineering, Springer, v. 47, n. 2, p. 638-645, 2019.

MURGO, J. P.; WeSterhoF, N.; GIOLMA, J. P.; Altobelli, S. A. Aortic input impedance in normal man: relationship to pressure wave forms. Circulation, Citeseer, v. 62 , n. 1, p. 105-116, 1980.

OOSTVEEN, E.; MACLEOD, D.; LORINO, H.; FARRE, R.; HANTOS, Z.; DESAGER, K.; MARCHAL, F. et al. The forced oscillation technique in clinical practice: methodology, recommendations and future developments. European Respiratory Journal, Eur Respiratory Soc, v. 22, n. 6, p. 1026-1041, 2003.

PEEBLES, P. Z.; READ, J.; READ, P. Probability, random variables, and random signal principles. [S.l.]: McGraw-Hill New York, NY, USA:, 2001. v. 3. 
PESLIN, R.; JARDIN, P.; DUVIVIER, C.; BEGIN, P. In-phase rejection requirements for measuring respiratory input impedance. Journal of Applied Physiology, v. 56, n. 3, p. 804-809, 1984.

SCHUESSLER, T. F.; BATES, J. A computer-controlled research ventilator for small animals: design and evaluation. IEEE transactions on biomedical engineering, IEEE, v. 42, n. 9, p. 860-866, 1995.

SIMILOWSKI, T.; BATES, J. Two-compartment modelling of respiratory system mechanics at low frequencies: gas redistribution or tissue rheology? European Respiratory Journal, Eur Respiratory Soc, v. 4, n. 3, p. 353-358, 1991.

SLY, P. D.; SHACKLETON, C.; CZOVEK, D.; HANTOS, Z. Systematic error in respiratory impedance using commercial equipment calibrated according to the manufacturer's instructions. American journal of respiratory and critical care medicine, American Thoracic Society, v. 197, n. 4, p. 532-534, 2018.

SMITH, B. J.; BARTOLAK-SUKI, E.; SUKI, B.; ROY, G. S.; HAMLINGTON, K. L.; CHARLEBOIS, C. M.; BATES, J. H. Linking ventilator injury-induced leak across the blood-gas barrier to derangements in murine lung function. Frontiers in physiology, Frontiers, v. 8, p. 466, 2017.

SMITH, B. J.; BATES, J. H. Assessing the progression of ventilator-induced lung injury in mice. IEEE Transactions on Biomedical Engineering, IEEE, v. 60, n. 12, p. 3449-3457, 2013.

SMITH, B. J.; GRANT, K. A.; BATES, J. H. Linking the development of ventilatorinduced injury to mechanical function in the lung. Annals of biomedical engineering, Springer, v. 41, n. 3, p. 527-536, 2013.

SMITH, H.; REINHOLD, P.; GOLDMAN, M. Forced oscillation technique and impulse oscillometry. European Respiratory Monograph, European Respiratory Society, v. 31, p. $72,2005$.

SUKI, B. Nonlinear phenomena in respiratory mechanical measurements. Journal of Applied Physiology, v. 74, n. 5, p. 2574-2584, 1993.

SUKI, B.; HANTOS, Z.; DAROCZY, B.; ALKAYSI, G.; NAGY, S. Nonlinearity and harmonic distortion of dog lungs measured by low-frequency forced oscillations. Journal of Applied Physiology, Am Physiological Soc, v. 71, n. 1, p. 69-75, 1991.

SUKI, B.; LUTCHEN, K. Pseudorandom signals to estimate apparent transfer and coherence functions of nonlinear systems: applications to respiratory mechanics. IEEE transactions on biomedical engineering, IEEE, v. 39, n. 11, p. 1142-1151, 1992.

SUKI, B.; YUAN, H.; ZHANG, Q.; LUTCHEN, K. R. Partitioning of lung tissue response and inhomogeneous airway constriction at the airway opening. Journal of Applied Physiology, American Physiological Society Bethesda, MD, v. 82, n. 4, p. 1349-1359, 1997.

SUKI, B.; ZHANG, Q.; LUTCHEN, K. R. Relationship between frequency and amplitude dependence in the lung: a nonlinear block-structured modeling approach. Journal of Applied Physiology, v. 79, n. 2, p. 660-671, 1995. 
THAMRIN, C.; JÁNOSI, T. Z.; COLLINS, R. A.; SLY, P. D.; HANTOS, Z. Sensitivity analysis of respiratory parameter estimates in the constant-phase model. Annals of biomedical engineering, Springer, v. 32, n. 6, p. 815-822, 2004.

VITORASSO, R. d. L. Análise da aplicação do modelo de fase constante na avaliação da mecânica respiratória em animais durante broncoconstrição. Tese (Doutorado) — Universidade de São Paulo, 2016.

WAGERS, S.; LUNDBLAD, L.; MORIYA, H. T.; BATES, J. H.; IRVIN, C. G.

Nonlinearity of respiratory mechanics during bronchoconstriction in mice with airway inflammation. Journal of Applied Physiology, Am Physiological Soc, v. 92, n. 5, p. 1802-1807, 2002.

WESTERHOF, N.; BOSMAN, F.; VRIES, C. J. D.; NOORDERGRAAF, A. Analog studies of the human systemic arterial tree. Journal of biomechanics, Elsevier, v. 2, n. 2, p. 135-136, 1969.

WOESTIJnE, K. Van de; FRANKEN, H.; CAUBERGHS, M.; LANDSER, F.; CLEMENT, J. A modification of the forced oscillation technique. In: Respiration. [S.l.]: Elsevier, 1981. p. 655-660.

ZHANG, Q.; SUKI, B.; LUTCHEN, K. R. Harmonic distortion from nonlinear systems with broadband inputs: applications to lung mechanics. Annals of biomedical engineering, Springer, v. 23, n. 5, p. 672-681, 1995.

ZIMMERMANN, S. C.; WATTS, J. C.; BERTOLIN, A.; JETMALANI, K.; KING, G. G.; THAMRIN, C. Discrepancy between in vivo and in vitro comparisons of forced oscillation devices. Journal of clinical monitoring and computing, Springer, p. 1-4, 2017. 